\title{
ESTUDIO
}

\section{SITUACIÓN SOCIOECONÓMICA RECIENTE DE LOS MAPUCHES EN LA REGIÓN DE LA ARAUCANÍA ${ }^{1}$}

\author{
Rodrigo A. Cerda
}

Este trabajo presenta un análisis de la situación socioeconómica de la población mapuche en la IX Región de Chile (Región de la Araucanía) y sus determinantes. Para ello, primero se examinan datos macroeconómicos de la región, con especial énfasis en la evolución del crecimiento, el PIB per cápita y la estructura productiva. El estudio muestra que la IX Región es la más rezagada del país en términos de PIB per cápita, situación que se ha mantenido en los últimos cuarenta años. Aun cuando el crecimiento económico se ha acelerado en tiempos recientes, la Región de la Araucanía sigue siendo la más pobre y exhibe, además, los peores índices de desigualdad de Chile.

En la segunda sección del trabajo se examinan las características demográficas y socioeconómicas de la población mapuche en la Región de la Araucanía, utilizando principalmente datos de las encuestas Casen de 1996, 2000, 2003 y 2006. El análisis se centra aquí en ingresos laborales, tasas de pobreza, niveles de educación y ocupación y tenencia de tierras indígenas. En 2006, los mapuches de la IX Región ascen-

Rodrigo A. Cerda. Ph.D. en Economía, Universidad de Chicago. Actualmente es profesor del Instituto de Economía de la P. Universidad Católica de Chile. Afiliado al núcleo mileno Economic History and Cliometrics Lab (EH-CLIOLab) de la Pontificia Universidad Católica de Chile. Correo electrónico: rcerda@faceapuc.cl.

${ }^{1}$ Se agradecen los detallados comentarios de Arturo Fontaine y Lucas Sierra a una versión preliminar de este trabajo, así como los comentarios de Harald Beyer, Francisco Huenchumilla y demás participantes del seminario realizado en el Centro de Estudios Públicos el 6 de noviembre del 2008. Todos los errores son exclusiva responsabilidad del autor.

Estudios Públicos, 113 (verano 2009). 
dían a casi 250.000 personas (alrededor del 27\% de la población total de la región). Cerca del 70\% de la población mapuche de la Región de la Araucanía vive en el sector rural. La tasa de pobreza de los mapuches de la región es sorprendentemente alta (llegando a casi el 18\% en el 2006), y aunque se ha reducido de manera considerable en los últimos doce años, continúa siendo elevada si se compara con el resto de la población. Parte de esto se explica por bajos niveles de escolaridad, pero también por las fluctuaciones en sus tasas de participación laboral y su alto nivel de informalidad en el mercado laboral. En cuanto a la tenencia de tierras, los mapuches son en general pequeños propietarios y la productividad de sus predios es muy baja.

Palabras clave: Población mapuche; Región de la Araucanía, Chile; variables socioeconómicas.

Recibido: noviembre de 2008. Aceptado: diciembre de 2008.

\section{Introducción}

E 1 Estado de Chile ha tenido un política bastante activa hacia los pueblos indígenas en los últimos veinte años. Por un lado, la Ley No 19.245 de 1993 abordó la situación de los pueblos originarios en varias dimensiones como, por ejemplo, el reconocimiento de las etnias y sus derechos como tales, consagración del derecho a la tierra, protección de su cultura, fomento de la participación de la población indígena a través de organizaciones reconocidas por la ley, y la creación de la Corporación Nacional de Desarrollo Indígena (Conadi), cuya finalidad es atender y satisfacer las demandas de los pueblos originarios, especialmente en lo que respecta a restitución de tierras, fomento productivo y fortalecimiento cultural. Recientemente se ha ratificado el Convenio 169 de la OIT² y existe además un proyecto de reforma constitucional en el Senado que "reconoce a los pueblos indígenas".

Dentro de la política general para los pueblos originarios, el traspaso de tierras a la población indígena ha sido una medida de gran envergadura. De acuerdo a Mideplan (2006), entre 1993 y 2005 se traspasaron “más de 491 mil hectáreas de tierras a comunidades indígenas”. Además se puso en marcha el programa Orígenes que se focaliza en el desarrollo productivo de los predios adquiridos por la Conadi.

No obstante la implementación de todo este conjunto de políticas públicas, aún es común leer en la prensa artículos sobre el “conflicto mapu-

${ }^{2}$ El Convenio establece el reconocimiento a los pueblos indígenas y contempla un conjunto de derechos suyos. Para más detalle véase Donoso (2008). 
che" y en particular sobre acciones que realizan algunos grupos de personas de la etnia mapuche —o simpatizantes de ellos_ en la región de la Araucanía. El “conflicto mapuche”, por consiguiente, permanece como un tema destacado de la agenda pública.

Existe la idea de que una de las raíces de la problemática relacionada con los pueblos indígenas, y en especial con el pueblo mapuche, se encuentra en sus atrasadas condiciones económicas en comparación con el resto del país. Mediante una recopilación sistemática de datos y su posterior análisis, este trabajo se propone entregar una visión global y actualizada de la situación socioeconómica de la población mapuche en la IX Región y de sus determinantes.

En primer lugar, se busca comprender el entorno económico en el que se desenvuelven los mapuches de la IX Región, y cómo este entorno ha evolucionado a través del tiempo. Así, en la sección II del trabajo se presenta un análisis de la situación macroeconómica de la IX Región de la Araucanía, describiéndose el crecimiento de la región y su relación con el crecimiento del país. Además, se da una mirada al mercado laboral de la región y cómo ha evolucionado su estructura productiva. Esto último es de particular interés porque, como se mostrará posteriormente, los mapuches trabajan de manera más intensa en ciertas ramas de actividad económica —específicamente en los sectores agropecuario y construcción-, y la mirada macroeconómica nos permite saber si estos sectores han sido y siguen siendo más o menos dinámicos en cuanto a actividad económica y creación de puestos de trabajo.

En segundo lugar, en la sección III, se examinan las características socioeconómicas de los mapuches de la IX Región. Aquí se procura obtener alguna idea acerca de los flujos de la población mapuche hacia y fuera de los sectores rurales y urbanos de la IX Región. También se calculan tasas de pobreza y se exploran sus relaciones con niveles de educación y tasas de ocupación. Temas asociados son los ingresos laborales y las condiciones laborales que los mapuches enfrentan en la IX Región. Al respecto, se encuentra que existe cierta informalidad en sus contratos, lo que a su vez redunda en bajas cotizaciones en los sistemas de pensiones y de salud, con la consecuente desprotección en estos ámbitos. Finalmente, se analiza la tenencia de tierras de los indígenas utilizando datos del censo agrícola.

En la sección IV se discuten los principales problemas que aquejan al pueblo mapuche conforme a los datos obtenidos en el estudio. Entre ellos: la baja productividad de las tierras indígenas, los bajos niveles de escolaridad y su relación con las fluctuaciones en tasas de participación laboral y la alta informalidad en el mercado laboral. 
Es importante indicar que este trabajo presenta los datos y los interpreta a la luz de la metodología económica. De seguro hay otras causas o fenómenos envueltos en todos los procesos aquí descritos. Por ejemplo, la cultura propia del pueblo mapuche y la institucionalidad de este pueblo podrían también explicar parte de los datos aquí expuestos. Nuestro análisis no niega esas posibilidades sino que utiliza una metodología propia de la ciencia económica $y$, en este sentido, es una forma de aproximarse a la interpretación de la realidad mostrada en los datos. Trabajos posteriores que ofrezcan otras miradas como, por ejemplo, de tipo sociológico, antropológico o del mundo de la cultura, serán un complemento interesante a nuestro análisis.

\section{EL ENTORNO MACROECONÓMICO DE LA IX REGIÓN}

En esta sección comenzaremos analizando las condiciones macroeconómicas de la IX Región y su evolución en el tiempo. El análisis de estas variables nos permitirá comprender el entorno económico en que se desenvuelven los mapuches que residen en la región de la Araucanía. Como se mostrará más adelante, el pueblo mapuche en la IX Región es numeroso, llegando a cerca de 250.000 personas en el año 2006, lo que representa algo más de un cuarto de la población total de la región, y de ellos casi un 70\% se encuentra en el sector rural. Si se considera que cerca del 30\% de la población total de mapuches del país reside en la IX Región, las condiciones de esta región tienen, en consecuencia, un fuerte impacto en la población de mapuches de Chile.

Éste es un aspecto relevante porque cambios bruscos en las condiciones macroeconómicas pueden tener un impacto importante en la vida de los habitantes de la IX Región - y, por consiguiente, de los mapuches de la IX Región-, al afectar a los mercados, incluido el mercado laboral, y generar por ende aumentos en tasas de desempleo o disminuciones en salarios reales, variables que tienen una influencia directa en la pobreza y el bienestar de las personas.

\section{II. a) Actividad económica}

Comenzaremos analizando la evolución del PIB de la región. La Figura $N^{\circ} 2.1$ compara la evolución de la tasa de crecimiento del PIB de la IX Región con la evolución de la tasa de crecimiento del país desde 1977 hasta el año 2006. Tal como puede observarse, los movimientos de ambas series 
FIGURA No 2.1: TASA DE CRECIMIENTO ANUAL DE PIB IX REGIÓN Y PIB DE CHILE, 1977-2006

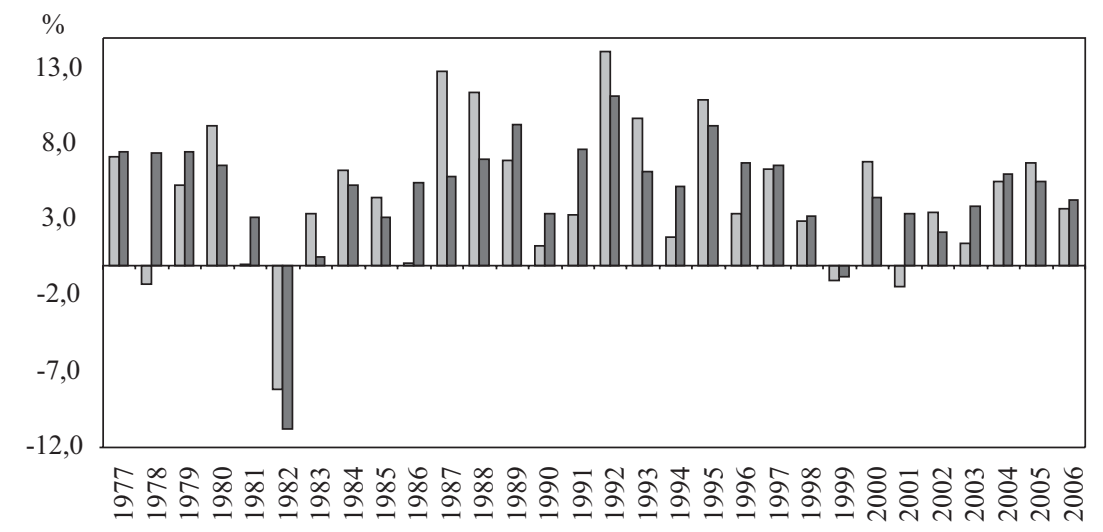

$\square$ PIB IX Región $\square$ PIB total

son muy parecidos, y, de hecho, si se calcula el coeficiente de correlación entre ambas, éste es del orden del 73\% en este período. Este coeficiente de correlación, que mide la relación entre nuestras dos variables, indica en este caso que por cada aumento de $1 \%$ en la tasa de crecimiento del PIB de Chile, se observaría un aumento de $0,73 \%$ en la tasa de crecimiento del PIB de la IX Región.

La Tabla $N^{\circ} 2.1$ entrega información adicional. En primer lugar, la IX Región tuvo tasas de crecimiento bastante modestas hasta 1986: en promedio fue de 2,3\% anual entre 1960-1997 y 2,5\% anual entre 1977-1986. Sin embargo, desde 1986 la región sufre un despegue significativo al pasar su tasa de crecimiento a un 6,6\% promedio anual entre 1986-1996 y algo menor, 5,1\% promedio, si tomamos el período más largo entre 1986 y 2006. Esta dinámica tasa de crecimiento ha tendido a desacelerarse en los últimos años, llegando a un 3,4\% promedio anual entre 1997-2006. Obviamente este recorrido de la tasa de crecimiento de la IX Región se asemeja mucho a la trayectoria de la tasa de crecimiento del país en su conjunto, algo que ya habíamos advertido en la Figura $\mathrm{N}^{\circ} 2.1$.

Sin perjuicio de las semejanzas con el país como un todo, una segunda característica que emerge de la tabla es que la tasa de crecimiento del PIB de Chile es en promedio más alta que la tasa de crecimiento de la IX Región. Esto ocurre para los distintos períodos considerados, y si bien las diferencias pueden parecer menores, en realidad los efectos de largo plazo no lo 
TABLA N N $^{\circ}$.1: $\quad$ CRECIMIENTO DE CHILE Y DE LA IX REGIÓN, VARIOS PERÍODOS

$1960-2006 \quad 1960-1977 \quad 1977-1986 \quad 1986-2006 \quad 1997-2006$

\begin{tabular}{llllll} 
Crecimiento PIB Chile & 3,9 & 2,7 & 3,4 & 5,4 & 3,8 \\
Std, \% PIB Chile & 4,4 & 5,1 & 5,6 & 2,5 & 2,0 \\
Crecimiento IX Región & 3,5 & 2,3 & 2,5 & 5,1 & 3,4 \\
Std, \% IX Región & 4,9 & 5,2 & 5,0 & 4,2 & 2,9 \\
Correlación & 0,64 & 0,51 & 0,75 & 0,70 & 0,75 \\
\hline
\end{tabular}

Fuente: Cálculos propios.

son. De hecho, si se toma la diferencia entre la tasa de crecimiento del PIB de Chile entre 1960-2006 (3,9\%) y se compara con la de la IX Región (3,4\%), se obtiene una diferencia que en el horizonte de los 46 años transcurridos entre 1960 y el 2006 producen una diferencia acumulada de 27\%, lo que indica que en promedio las cantidades de bienes y servicios disponibles en el año 2006 deberían ser aproximadamente 27\% inferiores que en el promedio de Chile debido a este factor de diferencial de crecimiento.

En tercer lugar, la IX Región muestra una mayor desviación estándar en su tasa de crecimiento comparado con el país; lo que indica que las tasas de crecimiento del PIB de la IX Región son más volátiles que las del resto del país en promedio y por lo tanto es más factible observar en la IX Región tasas de crecimiento muy altas o muy negativas en comparación a lo que ocurre en el resto del país.

En cuarto lugar, tal como se aprecia en la tabla, es posible calcular correlaciones entre las tasas de crecimiento del PIB de la Araucanía y del PIB de Chile. La correlación varía si tomamos distintas ventanas de tiempo: llega sólo a 51\% en el período 1960-1977, para posteriormente estabilizarse en la cercanía del $75 \%$. De esta forma, en los años sesenta y setenta la economía de la IX Región se encontraba bastante más aislada de lo que era la situación general del país en comparación a lo que sucede en la actualidad.

Para entender un poco más la evolución de las tasas de crecimiento se procede a separar esta variable en un componente de tendencia y un componente cíclico. El componente tendencia se relaciona con la tasa de crecimiento que depende de fundamentos de largo plazo mientras que el componente cíclico se relaciona con desviaciones respecto a la tendencia de largo plazo. La serie componente cíclico debería entonces mostrar impac- 
tos de aumentos (disminuciones) de corto plazo de variables como tasas de interés o términos de intercambio, separando estos efectos del crecimiento de largo plazo de la actividad económica, que depende finalmente de las tendencias de largo plazo en empleo, acumulación de capital y productividad de factores. Las Figuras Nos. 2.2 y 2.3 muestran la evolución del componente tendencia y del componente cíclico tanto para Chile como para la Región de la Araucanía ${ }^{3}$.

La Figura $N^{0} 2.2$ señala que la tendencia de crecimiento tanto de Chile como de la Región de la Araucanía ha cambiado drásticamente a través del tiempo, pasando por etapas de muy modesto crecimiento de largo plazo en los años 70 para acelerarse considerablemente en los 80 , llegando a peaks de $6 \%$ en la mitad de los 90 . Desde esa fecha, tanto el país como la Región de la Araucanía han mostrado una desaceleración considerable en su crecimiento de tendencia, pero además la IX Región ha convergido a tasas menores (3,3\%) que las de Chile (3,9\%), por lo que en la actualidad la región presentaría un potencial de crecimiento menor al del resto de Chile.

De manera concordante con las crisis económicas enfrentadas por nuestro país, la serie de movimiento cíclico de Chile (véase Figura No 2.3) muestra que el PIB estaba cerca de $14 \%$ por debajo de sus niveles de tendencia en el año 1975 y cerca de 5\% por debajo de sus niveles de tendencia en los años 1982-1983. La irrupción de la crisis asiática también muestra efectos negativos al alcanzar una desviación respecto a la tendencia de largo plazo de casi -3\% en el año 2002. La serie de movimiento cíclico de la

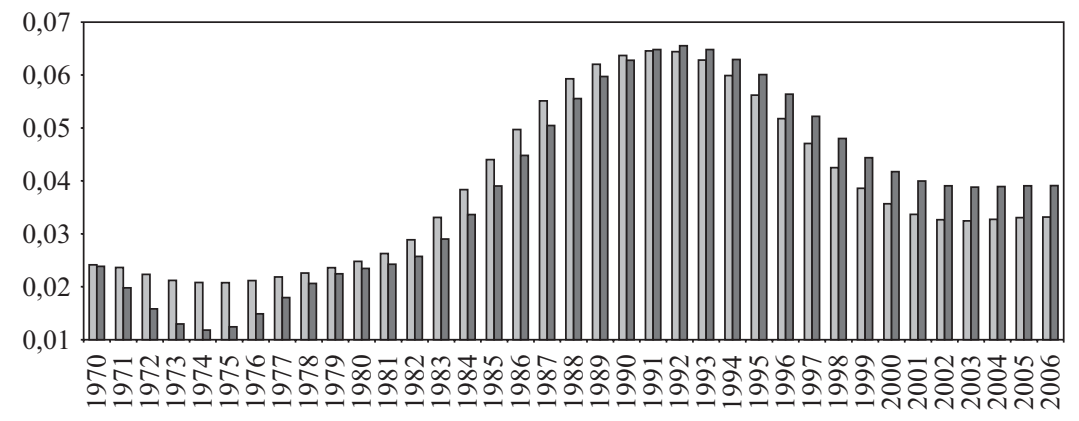

Tendencia IX Región $\quad \square$ Tendencia Chile

${ }^{3}$ Estas series se calculan utilizando el filtro de Hodrick y Prescott a datos anuales desde 1960 a 2006. 
FIGURA N ${ }^{\circ}$ 2.3: $\quad$ CICLO ECONÓMICO IX REGIÓN VERSUS CHILE, 1977-2006

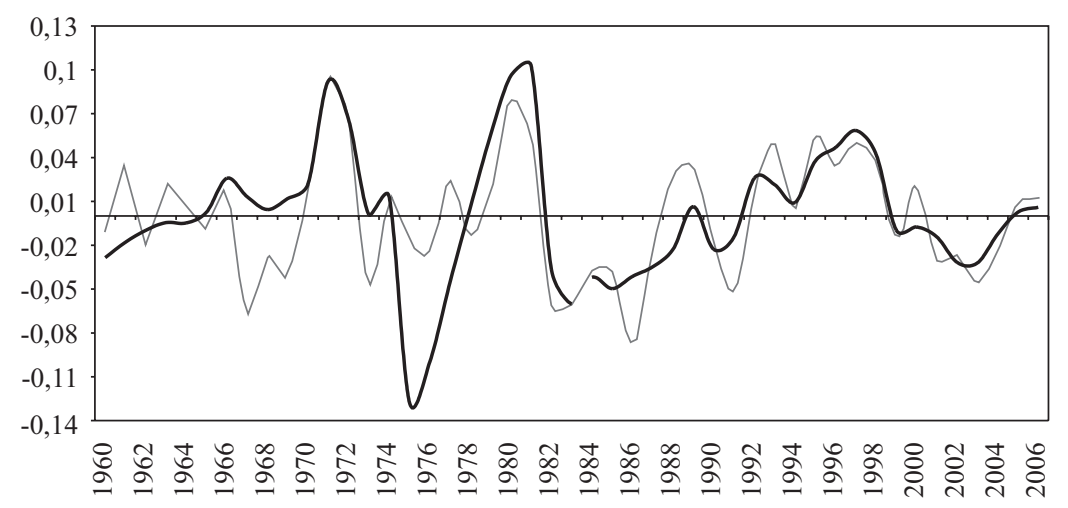

- Ciclo país - Ciclo IX Región

Región de la Araucanía exhibe una alta similitud con la serie para Chile, aunque con excepciones, como en la crisis de 1975 que parece haber afectado algo menos a esta región. Sin embargo, a partir de la década de los 80, la similitud entre la serie pasa a ser bastante mayor, coincidiendo marcadamente en las épocas de crisis. En este caso, también podemos calcular correlaciones, tal como lo hicimos en la Tabla $\mathrm{N}^{\circ}$ 2.1, pero las correlaciones indican coincidencia en movimientos cíclicos. Si tomamos el período 1960-2006, la correlación entre movimiento cíclicos de Chile y de la Región de la Araucanía es de 68\%, pero con posterioridad a 1982 esta correlación aumenta a 85\% y desde 1996 alcanza el 92\%; confirmando una muy alta y creciente asociación desde inicios de los 80.

La Tabla N N $^{0} .2$ nos entrega información adicional, al permitirnos comparar la correlación con el PIB en la IX Región versus lo que ocurre en otras regiones. La Región Metropolitana muestra una altísima correlación con el PIB de Chile y esta correlación es altamente estable a través de distintos períodos de tiempo, tal como se aprecia en la tabla. Las correlaciones de otras regiones son, en promedio, mayores entre 1960 y 1985 y disminuyen considerablemente con posterioridad. De hecho, la mayoría de las regiones tienden a disminuir sus correlaciones con el crecimiento del PIB, como es el caso de las regiones I, V, VIII, XI, XII. Por su parte, la IX Región muestra un comportamiento atípico, al aumentar su correlación con la actividad económica del país, pasando desde un 0,49 en el período 1060-1976 hasta un 0,75 en el período 1997-2006. 
TABLA N N $^{\circ .2:} \quad$ CORRELACIONES ENTRE TASA DE CRECIMIENTO DE CHILE Y DE REGIONES

\begin{tabular}{lrrrrc}
\hline Región & $1960-1976$ & $1977-1985$ & $1986-1996$ & $1997-2006$ & $1960-2006$ \\
\hline I & 0,70 & 0,79 & 0,55 & 0,08 & 0,65 \\
II & 0,61 & $-0,02$ & 0,20 & 0,36 & 0,41 \\
III & 0,20 & 0,69 & 0,47 & 0,41 & 0,44 \\
IV & 0,23 & 0,58 & 0,36 & 0,10 & 0,37 \\
V & 0,85 & 0,95 & 0,56 & 0,06 & 0,84 \\
VI & 0,27 & 0,20 & 0,23 & 0,43 & 0,29 \\
VII & 0,26 & 0,30 & 0,40 & 0,79 & 0,41 \\
VIII & 0,92 & 0,84 & 0,64 & 0,67 & 0,84 \\
IX & 0,49 & 0,79 & 0,61 & 0,75 & 0,65 \\
X & 0,59 & 0,81 & $-0,02$ & 0,69 & 0,67 \\
XI & 0,13 & 0,06 & $-0,42$ & 0,04 & 0,09 \\
XII & 0,83 & 0,56 & 0,36 & $-0,06$ & 0,62 \\
Región Metrop. & 0,93 & 0,99 & 0,91 & 0,98 & 0,96 \\
Promedio & 0,54 & 0,58 & 0,37 & 0,41 & 0,55 \\
\hline
\end{tabular}

Fuente: Cálculos propios.

\section{II. b) Actividades productivas}

Como hemos visto, la IX Región ha aumentado su grado de asociación con la actividad económica del país en el transcurso del siglo XX. Parte de la explicación del aumento en este grado de asociación puede deberse a que la matriz productiva de la región ha evolucionado y se comienza a parecer cada vez más a la estructura productiva del país. A continuación nos extenderemos sobre este punto.

La Tabla $\mathrm{N}^{\circ} 2.3$ muestra la participación de distintas actividades productivas en relación con el PIB tanto en la IX Región como en Chile en su conjunto. Como puede observarse, la IX Región a comienzos de los ochenta tenía un sector productivo muy concentrado en el sector agropecuariosilvícola (25\%), mientras que su sector manufacturero era relativamente pequeño (8,5\% del PIB), comparado con el resto del país (17,9\% del PIB). Algo similar ocurría con los servicios financieros (8,5\% versus $12,2 \%$ en Chile). Estas cifras cambian radicalmente a comienzos del siglo XXI, y de acuerdo con los datos del 2006 (basados en la matriz insumo-producto de 1996), el sector agropecuario-silvícola ha disminuido su tamaño a sólo un 11,3\% del PIB mientras que la cifra para el país como un todo es del 6\%. Por otro lado, tanto la industria manufacturera como el sector financiero han aumentado 
TABLA N ${ }^{\circ}$ 2.3: $\quad$ EVOLUCIÓN DE PARTICIPACIÓN DE ACTIVIDADES ECONÓMICAS EN PIB, IX REGIÓN Y CHILE

\begin{tabular}{|c|c|c|c|c|c|c|c|c|}
\hline \multirow[b]{2}{*}{ Especificación } & \multicolumn{8}{|c|}{ IX Región de la Araucanía } \\
\hline & 1986 & 1990 & 1996 & 2000 & 2003 & 2004 & 2005 & 2006 \\
\hline Agropecuario-silvícola & 25,0 & 27,9 & 15,0 & 13,8 & 10,4 & 10,5 & 11,2 & 11,3 \\
\hline Pesca & 0,1 & 0,3 & 0,1 & 0,0 & 0,1 & 0,0 & 0,0 & 0,0 \\
\hline Minería & 0,3 & 0,3 & 0,1 & 0,1 & 0,4 & 0,4 & 0,4 & 0,4 \\
\hline Industria manufacturera & 8,5 & 10,1 & 11,6 & 10,3 & 13,6 & 14,9 & 15,5 & 16,3 \\
\hline Electricidad, gas y agua & 1,5 & 1,2 & 1,9 & 1,9 & 2,0 & 1,9 & 1,9 & 2,0 \\
\hline Construcción & 7,5 & 8,8 & 16,5 & 18,6 & 10,2 & 9,8 & 10,1 & 9,8 \\
\hline \multicolumn{9}{|l|}{ Comercio, restaurantes } \\
\hline y hoteles & 15,3 & 17,2 & 9,6 & 9,4 & 8,8 & 9,3 & 9,3 & 9,3 \\
\hline \multicolumn{9}{|l|}{ Transporte y } \\
\hline Servicios financieros (1) & 8,5 & 9,0 & 8,0 & 7,9 & 9,1 & 9,1 & 9,3 & 9,9 \\
\hline Propiedad de vivienda & 11,8 & 8,9 & 12,1 & 11,8 & 8,7 & 8,4 & 8,1 & 8,1 \\
\hline Servicios personales (2) & 15,5 & 11,7 & 16,0 & 16,3 & 20,5 & 19,7 & 19,1 & 18,3 \\
\hline \multirow[t]{2}{*}{ Administración pública } & 6,1 & 4,6 & 6,3 & 6,1 & 8,6 & 8,3 & 8,1 & 7,8 \\
\hline & \multicolumn{8}{|c|}{ Chile } \\
\hline Especificación & 1986 & 1990 & 1996 & 2000 & 2003 & 2004 & 2005 & 2006 \\
\hline Agropecuario-silvícola & 7,4 & 6,7 & 5,3 & 5,2 & 5,6 & 6,7 & 6,7 & 6,0 \\
\hline Pesca & 1,2 & 1,5 & 1,4 & 1,5 & 1,6 & 1,5 & 1,5 & 1,5 \\
\hline Minería & 10,0 & 12,6 & 7,0 & 8,4 & 8,2 & 12,6 & 12,6 & 7,2 \\
\hline Industria manufacturera & 17,9 & 18,5 & 19,1 & 17,8 & 17,2 & 18,5 & 18,5 & 17,3 \\
\hline Electricidad, gas y agua & 2,7 & 2,6 & 3,0 & 3,1 & 3,1 & 2,6 & 2,6 & 3,0 \\
\hline Construcción & 4,8 & 5,6 & 7,1 & 6,0 & 6,1 & 5,6 & 5,6 & 6,1 \\
\hline \multicolumn{9}{|l|}{ Comercio, restaurantes } \\
\hline y hoteles & 14,1 & 13,9 & 12,6 & 12,3 & 12,2 & 13,9 & 13,9 & 13,0 \\
\hline \multicolumn{9}{|l|}{ Transporte y } \\
\hline comunicaciones & 6,3 & 6,7 & 7,1 & 8,0 & 8,7 & 6,7 & 6,7 & 9,0 \\
\hline Servicios financieros (1) & 12,2 & 9,8 & 11,2 & 11,6 & 11,6 & 9,8 & 9,8 & 12,3 \\
\hline Propiedad de vivienda & 5,7 & 4,6 & 3,8 & 3,8 & 3,7 & 4,6 & 4,6 & 3,4 \\
\hline Servicios personales (2) & 8,9 & 8,6 & 12,2 & 12,3 & 12,2 & 8,6 & 8,6 & 11,6 \\
\hline Administración pública & 4,4 & 3,4 & 3,6 & 3,3 & 3,2 & 3,4 & 3,4 & 3,0 \\
\hline
\end{tabular}

(1) Incluye servicios financieros, seguros, arriendo de inmuebles y servicios prestados a empresas, (2) Incluye educación y salud públicas y privadas y otros servicios.

Fuente: Banco Central de Chile. 
su tamaño situándose en participaciones de 16,3\% y 9,9\% respectivamente, lo que se acerca al 17,3\% y 12,3\% de estas actividades en el país en su conjunto.

¿Cómo se explican estos cambios en la estructura productiva de la IX Región? Posiblemente por las continuas disminuciones en el tipo de cambio real observadas desde principios de los noventa. Como sabemos, el tipo de cambio real es un factor fundamental en la asignación de recursos entre sectores transables y no transables y la disminución en el tipo de cambio real indica un encarecimiento de los precios de los bienes no transables en términos de bienes transables, lo que entrega señales para que se produzca más en el sector no transable versus el sector transable (véase Cerda, Donoso y Lema, 2005). De esta forma sectores transables, como lo es el sector agropecuario-silvícola, deberían verse perjudicados, mientras que sectores que producen bienes y servicios no transables deberían verse beneficiados, como es el caso del sector de servicios financieros y en alguna medida de la industria manufacturera.

El factor tipo de cambio real puede ser relevante para explicar cambios en la participación relativa de los sectores productivos en la IX Región debido a que el tipo de cambio real disminuyó cerca de $30 \%$ en el período 1990-1998, de acuerdo con la medida publicada por el Banco Central de Chile ${ }^{4}$.

\section{II. c) PIB per cápita}

Por el momento el acento de la discusión macroeconómica ha estado en la evolución del PIB tanto de Chile como de la Región de la Araucanía. Sin embargo, una variable más indicativa del nivel de bienestar de la población es el PIB por habitante (PIB per cápita). La Tabla No 2.4 muestra datos de PIB per cápita a nivel regional para varios años, a partir de 1960. Los datos corresponden a pesos del año 2000. Al observar los datos, la primera impresión es que existe una alta dispersión de ingreso per cápita entre regiones y que este fenómeno tiene antiguas raíces porque ya se observaba en 1960 (posiblemente antes, pero nuestros datos se remontan sólo a 1960). De hecho, los datos de 1960 muestran que la XII Región era lejos la de mayor ingreso per cápita del país en 1960, con un ingreso per cápita de 4,5 millones por año, es decir algo así como 381.500 pesos mensuales. Por otro lado, la región “más pobre” era la IX Región, con sólo 0,34 millones por año, o algo cercano a los 28.000 pesos mensuales por habitante. De esta forma, la Región de la Araucanía en el año 1960 representaba sólo el 30\% del PIB

\footnotetext{
${ }^{4}$ En el período 1998-2007, esta caída se ha revertido sólo parcialmente.
} 
TABLA N 2.4: $\quad$ PIB PER CÁPITA REGIONAL, MILES DE PESOS AÑO 2000

\begin{tabular}{lrrrrrr}
\hline Región & 1960 & 1970 & 1980 & 1990 & 2000 & 2006 \\
\hline I & 1.650 & 1.626 & 1.880 & 1.921 & 3.123 & 3.583 \\
II & 1.622 & 2.222 & 2.914 & 3.371 & 5.610 & 6.591 \\
III & 950 & 1.097 & 1.222 & 1.508 & 3.202 & 3.542 \\
IV & 517 & 678 & 827 & 1.068 & 1.709 & 1.810 \\
V & 1.089 & 1.203 & 1.282 & 1.396 & 1.917 & 2.257 \\
Región Metropolitana & 1.231 & 1.599 & 1.516 & 1.667 & 2.566 & 3.039 \\
VI & 914 & 1.074 & 1.284 & 1.460 & 2.126 & 2.565 \\
VII & 495 & 637 & 685 & 971 & 1.667 & 2.099 \\
VIII & 760 & 923 & 1.048 & 1.206 & 1.532 & 1.927 \\
IX & 340 & 403 & 489 & 631 & 961 & 1.100 \\
X & 458 & 530 & 636 & 863 & 1.392 & 1.633 \\
XI & 690 & 1.158 & 1.134 & 1.220 & 1.910 & 2.446 \\
XII & 4.578 & 3.959 & 3.716 & 4.145 & 4.452 & 5.215 \\
Promedio & 1.176 & 1.316 & 1.433 & 1.648 & 2.474 & 2.908 \\
& & & & & & \\
\hline
\end{tabular}

Ranking PIB per cápita

\begin{tabular}{lrrrrrr} 
I & 2 & 3 & 3 & 3 & 3 & 3 \\
II & 3 & 2 & 2 & 2 & 1 & 1 \\
III & 7 & 8 & 7 & 5 & 4 & 4 \\
IV & 10 & 10 & 10 & 10 & 9 & 11 \\
V & 5 & 5 & 6 & 7 & 7 & 8 \\
Región Metropolitana & 4 & 4 & 4 & 4 & 5 & 5 \\
VI & 6 & 7 & 5 & 6 & 6 & 6 \\
VII & 11 & 11 & 11 & 11 & 10 & 9 \\
VIII & 8 & 9 & 9 & 9 & 11 & 10 \\
IX & 13 & 13 & 13 & 13 & 13 & 13 \\
X & 12 & 12 & 12 & 12 & 12 & 12 \\
XI & 9 & 6 & 8 & 8 & 8 & 7 \\
XII & 1 & 1 & 1 & 1 & 2 & 2 \\
\hline
\end{tabular}

Fuente: Cálculos propios.

promedio regional de Chile y sólo el 7,4\% del PIB per cápita de la región más “rica” de Chile.

La Tabla Nº 2.4 también nos presenta la evolución del PIB per cápita y el ranking regional de acuerdo al tamaño del PIB per cápita. Este último dato trae malas noticias para la IX Región, en el año 2006 y en cada uno de los años reportados la IX Región se mantiene como la región "más pobre” de Chile. En general existe poca movilidad de las regiones, salvo los casos de las que encabezan la clasificación. Por otro lado, la tabla trae algunas buenas noticias: el ingreso per cápita (medido en pesos constantes) de la Región de la Araucanía es en 2006 más de tres veces mayor al de 1960. 
Estas cifras parecen contrariar la evidencia acerca del rápido crecimiento de la Región de la Araucanía mostrada en la subsección anterior. Además, contrariaría también la evidencia a nivel internacional de que existiría una convergencia en el PIB per cápita, al menos cuando se consideran regiones relativamente homogéneas o con características comunes (véase Barro y Sala-i-Martin, 2004). Esta evidencia indica que regiones que inicialmente tienen menores niveles de ingreso per cápita deberían crecer más rápido para converger o "alcanzar" niveles de desarrollo similares a los de las más ricas. Esto se debe a que las regiones más atrasadas pueden aprovechar fases de crecimiento fácil, que se basa en acumulación de capital y empleo, y en menor medida en crecimiento de productividad. Las regiones más desarrolladas en general ya han pasado por la etapa de mayor acumulación de capital físico y empleo, y deben basar su crecimiento mayormente en la productividad de los factores.

La Figura $N^{0} 2.4$ ilustra la existencia de una posible convergencia regional en el caso de Chile (una buena y extensa discusión se encuentra en Soto y Torche, 2004). Tal como se puede apreciar en la Figura $N^{0} 2.4$, que relaciona el logaritmo del ingreso per cápita en 1960 con la tasa de crecimiento promedio entre 1960 y el 2006, se tiende a observar que regiones que inicialmente eran más pobres crecen a tasas mayores, en términos de ingreso per cápita. De hecho, la IX Región, que era la más pobre en 1960, crece a un promedio de 2,5\% anual en términos per cápita, cifra bastante superior a la de otras regiones inicialmente más ricas.

Si esta evidencia es correcta, deberíamos observar que la IX Región se acerca más a las restantes en términos de producto per cápita, algo que

FIGURA N N 2.4: CONVERGENCIA REGIONAL, PIB PER CÁPITA, 1960-2006

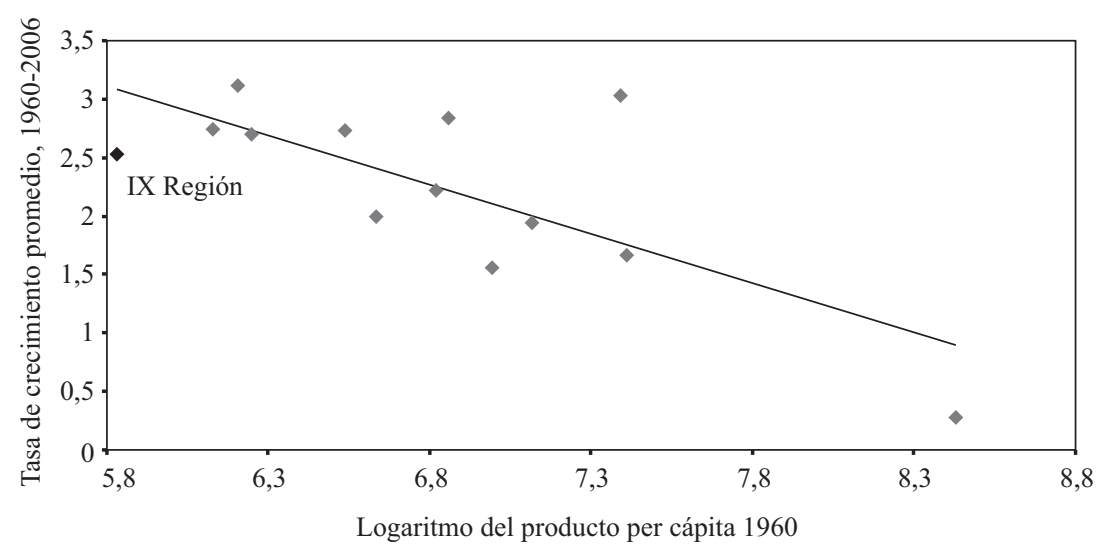


FIGURA N ${ }^{\circ}$ 2.5: $\quad$ PIB PER CÁPITA IX REGIÓN COMO FRACCIÓN DE PIB PER CÁPITA PROMEDIO NACIONAL

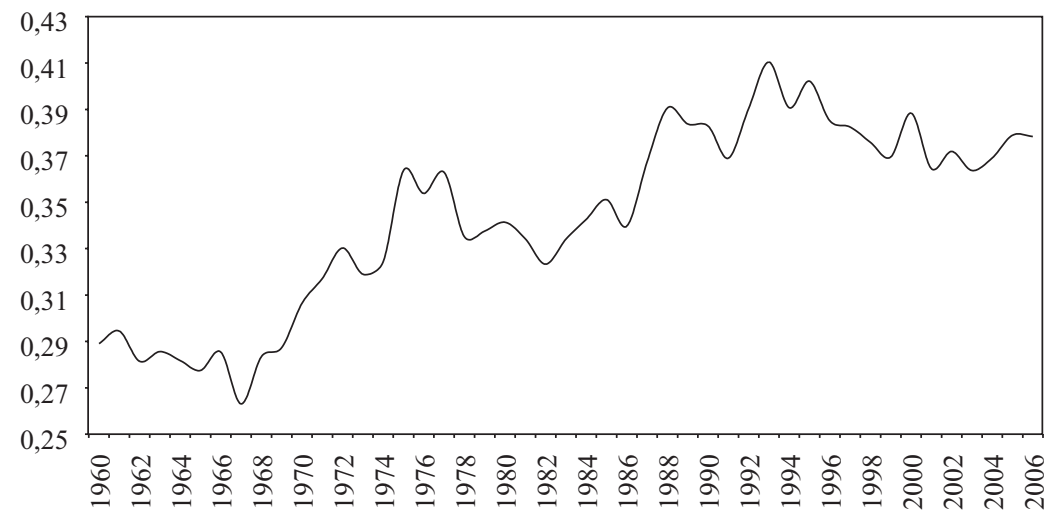

parece no ocurrir dado que esta región se mantuvo siempre última en el ranking de ingreso per cápita (véase Tabla $N^{\circ}$ 2.3). Sin embargo, la Figura No 2.5, que mide la evolución del PIB per cápita de la IX Región como fracción del PIB per cápita promedio, indica que el PIB per cápita de la Araucanía ha crecido más rápido que el promedio, aumentando significativamente en los años 70 y posteriormente a finales de los 80. Esta evidencia si bien señala que existe cierto tipo de convergencia en PIB per cápita de la Región de la Araucanía, esta convergencia es relativamente lenta y hasta el momento no le ha permitido dejar de ser la región más pobre (en términos de ingreso per cápita promedio) de Chile.

\section{II. d) Estructura del mercado laboral}

La Tabla N 2.5 muestra que la IX Región representa en la actualidad cerca de un 5\% del empleo total del país (cerca de 350.000 empleos sobre un total de 6.642.390 empleos). Este tamaño es similar al de regiones tales como la VI y VII, y algo superior al de las regiones I, II y IV. El empleo regional se concentra en los sectores agricultura, pesca y silvicultura (28\%), servicios comunales $(24,6 \%)$ y comercio $(16,1 \%)$. Es interesante notar que la proporción del empleo en agricultura, pesca y silvicultura es bastante superior a la proporción del PIB que se produce en este sector en la IX Región, que representa sólo el 7,5\% (véase Tabla $N^{\circ} 2.3$ ). Esto no ocurre con servicios ni comercio. De hecho el sector comercio representa cerca del 10\% del PIB mientras que la suma de los sectores servicios financieros, servicios perso- 
TABLA N ${ }^{\circ}$ 2.5: $\quad$ EMPLEO REGIONAL SEGÚN CLASE DE ACTIVIDAD ECONÓMICA, MILES DE PERSONAS, DICIEMBRE 2007

\begin{tabular}{|c|c|c|c|c|c|c|c|c|c|c|}
\hline Región & $\begin{array}{c}\text { Agri- } \\
\text { cultura, } \\
\text { pesca, } \\
\text { silvicul- } \\
\text { tura }\end{array}$ & $\begin{array}{l}\text { Comer- } \\
\text { cio }\end{array}$ & $\begin{array}{l}\text { Cons- } \\
\text { trucción }\end{array}$ & $\begin{array}{l}\text { Electri- } \\
\text { cidad, } \\
\text { gas y } \\
\text { agua }\end{array}$ & $\begin{array}{l}\text { Sector } \\
\text { finan- } \\
\text { ciero }\end{array}$ & $\begin{array}{c}\text { Minas } \\
\mathrm{y} \\
\text { canteras }\end{array}$ & Industria & $\begin{array}{l}\text { Servi- } \\
\text { cios } \\
\text { comu- } \\
\text { nales }\end{array}$ & $\begin{array}{l}\text { Transporte, } \\
\text { almacena- } \\
\text { miento y } \\
\text { comunica- } \\
\text { ciones }\end{array}$ & , Total \\
\hline I & 16,96 & 52,37 & 15,14 & 1,09 & 11,38 & 5,09 & 22,46 & 51,65 & 23,2 & 199,34 \\
\hline II & 6,23 & 44,82 & 33,81 & 1,98 & 20,81 & 23,08 & 27,17 & 40,03 & 23,81 & 221,74 \\
\hline III & 14 & 20,3 & 18,63 & 0,26 & 7,39 & 13,87 & 4,85 & 22,9 & 7,37 & 109,57 \\
\hline IV & 54,27 & 52,55 & 21,44 & 0,71 & 17,12 & 14,79 & 15,9 & 53,6 & 21,04 & 251,42 \\
\hline V & 67,22 & 153,67 & 47,57 & 5,73 & 51,97 & 11,44 & 58,04 & 221,29 & 59,11 & 676,04 \\
\hline VI & 118,52 & 46,87 & 24,98 & 2,52 & 14,17 & 8,31 & 31,27 & 65,98 & 25,47 & 338,09 \\
\hline VII & 144,89 & 67,32 & 23,92 & 1,66 & 14,74 & 2,83 & 33,7 & 73,11 & 28,12 & 390,29 \\
\hline VIII & 112,3 & 126,77 & 46,68 & 3,97 & 41,69 & 2,57 & 99,67 & 194,13 & 57,26 & 685,04 \\
\hline IX & 98,35 & 56,41 & 33,67 & 1,62 & 16,97 & 0,16 & 36,75 & 86,34 & 20,66 & 350,93 \\
\hline$X$ & 115,18 & 77,26 & 26,45 & 3,03 & 23,12 & 0,33 & 68,05 & 110,18 & 32,48 & 456,08 \\
\hline XI & 6,96 & 7,52 & 4,83 & 0,52 & 1,93 & 1,2 & 5,8 & 14,78 & 3,64 & 47,18 \\
\hline XII & 7,03 & 11,79 & 7,88 & 0,55 & 4,41 & 2,79 & 5,5 & 17,88 & 6,34 & 64,17 \\
\hline Reg. Metrop. & 85,99 & 600,92 & 265,44 & 17,61 & 378,79 & 7,56 & 447,41 & 785,59 & 263,19 & 2852,5 \\
\hline
\end{tabular}

nales y administración pública representan cerca de un 36\% del PIB de la IX Región.

Cabe notar que la gran participación del sector agricultura, pesca y silvicultura en el empleo en la Región de la Araucanía no es algo que se repita a través del país. De hecho, en el país como un todo representa sólo el $12,8 \%$ mientras que en las regiones metropolitana y segunda las cifras son sólo 3\% y 2,8\% del total del empleo respectivamente, y en las regiones VI y VII se encuentra el otro lado de la medalla, donde el empleo en este sector representa algo más de 35\% del empleo total.

Esta observación, de una amplia participación del sector agricultura, pesca y silvicultura en el empleo de la IX Región, junto al hecho que esta área de la economía ha disminuido su tamaño como proporción del PIB a través del tiempo y que es posible que continúe disminuyendo en el futuro, puede significar que el sector tendrá problemas para mantener los actuales puestos de trabajo y que podría generarse mayor desempleo en el futuro.

El desempleo en la IX Región, tal como se puede apreciar en la Figura $\mathrm{N}^{\circ}$ 2.6, ha mostrado históricamente tasas menores a las del promedio del país. De hecho entre 1996 y 1998, cuando el desempleo en el país fluctuaba alrededor del 6\%, en la IX Región lo hacía cerca del 5\%, y si bien la irrupción de la crisis asiática inicialmente aumentó la tasa de desempleo a niveles 


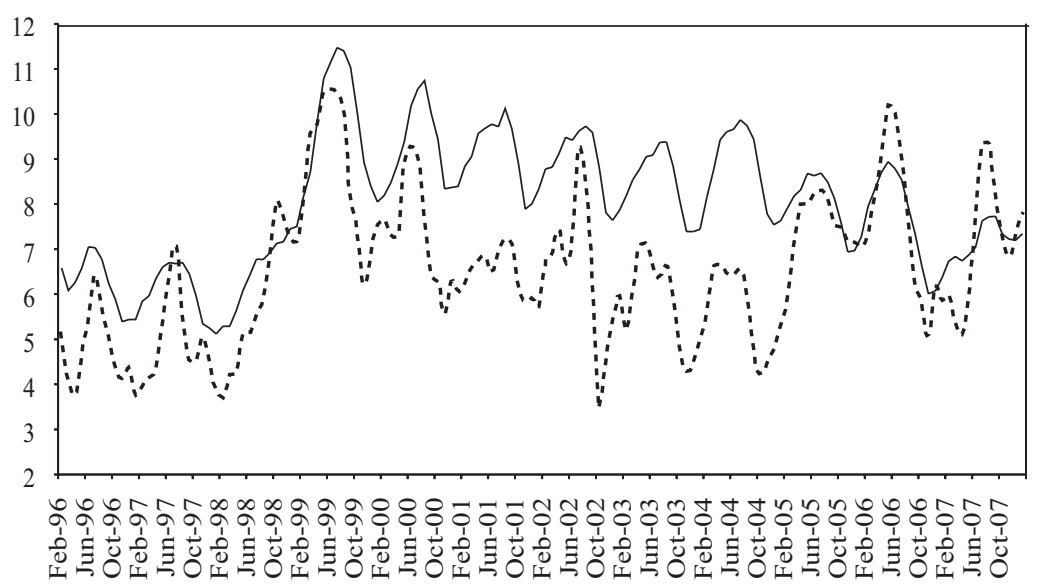

- - - Tasa desocupación, IX región _ Tasa de desocupación nacional

similares en el país y en la IX Región, el desempleo en la IX Región fue bastante menos rebelde, estabilizándose en la cercanía del 5 y 6\% en 2003, cuando en el país aún fluctuaba en cifras superiores al 8\%. Sin embargo, desde el año 2005 ambas tasas de desempleo tienden a converger a niveles algo superiores del 6\%, debido, por un lado, a una disminución en la tasa de desempleo del país, pero también a un aumento en la tasa de desempleo de la Región de la Araucanía. Este comportamiento del desempleo en la IX Región puede estar indicando incipiente estrechez en el mercado laboral de esta región debido a los cambios en la estructura productiva, y en particular del sector agricultura, pesca y silvicultura, o simplemente que la estructura laboral de esta región se asemeja cada día más a la del resto del país.

\section{II. e) Evolución de desigualdad regional, 1987-2006}

Finalmente, en nuestra mirada macroeconómica de la IX Región analizaremos la desigualdad de ingresos. Examinaremos dos medidas distintas de desigualdad de ingresos. La primera de ellas es el tradicional índice de Gini mientras que la segunda es la relación de ingresos del percentil 90 versus el percentil 10 de la distribución de ingresos (P90/P10). Mientras el índice de Gini utiliza toda la información de la distribución de ingresos, la medida P90/P10 ordena a los individuos en forma ascendente de acuerdo a 
sus ingresos y obtiene como P10 a la persona que se encuentra en el 10\% de la distribución, y como P90 el nivel de ingresos de la persona que se encuentra en el 90\% de la distribución. Mientras mayor sea la relación P90/ P10 mayor es el nivel de desigualdad.

Las Tablas No 2.6 y No 2.7 muestran la evolución de estos índices para las regiones del país desde 1987 a 2006. Estas tablas fueron construidas utilizando los datos de ingresos autónomos del hogar disponibles en las encuestas Casen.

En relación al índice de GINI, como es bien sabido nuestro país muestra altos grados de desigualdad de ingresos. Esta situación se mantiene bastante estable a través del tiempo con un pequeño mejoramiento en el año 2006. Por otro lado, las regiones del Norte Grande (I a III Región) muestran niveles de desigualdad algo menores y con avances significativos desde 1994, especialmente en 2006. Las regiones del extremo sur (XI y XII) muestran un escenario similar, al disminuir sus niveles de desigualdad desde algo más de 50 en el año 1987 a niveles menores a 46 en el 2006. Las regiones centrales ( $\mathrm{V}$ a VII) muestran también avances, pero no tan significativos. Los casos de la Región Metropolitana y la IX Región merecen atención especial. La Región Metropolitana tiene niveles de desigualdad bastante altos (55 y más) y estables, mostrando un pequeño mejoramiento en 2006. La IX Región por su parte muestra también niveles de desigualdad inicialmente altos (55,3 en 1987), que incluso se agravan desde mediados de los 90, llegando casi a un GINI de 60 en el año 2000. En el año 2006 se

TABLA N N 2.6: EVOLUCIÓN ÍNDICE DE GINI A NIVEL REGIONAL, 1987-2006

\begin{tabular}{llllllllll}
\hline & 1987 & 1990 & 1992 & 1994 & 1996 & 1998 & 2000 & 2003 & 2006 \\
& & & & & & & & & \\
\hline & & & & & & & & & \\
País & 55,8 & 54,4 & 55,3 & 55,8 & 55,5 & 56,1 & 56,5 & 55 & 52,4 \\
I Región & 51 & 52,1 & 52,5 & 47,5 & 49,2 & 47,9 & 49,7 & 48,3 & 41,4 \\
II Región & 49,8 & 51,7 & 42,9 & 49,5 & 48,9 & 47,6 & 49,2 & 42,4 & 46,1 \\
III Región & 50 & 51 & 48 & 43,7 & 58,1 & 46,1 & 45,5 & 45,9 & 44,4 \\
IV Región & 49,2 & 51,8 & 48,5 & 49 & 50,1 & 51,7 & 51,8 & 55,3 & 49,3 \\
V Región & 53,1 & 51,7 & 53,1 & 46,3 & 48,1 & 50,4 & 49,1 & 45,2 & 47,7 \\
VI Región & 52,3 & 51,7 & 51,6 & 49,5 & 50,7 & 52,2 & 49 & 46,9 & 46,8 \\
VII Región & 53,6 & 56 & 53,1 & 53,1 & 52,8 & 52,4 & 55,1 & 50,7 & 49,8 \\
VIII Región & 57,3 & 53,8 & 52,1 & 51,8 & 56 & 57,8 & 59,1 & 53,7 & 51,7 \\
IX Región & 55,3 & 56,7 & 46,3 & 58,7 & 53,8 & 58,5 & 59,4 & 58,1 & 53 \\
X Región & 56 & 53,1 & 51,3 & 54,4 & 52,8 & 52,4 & 50,9 & 52,3 & 49,9 \\
XI Región & 52,1 & 48,6 & 49,6 & 50 & 47,3 & 64,8 & 52,8 & 55,5 & 43,4 \\
XII Región & 49,9 & 50,5 & 50,9 & 41,7 & 47,4 & 53,1 & 56,1 & 49,2 & 45,2 \\
Región Metr. & 55,9 & 54 & 57,4 & 57,3 & 55,6 & 56,5 & 57,4 & 56,3 & 53,2 \\
\hline
\end{tabular}


TABLA N².7: EVOLUCIÓN ÍNDICE P90/P10 A NIVEL REGIONAL, 1987-2006

\begin{tabular}{lcccccrrrrr}
\hline & 1987 & 1990 & 1992 & 1994 & 1996 & 1998 & 2000 & 2003 & 2006 \\
\hline País & & & & & & & & & \\
I Región & 13,1 & 11,1 & 10,61 & 11,52 & 12,13 & 12,67 & 11,16 & 11,13 & 10,68 \\
II Región & 9,76 & 10,75 & 10,24 & 8,15 & 10,12 & 9,64 & 9,73 & 9,53 & 7,47 \\
III Región & 10,44 & 12,04 & 7,9 & 7,87 & 7,58 & 8,67 & 10,17 & 7,96 & 7,95 \\
IV Región & 8,32 & 9,16 & 8,5 & 8,15 & 12,07 & 9,76 & 9,13 & 9,58 & 8,78 \\
V Región & 9,22 & 9,32 & 8,6 & 8,56 & 9,75 & 9,79 & 9,54 & 10,26 & 7,82 \\
VI Región & 12,42 & 8,91 & 9,81 & 9,2 & 9,17 & 11,11 & 8,96 & 8,55 & 8,09 \\
VII Región & 9,65 & 10,93 & 9,8 & 8,52 & 9,16 & 9,74 & 8,46 & 9,08 & 8,52 \\
VIII Región & 11,72 & 11,92 & 10,08 & 9,23 & 9,34 & 9,39 & 9,48 & 8,41 & 9,52 \\
IX Región & 11,51 & 12,6 & 9,39 & 10,64 & 11,33 & 12,68 & 9,77 & 10,68 & 11,16 \\
X Región & 11,78 & 13,18 & 7,95 & 9,52 & 10,87 & 13,13 & 14,56 & 13,45 & 11,63 \\
XI Región & 12,91 & 9,76 & 10,26 & 9,51 & 10,19 & 9,99 & 10,2 & 10,69 & 10,65 \\
XII Región & 12,55 & 11,03 & 8,17 & 8,64 & 8,9 & 10,74 & 9,93 & 15,14 & 10,49 \\
Región Metr. & 14,41 & 11,2 & 11,5 & 1,83 & 10,11 & 9,14 & 17,99 & 9,37 & 9,34 \\
& & & & & 11,29 & 11,77 & 11,63 & 11,3 & 11,1 \\
\hline
\end{tabular}

observa un mejoramiento importante, aunque el índice de GINI sólo disminuye a 53. El caso de la VIII Región es similar al de la Región de la Araucanía, pero con un mejoramiento en sus índices de desigualdad que empieza a ocurrir antes que en la IX Región.

La Tabla No 2.7 muestra la evolución de la relación P90/P10. En el país, esta relación es bastante estable y cercana a 11 en la primera mitad de los años noventa. Esto quiere decir que la persona en el 90 percentil tenía ingresos (autónomos del hogar) once veces superiores a una persona en el percentil 10. Esta relación empeora con la llegada de la crisis asiática alcanzando un 12,67 en el año 1998. Desde ese peak, el índice disminuye paulatinamente hasta llegar a 10,68. La IX Región presenta niveles de desigualdad importantes en el año 1990 pero mejora sustancialmente durante la década de los noventa. Sin embargo, la irrupción de la crisis asiática golpea fuerte el nivel de desigualdad en esta región porque la IX Región presenta los peores índices P90/P10 en el período de la crisis asiática, llegando a 14,56 en el año 2000. Esta cifra está dentro de las peores cifras en Chile en esa época. La cifra del año 2006 muestra un mejoramiento importante.

Lo que sugieren estas cifras es que la IX Región tiene niveles de desigualdad importantes, pero que se revierten sustancialmente en épocas de expansión económica como lo fue la década de los noventa. De la misma manera, las crisis económicas producen aumentos importantes en desigualdad de ingresos en esta zona, sugiriendo que los ingresos laborales pueden ser altamente pro-cíclicos, y los ingresos laborales de los individuos más pobres se ven afectados de forma más intensa por el efecto ciclo. 


\section{CARACTERÍSTICAS SOCIOECONÓMICAS DE LOS MAPUCHES EN LA IX REGIÓN}

La sección II de este trabajo analiza las condiciones macroeconómicas de la IX Región con el fin de contextualizar el entorno económico que enfrentan los individuos del pueblo mapuche en la Región de la Araucanía. Ya no nos centramos en la región como un todo sino que nos proponemos analizar de modo específico al grupo de personas que se definen como mapuches y que viven en la IX Región. La mirada que entregamos es de corte socioeconómico.

Para el análisis de las características socioeconómicas de la población mapuche en la IX Región utilizaremos principalmente datos disponibles en las encuestas Casen. Esta encuesta contiene información de tipo socioeconómico y demográfico de la población chilena y se ha realizado los años 1987, 1990, 1992, 1994, 1996, 2000, 2003 y 2006. La información socioeconómica incluye preguntas sobre educación, salud, vivienda y empleo, entre otros. Además, contiene temas especiales en sus distintas versiones. Entre éstos, se han incluido preguntas sobre etnias en los años 1996, 2000, 2003 y 2006. A continuación utilizaremos los resultados de las encuestas Casen de los años 1996, 2000, 2003 y 2006, los que complementaremos con información sobre medidas de calidad de educación provenientes del Simce (sistema de medición de la calidad de la educación), y con resultados de sondeos de opinión pública del CEP de mayo 2006 y datos del VI Censo Agropecuario de 1997.

La discusión permitirá analizar las diferencias de los mapuches versus otros grupos y cómo esas diferencias han variado entre 1996 y 2006. Inicialmente se discutirán las características de la población mapuche en la IX Región, para posteriormente centrarse en tópicos tales como tasas de pobreza, educación, mercado laboral, acceso a salud y vivienda, y situación patrimonial.

\section{III. a) Población mapuche en la IX Región: Evolución 1996-2006}

Comenzaremos analizando la evolución de la población mapuche en la Región de la Araucanía. Entenderemos como mapuches a aquellas personas que se auto-declaran como pertenecientes a ese grupo indígena en las encuestas que analizamos. Obviamente pueden existir otras dimensiones que definan la pertenencia a pueblos indígenas, como por ejemplo la des- 
cendencia de poblaciones originarias, sin embargo este tipo de dimensiones no son posibles de reconocer en nuestras fuentes de datos y la única manera de identificar pertenencia a pueblos indígenas es la auto-declaración ${ }^{5}$.

Dicho esto, las Tablas No 3.1 y N 3.2 presentan datos del Censo 2002. La Tabla $N^{0} 3.1$ muestra el número (y porcentaje) de personas que se identifican con algún grupo étnico en el año 2002 y su distribución a través del país. La población identificada con grupos étnicos asciende a casi 700.000 personas (4,6\% de la población total del país) y casi la mitad de la población indígena se concentra en la IX Región y la Región Metropolitana, siendo la IX Región aquella con mayor población indígena en el país. Además la población de grupos étnicos representa casi un cuarto de la población de la Región de la Araucanía. La Tabla No 3.2 muestra que la mayoría (casi el 90\%) de las personas que se identifican con grupos étnicos corresponden al pueblo mapuche.

Estos datos se ratifican al utilizar los datos de las series de encuestas Casen. De acuerdo con esta fuente de datos, la población chilena mayoritariamente no se identifica como perteneciente a grupo indígena alguno. Como se observa en la Tabla $N^{\circ} 3.3$, cerca del 95\% de los chilenos dice no pertenecer a ningún pueblo indígena. Las personas que indicaban pertenecer al pueblo mapuche en 1996 eran algo más de 500.000, es decir, alrededor del 3,5\% de la población ${ }^{6}$, cifras bastantes similares a las del Censo 2002.

De acuerdo a los datos de la Tabla $N^{\circ}$ 3.3, el tamaño de la población mapuche a nivel nacional ha aumentado significativamente en el período

\footnotetext{
${ }^{5}$ Esta definición puede diferir de otras definiciones como la esbozada en el Convenio 169 de la OIT (véase Donoso, 2008), pero mantiene ciertas dimensiones de esta última. De hecho, de acuerdo con el Convenio 169 de la OIT, los pueblos indígenas se definen como aquellos "países independientes, considerados indígenas por el hecho de descender de poblaciones que habitaban en el país o en una región geográfica a la que pertenece el país en la época de la conquista o la colonización o del establecimiento de actuales fronteras estatales y que, cualquiera que sea su situación jurídica, conservan sus propias instituciones sociales, económicas, culturales y políticas, o parte de ellas”. Si bien esta definición no establece como criterio la identificación con el grupo indígena, el convenio posteriormente agrega que "la conciencia de su identidad indígena o tribal deberá considerarse un criterio fundamental para determinar los grupos a los que se aplican las disposiciones del presente convenio".

${ }^{6}$ Vale la pena indicar que de acuerdo al Censo de población y vivienda de 1992, la cantidad de personas identificadas con el pueblo mapuche era cercana a 928.060. Esto se debió a la manera en que se redactó la pregunta (wording) en 1992. Su redacción fue demasiado imprecisa, algo así como “¿Pertenece Ud. a algún pueblo originario?” Para el del 2002 la Ley Indígena ya había sido dictada, definiendo ciertos “pueblos originarios”. Ahora la pregunta fue cerrada, circunscribiéndose a estos pueblos específicos. Esto puede explicar la disminución de la población que se autoidentifica como indígena.
} 
TABLA No 3.1: POBLACIÓN EN CHILE CON IDENTIFICACIÓN ÉTNICA POR REGIONES, CENSO 2002

\begin{tabular}{lrrr}
\hline Región & Número de personas $^{\mathrm{a}}$ & \% Regional & \\
& & & $\%$ país $^{\mathrm{c}}$ \\
\hline I & 48.665 & 11,5 & 7,0 \\
II & 22.808 & 4,7 & 3,3 \\
III & 7.407 & 2,9 & 1,1 \\
IV & 5.177 & 0,9 & 0,7 \\
V & 18.708 & 1,2 & 2,7 \\
VI & 9.958 & 1,3 & 1,4 \\
VII & 8.157 & 0,9 & 1,2 \\
VIII & 54.078 & 2,9 & 7,8 \\
IX & 204.195 & 23,5 & 29,5 \\
X & 101.733 & 9,5 & 14,7 \\
XI & 8.063 & 9,0 & 1,2 \\
XII & 9.544 & 6,5 & 27,6 \\
RM & 191.362 & 3,2 & 100,0 \\
Total & 692.192 & 4,6 & \\
\hline
\end{tabular}

a Dentro del total se incluyen también personas que residen en el extranjero o cuyo lugar de residencia se ignora.

b Proporción de indígenas en el total de habitantes de cada región, salvo en el total que indica porcentaje del total del país.

${ }^{\mathrm{C}}$ Indígenas de cada región como proporción de la población indígena en el país.

Fuente: INE.

1996-2006, llegando casi a doblarse en ese horizonte de tiempo (aumento de tamaño de un 81\%). Por otro lado, la población de Chile pasó de algo más de 14,3 millones en 1996 a cerca de 16,2 millones en 2006, lo que representa un aumento de sólo $12 \%$, y, como consecuencia, el grupo de personas identificadas con el pueblo mapuche ha aumentado significativamente como porcentaje de la población, llegando a casi el 6\% del total en 2006.

Este significativo aumento de población mapuche, en especial entre los años 2000 y 2006, parece difícil de explicar a partir de estadísticas demográficas como variaciones en tasas de fertilidad o mortalidad. De hecho, es muy factible que lo que muestra este tipo de datos es que en las encuestas iniciales personas que eventualmente pertenecían al pueblo mapuche no se declaraban pertenecientes a este grupo, y que, con el paso del tiempo, este grupo de personas empieza a reconocerse como mapuche.

La Tabla N 3.4 nos entrega información adicional, pero en este caso relacionada solamente con la IX Región de la Araucanía. El grupo de individuos identificados con el pueblo mapuche crece sólo 8\% entre 1996 y 2006, manteniéndose en la cercanía de 250.000. Éste es un grupo bastante impor- 


\begin{tabular}{lcc}
\hline & Número personas $^{\mathrm{b}}$ & $\%^{\mathrm{c}}$ \\
\hline Mapuche & 604.349 & 87,3 \\
Aimara & 48.501 & 7,0 \\
Atacameño & 21.015 & 3,0 \\
Quechua & 6.175 & 0,9 \\
Rapa Nui & 4.647 & 0,7 \\
Colla & 3.198 & 0,5 \\
Alacalufe & 2.622 & 0,4 \\
Yámana & 1.685 & 0,2 \\
Total & 692.192 & 100 \\
\hline
\end{tabular}

a La variación experimentada en las cifras absolutas de población para algunos pueblos considerados, tanto en la Casen 1996 como 2000, requiere de una revisión en profundidad, en particular el incremento de la población aimara y kawashkar. La encuesta Casen no es específica para pueblos indígenas, por lo que la baja representatividad de ellos en algunas comunas puede hacer dudar de la confiabilidad de los datos. Con todo, es la mejor información que está disponible, y las conclusiones generales que acá se presentan se asumen con un rango apropiado de validez.

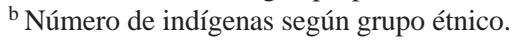

${ }^{\mathrm{c}}$ Indígenas de cada etnia como proporción de la población indígena en el país.

Fuente: INE.

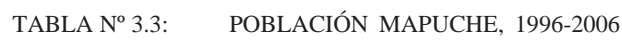

\begin{tabular}{cccc}
\hline & Mapuches & \% de población total & $\begin{array}{c}\text { \%, que no pertenece } \\
\text { a ningún pueblo }\end{array}$ \\
\hline 1996 & 510.805 & 3,55 & 95,48 \\
2000 & 563.542 & 3,72 & 95,64 \\
2003 & 733.953 & 4,72 & 94,6 \\
2006 & 924.560 & 5,72 & 93,32 \\
\hline
\end{tabular}

Fuente: Estimaciones propias a partir de encuestas Casen.

tante en términos de tamaño en la IX Región porque representa cerca del 30\% de la población total, tal como indicaban los datos del Censo 2002. La importancia de este grupo de mapuches de la IX Región tiende a disminuir como fracción de los mapuches totales del país, debido a que ese último grupo a nivel país aumenta significativamente su número, tal como se mostró en la Tabla No 3.3, mientras que los mapuches en la Región de la Araucanía aumentan sólo moderadamente. 
TABLA N N $^{0}$ 3.4: POBLACIÓN IX REGIÓN, MAPUCHES Y NO MAPUCHES, SECTOR RURAL Y SECTOR URBANO

\begin{tabular}{|c|c|c|c|c|}
\hline \multicolumn{5}{|c|}{ IX Región } \\
\hline & $\begin{array}{l}\text { Mapuches } \\
\text { IX Región }\end{array}$ & $\begin{array}{c}\% \\
\text { Población IX R. }\end{array}$ & $\begin{array}{c}\text { No pertenece } \\
\text { a ningún pueblo }\end{array}$ & $\begin{array}{l}\text { \% mapuches sobre } \\
\text { mapuches totales }\end{array}$ \\
\hline 1996 & 233.076 & 27,39 & 71,89 & 45,63 \\
\hline 2000 & 217.380 & 25,35 & 74,39 & 38,57 \\
\hline 2003 & 253.531 & 28,94 & 70,76 & 34,54 \\
\hline 2006 & 252.235 & 27,55 & 72,19 & 27,28 \\
\hline
\end{tabular}

IX Región, población total

\begin{tabular}{lccccc} 
& Urbano & $\%$ & & Rural & $\%$ \\
\cline { 2 - 3 } \cline { 5 - 6 } 1996 & 541.112 & 63,58 & & 309.993 & 36,42 \\
2000 & 573.313 & 66,85 & & 284.352 & 33,15 \\
2003 & 591.093 & 67,47 & & 284.976 & 32,53 \\
2006 & 619.703 & 67,69 & & 295.760 & 32,31
\end{tabular}

IX Región, mapuches

\begin{tabular}{lccccc} 
& Urbano & $\%$ & & Rural & $\%$ \\
\cline { 2 - 3 } \cline { 5 - 5 } 1996 & 49.447 & & & 183.629 & 78,79 \\
2000 & 64.863 & 29,81 & & 152.517 & 70,16 \\
2003 & 81.523 & 32,16 & & 172.008 & 67,84 \\
2006 & 78.402 & 31,08 & & 173.833 & 68,92 \\
\hline
\end{tabular}

IX Región, no mapuches

\begin{tabular}{|c|c|c|c|c|}
\hline & Urbano & $\%$ & Rural & $\%$ \\
\hline 1996 & 491.665 & 79,55 & 126.364 & 20,45 \\
\hline 2000 & 508.450 & 79,41 & 131.835 & 20,59 \\
\hline 2003 & 509.570 & 81,85 & 112.968 & 18,15 \\
\hline 2006 & 541.301 & 81,62 & 121.927 & 18,38 \\
\hline
\end{tabular}

Fuente: Estimaciones propias a partir de encuestas Casen.

La población mapuche en la IX Región tiende a disminuir entre 2003 y 2006 en -0,5\%, mostrando un posible proceso de emigración hacia otras regiones. Éste es un fenómeno que ocurrió con mayor intensidad entre 1996 y el año 2000, cuando la población mapuche en la IX Región disminuyó cerca de un $6,7 \%$.

Para entender este proceso de emigración neta regional de personas identificadas con el pueblo mapuche es conveniente separar el análisis en- 
tre sector rural y sector urbano. De hecho, tal como lo indica la Tabla $\mathrm{N}^{\circ} 3.4$, la población total del sector rural de la IX Región disminuyó bruscamente entre 1996 y el año 2000; y más interesante aún, si se descompone la población rural de esta región entre mapuches y no mapuches, son los mapuches quienes explican esta disminución de población rural.

La incipiente emigración del pueblo mapuche desde la IX Región entre 2006 y 2003 obedece a otro tipo de fenómeno, en el que tiende a disminuir la población urbana mientras que la población rural tiende a mantenerse.

La Tabla $\mathrm{N}^{\circ} 3.5$ entrega mayor información al respecto, mostrando que en la etapa en que diminuye la población rural mapuche en la IX Región, es decir, entre los años 1996 y 2000, disminuye el número de personas de todos los grupos de distintas edades en el sector rural, pero con una

TABLA N ${ }^{\circ}$ 3.5: $\quad$ POBLACIÓN MAPUCHE IX REGIÓN, URBANO VERSUS RURAL

\begin{tabular}{lcccc}
\hline \multicolumn{5}{c}{ IX Región, mapuches } \\
Grupo de edad & 1996 & 2000 & 2003 & 2006 \\
$1-18$ años & 91.272 & 80.496 & 96.289 & 90.298 \\
19 a 30 años & 47.526 & 41.961 & 46.514 & 43.354 \\
31 a 60 años & 66.234 & 68.383 & 77.446 & 86.731 \\
Mayores de 60 & 23.048 & 23.221 & 28.689 & 27.844 \\
\hline
\end{tabular}

IX Región, mapuches, sector urbano

\begin{tabular}{lrrrr} 
Grupo de edad & 1996 & 2000 & 2003 & 2006 \\
& & & & \\
$1-18$ años & 20.689 & 24.616 & 34.458 & 29.079 \\
19 a 30 años & 11.257 & 15.658 & 18.882 & 16.203 \\
31 a 60 años & 13.855 & 19.207 & 21.325 & 27.546 \\
Mayores de 60 & 2.359 & 4.329 & 4.866 & 4.077 \\
\hline
\end{tabular}

IX Región, mapuches, sector rural

$\begin{array}{lrrrr}\text { Grupo de edad } & 1996 & 2000 & 2003 & 2006 \\ 1-18 \text { años } & 70.583 & 55.880 & 61.831 & 61.219 \\ 19 \text { a } 30 \text { años } & 36.269 & 26.303 & 27.632 & 27.151 \\ 31 \text { a } 60 \text { años } & 52.379 & 49.176 & 56.121 & 59.185 \\ \text { Mayores de } 60 & 20.689 & 18.892 & 23.823 & 23.767\end{array}$

Fuente: Estimaciones propias a partir de encuestas Casen. 
mayor intensidad en los grupos de 1 a 18 años de edad, donde el tamaño del grupo se reduce en casi 15.000 personas (es decir 20,8\%), y en el grupo de 19 a 30 años de edad, que disminuye en casi 10.000 personas (27,5\%). El grupo de personas mayores de 30 años desciende sólo en aproximadamente 5.000 personas, lo que representa un 7\% para ese grupo. Por otro lado, en ese mismo período la población mapuche en el sector urbano de la IX Región aumentó en casi 15.000 personas, lo que obviamente no logra absorber los casi 30.000 mapuches que salieron del sector rural. Como resultado, la población mapuche total de la IX Región disminuyó en casi 15.000 personas en ese período. Además, de acuerdo con los datos de la Tabla $\mathrm{N}^{\circ} 3.5$, el descenso en la población mapuche total se debe básicamente a la emigración de personas menores de treinta años de edad, que disminuyó en casi 16.000 personas, mientras que el grupo de mayores de treinta años aumentó en casi 2.000 personas.

De esta forma, el período 1996-2000 muestra un proceso de emigración de la población mapuche fuera del sector rural de la IX Región, en especial en el grupo de personas jóvenes, que seguramente tienden a buscar mejores perspectivas económicas y de calidad de vida en las zonas urbanas. No sólo se produce un movimiento hacia la zona urbana de la IX Región, sino que también una parte importante de estas personas emigra fuera de la IX Región.

El período 2000-2003 exhibe una historia completamente distinta, que podría interpretarse como una reversión a los movimientos de personas ocurridos entre 1996 y 2000. El aumento total de población es cercano a 35.000 personas. En principio, no es posible explicar este aumento de población por medio de nacimientos, si se considera que la población total de personas mapuches tiende a aumentar considerablemente en cada uno de los grupos etarios de la IX Región. Nótese que del aumento total en población mapuche, cerca de 15.000 personas corresponden a aumentos en población urbana y 19.000 a población rural. Lo que sorprende de estos datos es que gran parte de esas 19.000 personas que migran hacia el sector rural corresponde a personas cuya edad es de sesenta años o más (cerca de 12.000 personas), mientras que gran parte de las 15.000 personas que migran hacia el sector urbano de la IX Región corresponden a personas menores de treinta años (casi 13.000 personas).

¿A qué se debe este aumento en población mapuche en la IX Región? Posiblemente a las apretadas condiciones económicas del momento en el resto del país. Chile aún se encontraba bajo los efectos negativos provocados por la crisis asiática de 1998, a raíz de los cuales personas que 
buscaban oportunidades fuera de sus lugares de origen tendieron a volver a ellos al encontrar pocas posibilidades en el resto del país.

El período 2003-2006 es uno sin crecimiento del tamaño del pueblo mapuche en la IX Región. Ahora, si bien el número de mapuches permanece relativamente constante en la región, la composición poblacional vuelve a cambiar en el sentido de acelerarse el envejecimiento del grupo. Tal como se muestra en la Tabla No 3.5, la población total de mapuches entre 2003 y 2006 disminuye para los grupos más jóvenes pero aumenta para los grupos de personas de mayor edad, lo que finalmente equilibraría la población total. Este fenómeno es bastante más acentuado en el sector urbano, dado que el sector rural prácticamente no cambia el tamaño de ninguno de sus grupos etarios.

\section{III. b) Tasas de pobreza de los mapuches}

A continuación se describirá la situación de pobreza de los mapuches en la IX Región a través del tiempo, por sector urbano y por sector rural. Además, se buscará hacer un análisis de distribución de ingreso mediante un examen de los deciles de ingresos a los que pertenecen mayoritariamente los mapuches de la IX Región.

Las Figura N N 3.1 y 3.2 muestran la evolución de las tasas de indigencias para distintos grupos de individuos: (1) el país como un todo, (2) los

FIGURA Nº 3.1: EVOLUCIÓN TASA DE INDIGENCIA, DISTINTOS GRUPOS 1996-2006

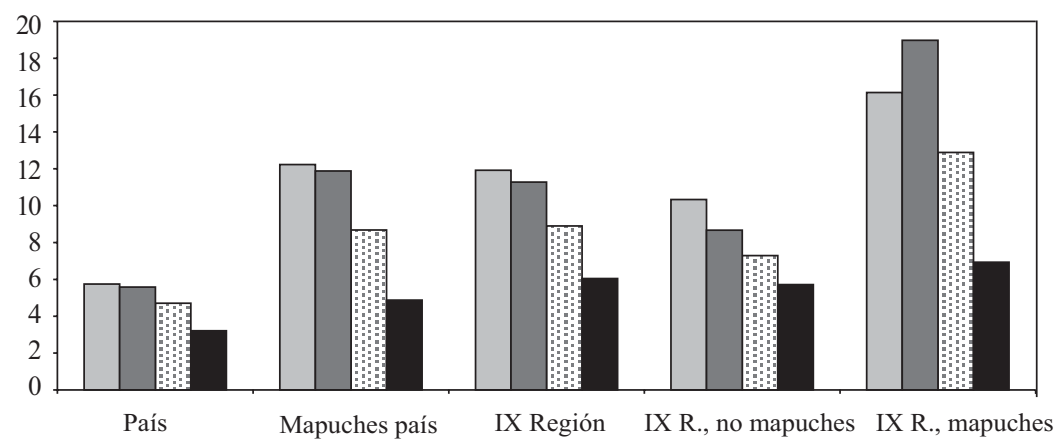

$$
1996 \square 2000 \square 2003 \square 2006
$$


mapuches de todo el país, (3) la IX Región, (4) los habitantes de la IX Región que no se declaran como mapuches y, finalmente, (5) los mapuches de la IX Región. Como es bien sabido, la tasa de indigencia a nivel del país era cercana al 5,8\% en 1996 y disminuyó a cerca de 3,2\% en el 2006. Esa disminución en indigencia ocurrió de forma paulatina pero sistemática entre 1996 y 2006. Las tasas de indigencia para mapuches (totales en el país) o para los habitantes de la IX Región son bastante mayores, llegando casi a doblar las tasas de indigencia a nivel del país. Si bien mayores, estas tasas han disminuido paulatinamente, tal como las tasas de indigencia del país, aunque aún se encuentran en niveles bastante superiores a las del resto de Chile.

La situación de los mapuches en la IX Región es incluso peor que la de otros grupos de comparación, dado que sus tasas de indigencia pueden llegar incluso a triplicar las tasas del resto del país en algunos años, como por ejemplo en 1996, cuando la tasa de indigencia llegaba al 16,1\%, o el año 2000 cuando esta tasa era de casi 19\%. Además, mientras prácticamente todos los grupos disminuyen sus tasas de indigencia, los mapuches de la IX Región, por el contrario, aumentaron su tasa de indigencia en el año 2000. Las buenas noticias para este grupo es que su tasa de indigencia ha disminuido a tasas mayores que las de los otros grupos desde el 2000 en adelante. Sin perjuicio de aquello, la tasa de indigencia actual es aún cercana al $7 \%$.

El Gráfico No 3.2 complementa el diagnóstico al mostrar la evolución de la tasa de pobreza — que no incluye indigencia — en el mismo horizonte de tiempo y para los mismos grupos. Tal como en el caso de la indigencia, las tasas de pobreza del grupo de mapuches en la IX Región son significativamente más altas que las del resto del país. Además, la tasa de pobreza de este grupo en 1996 era similar a la de otros grupos rezagados como los mapuches en el resto del país o individuos no mapuches que habitan en la IX Región. Si bien el punto de partida en 1996 parece ser el mismo para los mapuches de la IX Región y otros individuos, estos últimos tienen reducciones en tasas de pobreza a mayor velocidad que los mapuches de la IX Región. De hecho, estos últimos muestran una tasa de pobreza muy rebelde, que prácticamente se mantiene constante en 25\% hasta el año 2003.

De esta forma, una primera síntesis indica que una fracción muy significativa de los mapuches de la IX Región (mayor al 20\% de la población) aún se encuentra en situación de pobreza o indigencia y, que sobre todo, que la condición de pobreza ha sido bastante rebelde y sólo se han observado avances en la encuesta del año 2006. 
FIGURA N N ${ }^{\circ}$ 3.2: $\quad$ EVOLUCIÓN TASA DE POBREZA, DISTINTOS GRUPOS 1996-2006

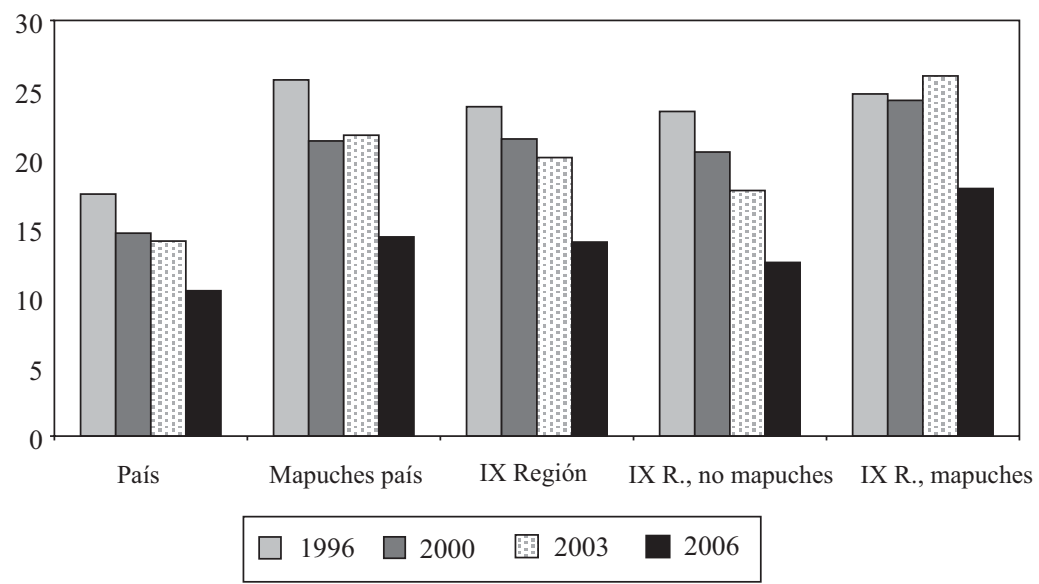

Las Figuras Nos. 3.3 y 3.4 muestran la evolución de tasas de indigencia en el sector urbano y el sector rural, respectivamente. Las Figuras Nos. 3.5 y 3.6 hacen lo mismo pero con tasas de pobreza. Los niveles de las tasas de indigencia de los mapuches en el sector urbano de la IX Región resultan altamente sorprendentes: entre 1996 y el 2000, cerca de uno de cada cinco mapuches era indigente, mientras en el resto del país esto ocurría para uno de cada veinte, en el caso de los mapuches a nivel nacional era uno de cada diez. Tan sorprendente como los niveles de tasas de indigencia, resulta la evolución de esta variable en los mapuches del sector urbano de la IX Región. Esta variable mejora considerablemente en sólo seis años, pasando desde niveles superiores al 20\% en 2000 a cerca de $7 \%$ en 2006, prácticamente convergiendo con tasas de indigencias en el sector urbano a nivel del país o de los otros grupos considerados en la Figura No 3.3. En el sector rural ocurre algo parecido, aunque los niveles de indigencia son algo menores llegando a un peak de $18 \%$ en el año 2000, para posteriormente disminuir considerablemente y llegar a tasas del orden de 7\% en 2006.

La situación de pobreza en el sector urbano de la IX Región para los mapuches es considerable y persistente. La magnitud de la tasa de pobreza es superior al $25 \%$ en cada uno de los años considerados y se acrecienta en el año 2003, acercándose al 37\%. Esta evolución contrasta claramente con la de los otros grupos observados, cuyos niveles de pobreza son muy inferiores y tal vez, más importante aún, decrecientes en el tiempo, en forma paulatina pero en general continua. Además, nótese que si se suma la tasa de 
FIGURA N N 3.3: $\quad$ EVOLUCIÓN TASA DE INDIGENCIA, SECTOR URBANO, DISTINTOS GRUPOS 1996-2006

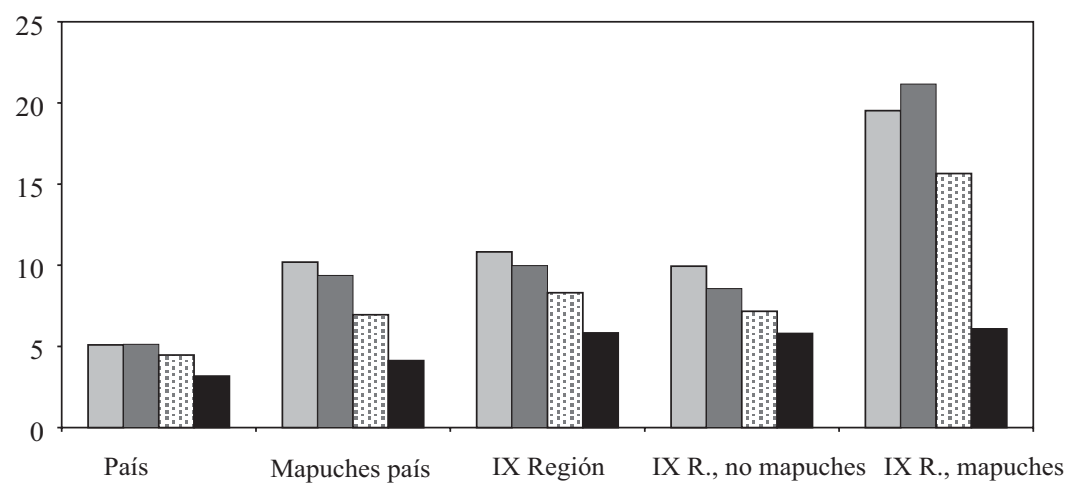

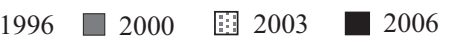

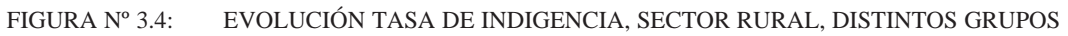
1996-2006

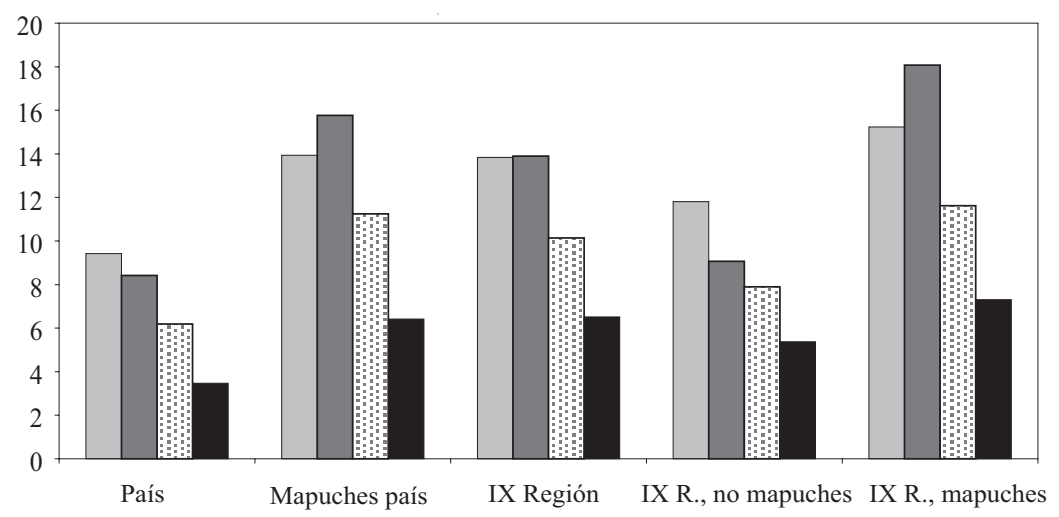

\section{$1996 \square 2000 \quad$ 国 $2003 \square 2006$}

pobreza e indigencia en el sector urbano para los mapuches de la IX Región, la cifra asciende a cerca del $45 \%$ en 1996 y 2000, sube a cerca del 50\% en 2003 y disminuye a cerca del 33\% en 2006.

Una pregunta que emerge de las tasas de pobreza e indigencia en el sector urbano es: ¿̇a qué se debe el inusual aumento en las tasas de pobreza de los mapuches en el sector urbano en el año 2003? Posiblemente la res- 
FIGURA N ${ }^{\circ}$ 3.5: $\quad$ EVOLUCIÓN TASA DE POBREZA, SECTOR URBANO, DISTINTOS GRUPOS 1996-2006

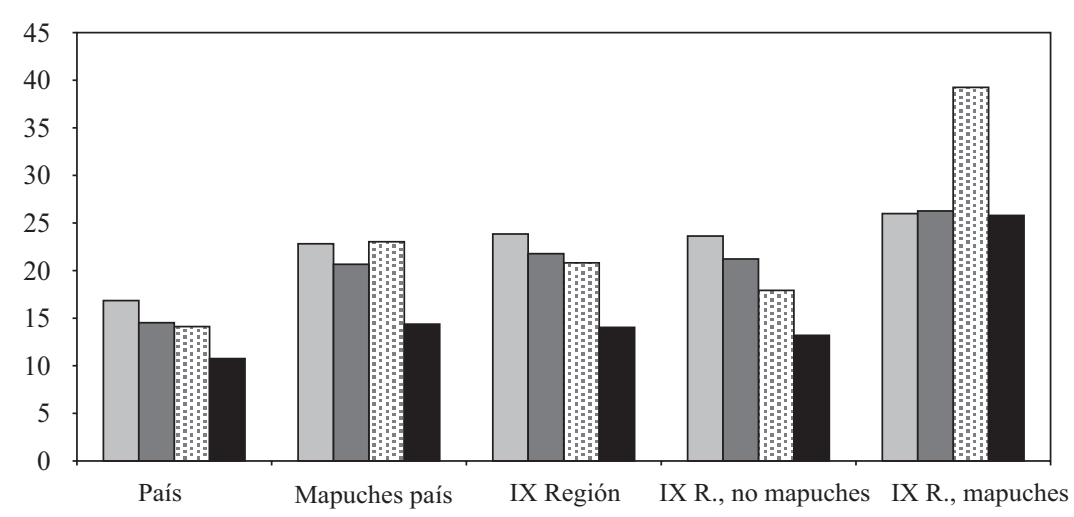

\section{$1996 \square 2000 \quad 2003 \square 2006$}

FIGURA No 3.6: EVOLUCIÓN TASA DE POBREZA, SECTOR RURAL, DISTINTOS GRUPOS 1996-2006
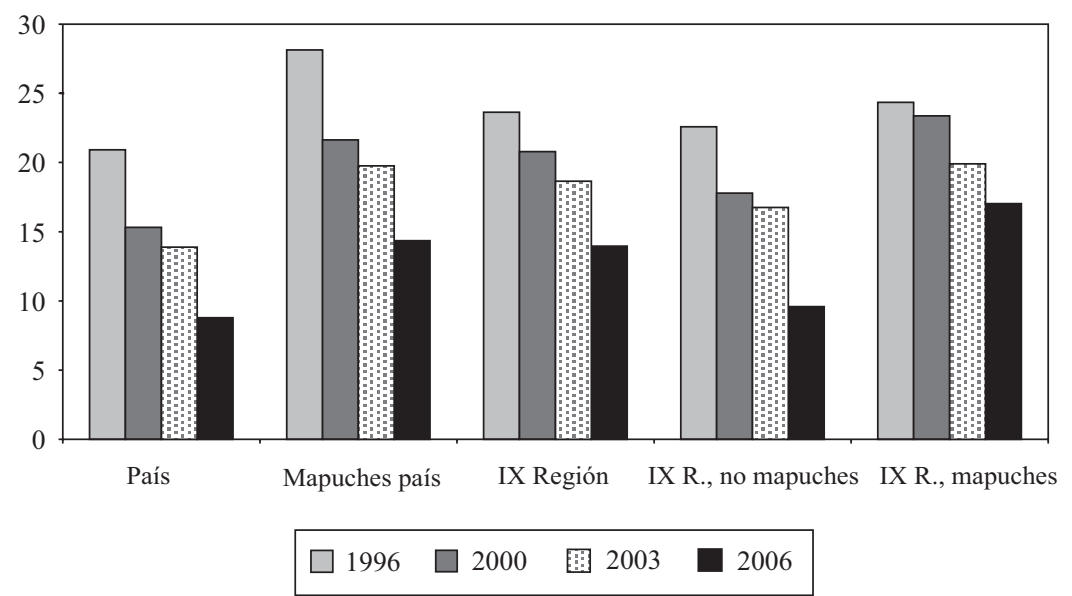

puesta provenga de las siguientes situaciones. Por un lado, varios individuos salen de la condición de indigencia, pero sus aumentos en ingresos no les permiten aún clasificarse como no pobres, y por lo tanto pasan a formar parte de los pobres no indigentes. En segundo lugar, aumenta considerablemente la población mapuche en el sector urbano de la IX Región, posiblemente por migración desde el sector rural al sector urbano, y parte de esa población 
puede no encontrar suficientes oportunidades económicas, lo que les lleva a engrosar la lista de personas desempleadas y bajo la línea de pobreza.

Los mapuches de la Región de la Araucanía en el sector rural muestran una historia algo distinta en términos de la incidencia de situaciones de indigencia y pobreza. La suma de personas que se encuentran en indigencia y pobreza ascendía a casi 40\% en 1996 y en 2000, cifra que disminuye a cerca de 31\% en 2003 y aproximadamente 24\% en 2006. Este grupo, entonces, muestra un mejoramiento paulatino desde el año 2000, algo que se observó sólo el año 2006 en el caso de los mapuches del sector urbano de la IX Región.

En resumen, pese a una incipiente disminución de las situaciones de pobreza e indigencia entre los mapuches de la Región de la Araucanía, todavía hay una alta incidencia de la pobreza, en especial en el sector urbano.

\section{III. c) Educación}

Como hemos visto, las tasas de pobreza e indigencia son bastantes altas entre los mapuches de la IX Región. Una de las posibles explicaciones de esta situación pueden ser las carencias en capital humano y, específicamente, en niveles de educación, las que se asocian con bajos ingresos laborales y pueden eventualmente disminuir la probabilidad de estar empleado, al no tener la calificación necesaria.

Las Tablas Nos. 3.6 y 3.7 nos entregan información sobre los niveles de educación en la IX Región. La Tabla N N $^{0} .6$ muestra que las tasas de analfabetismo son considerablemente más altas en los mapuches de la IX Región en comparación con el país como un todo e, incluso, con el resto de los habitantes de la IX Región o con los mapuches a través de todo Chile. Nótese que las tasas de analfabetismo de los mapuches en la IX Región son cercanas al 14\% entre 1996 y 2003, y disminuyen al 12,6\% en el 2006, cifras que casi doblan las tasas de la IX Región y casi triplican las cifras de analfabetismo de Chile.

Estas cifras, que resultan realmente altas al presentarlas de ese modo, parecen estar algo sobredimensionadas cuando uno descompone el análisis entre sectores urbanos y rurales. Nótese en la Tabla $N^{0} 3.6$ que en el sector urbano, si bien las tasas de analfabetismo en los mapuches de la IX Región siguen siendo altas al doblar las tasas de analfabetismo urbanas en Chile, no alcanzan a triplicar las tasas del país, tal como lo señalamos antes. Más aún, en el sector rural las tasas de analfabetismo de los mapuches 
TABLA N ${ }^{\circ}$ 3.6: $\quad$ TASAS DE ANALFABETISMO, 1996-2006

\begin{tabular}{|c|c|c|c|c|}
\hline & Chile & IX Región & Mapuches & $\begin{array}{l}\text { Mapuches, } \\
\text { IX Región }\end{array}$ \\
\hline 1996 & 4,80 & 8,70 & 10,90 & 14,70 \\
\hline 2000 & 3,90 & 7,30 & 8,60 & 13,50 \\
\hline 2003 & 4,03 & 8,71 & 9,48 & 14,83 \\
\hline 2006 & 3,89 & 7,32 & 7,16 & 12,61 \\
\hline
\end{tabular}

\begin{tabular}{lllll}
\multicolumn{5}{c}{ Sector urbano } \\
1996 & 3,28 & 5,54 & 5,24 & 7,41 \\
2000 & 2,61 & 4,15 & 4,33 & 5,57 \\
2003 & 2,83 & 5,69 & 4,96 & 6,51 \\
2006 & 2,85 & 4,74 & 4,10 & 5,67 \\
& & & \\
\hline \multicolumn{5}{c}{ Sector rural } \\
1996 & 13,63 & 14,18 & 15,92 & 16,46 \\
2000 & 12,19 & 13,74 & 15,49 & 16,87 \\
2003 & 11,76 & 15,1 & 16,19 & 18,61 \\
2006 & 10,89 & 12,89 & 13,49 & 15,69 \\
\hline
\end{tabular}

siguen siendo más altas que en el resto del país, pero en este caso no alcanzan a doblar a las tasas de Chile. ¿A qué se debe, entonces, que hayamos encontrado inicialmente tasas tan altas de analfabetismo entre los mapuches de la IX Región, en comparación con el promedio del país? Existe un efecto composición: los mapuches de la IX Región se encuentran casi en un $70 \%$ en el sector rural, mientras que en el resto del país el sector rural representa algo menos del $13 \%$. Como en el sector rural las tasas de analfabetismo son mayores, el efecto composición entre sector rural y urbano tiende a amplificar las diferencias en lo que respecta a tasas de analfabetismo.

Obviamente, y sin perjuicio de que efectivamente existe este efecto composición de sector rural versus sector urbano, las tasas de analfabetismo de los mapuches de la IX Región son bastante más altas que las de sus grupos de referencia y en el sector urbano alcanzan a doblar a las del resto del país.

Los niveles educacionales de los mapuches en la IX Región son también inferiores comparados con sus grupos de referencia, e incluso menores si se comparan con otras personas del pueblo mapuche en el resto de 
TABLA N ${ }^{\circ}$ 3.7: $\quad$ AÑOS DE ESCOLARIDAD PROMEDIO, 1996-2006

\begin{tabular}{|c|c|c|c|c|}
\hline & Chile & IX Región & Mapuches & $\begin{array}{l}\text { Mapuches, } \\
\text { IX Región }\end{array}$ \\
\hline 1996 & 9,47 & 8,03 & 7,00 & 6,08 \\
\hline 2000 & 9,91 & 8,78 & 8,01 & 6,72 \\
\hline 2003 & 10,12 & 9,08 & 8,16 & 7,21 \\
\hline 2006 & 10,14 & 9,19 & 8,60 & 7,46 \\
\hline \multicolumn{5}{|c|}{ Urbano } \\
\hline 1996 & 10,01 & 9,29 & 8,53 & 7,83 \\
\hline 2000 & 10,41 & 9,97 & 9,30 & 8,83 \\
\hline 2003 & 10,59 & 10,29 & 9,5 & 9,6 \\
\hline 2006 & 10,52 & 10,19 & 9,49 & 9,51 \\
\hline \multicolumn{5}{|c|}{ Rural } \\
\hline 1996 & 6,32 & 5,85 & 5,64 & 5,66 \\
\hline 2000 & 6,72 & 6,36 & 5,90 & 5,81 \\
\hline 2003 & 7,06 & 6,51 & 6,16 & 6,13 \\
\hline 2006 & 7,58 & 7,03 & 6,75 & 6,55 \\
\hline
\end{tabular}

Chile. Como puede observarse en la Tabla $\mathrm{N}^{\circ}$ 3.7, los mapuches de la IX Región tienen cerca de 3,5 años menos de años de escolaridad promedio en comparación con el resto del país, 2 años menos que otros habitantes de la IX Región y un 1 año menos que mapuches en otras regiones de Chile. La mayor diferencia parece en este caso provenir desde el sector urbano, donde en 1996 había algo más de dos años de diferencia en años de educación mientras que en el sector rural la diferencia en ese mismo año era sólo de algo más de medio año.

Si bien nuevamente el efecto composición entre sector urbano y rural existe, tal como cuando analizamos los datos de analfabetismo, parece más interesante examinar cómo evolucionan los años de escolaridad en los sectores urbano y rural. Nótese que si bien en el sector urbano la diferencia entre mapuches de la IX Región y el resto del país era de algo más de dos años de educación en 1996, esta diferencia disminuye considerablemente y en el año 2006 llega a ser sólo de un año de diferencia: los mapuches llegan a 9,51 años de educación promedio y el resto del país a 10,52. En el sector rural ocurre justo lo contrario, si bien la diferencia entre los mapuches de la IX Región y el resto del país era cercana a 0,5 años en 1996, esta diferencia 
se acrecienta y llega a un año de educación en el 2006. Una posible explicación para este fenómeno, que es concordante con el proceso de migración desde el sector rural al sector urbano que indicamos al iniciar esta sección, es que personas con mayores niveles de educación del sector rural han tendido a emigrar hacia el sector urbano, permitiendo una convergencia más rápida en educación en el sector urbano de la IX Región y una divergencia en el sector rural.

Las Tablas $N^{\text {os. }} 3.8$ y 3.9 describen la distribución de años de escolaridad en la población. Como se puede apreciar en la Tabla $N^{\circ} 3.8$, casi la mitad de la población del país tiene entre 9 y 12 años de escolaridad (43\%

TABLA N No 3.8: DISTRIBUCIÓN DE POBLACIÓN POR AÑOS DE EDUCACIÓN, 1996-2006

\begin{tabular}{|c|c|c|c|c|}
\hline Años educación & 1996 & 2000 & 2003 & 2006 \\
\hline \multicolumn{5}{|c|}{ Chile } \\
\hline 0 & 4,0 & 3,3 & 3,0 & 3,2 \\
\hline 1 a 6 & 22,2 & 19,6 & 18,1 & 17,6 \\
\hline 7 а 8 & 12,5 & 12,0 & 11,5 & 11,5 \\
\hline 9 а 12 & 43,0 & 44,5 & 45,6 & 46,4 \\
\hline 13 y más & 18,2 & 20,7 & 21,9 & 21,4 \\
\hline \multicolumn{5}{|c|}{ IX Región } \\
\hline 0 & 7,5 & 5,9 & 5,1 & 5,1 \\
\hline 1 a 6 & 32,1 & 27,4 & 24,8 & 23,6 \\
\hline 7 a 8 & 14,1 & 13,9 & 13,3 & 12,8 \\
\hline 9 a 12 & 34,1 & 36,8 & 38,4 & 42,9 \\
\hline 13 y más & 12,1 & 16,0 & 18,4 & 15,7 \\
\hline \multicolumn{5}{|c|}{ Mapuches } \\
\hline 0 & 9,0 & 6,5 & 6,4 & 5,3 \\
\hline 1 a 6 & 37,9 & 30,0 & 28,4 & 25,0 \\
\hline 7 a 8 & 17,9 & 16,9 & 17,1 & 16,0 \\
\hline 9 a 12 & 28,6 & 37,3 & 37,8 & 43,7 \\
\hline 13 y más & 6,7 & 9,2 & 10,3 & 10,0 \\
\hline \multicolumn{5}{|c|}{ Mapuches, IX Región } \\
\hline 0 & 12,4 & 10,5 & 8,8 & 8,5 \\
\hline 1 a 6 & 43,8 & 39,1 & 34,8 & 32,6 \\
\hline 7 а 8 & 17,6 & 19,3 & 17,8 & 16,9 \\
\hline 9 а 12 & 22,6 & 25,0 & 31,3 & 37,2 \\
\hline 13 y más & 3,6 & 6,1 & 7,3 & 4,8 \\
\hline
\end{tabular}




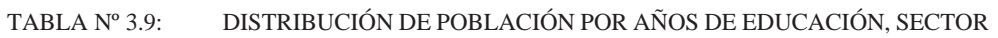
RURAL, 1996-2006

\begin{tabular}{crrrr}
\hline Años educación & 1996 & 2000 & 2003 & 2006 \\
\hline \multicolumn{5}{c}{ Sector rural, Chile } \\
\cline { 2 - 3 } & \multicolumn{2}{c}{} & \\
& & & \\
0 & 10,6 & 9,0 & 7,7 & 7,3 \\
1 a 6 & 44,0 & 41,3 & 38,8 & 33,8 \\
7 a 8 & 18,6 & 19,2 & 19,3 & 18,6 \\
9 a 12 & 23,1 & 25,9 & 29,3 & 34,0 \\
13 y más & 3,7 & 4,5 & 4,9 & 6,4
\end{tabular}

IX Región

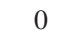

1 a 6

7 a 8

9 a 12

13 y más

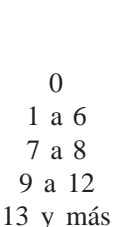

0
1 a 6
7 a 8
9 a 12
3 y más

12,1

47,5

17,8

19,6

3, 0

\begin{tabular}{rr} 
& Mapuches \\
\cline { 2 - 2 } 12,6 & 11,6 \\
48,1 & 46,6 \\
18,5 & 18,4 \\
18,6 & 21,2 \\
2,2 & 2,3
\end{tabular}

Mapuches, IX Región

\begin{tabular}{rrrr}
\hline 13,6 & 12,7 & 11,2 & 10,1 \\
46,4 & 46,6 & 42,1 & 40,7 \\
18,4 & 17,9 & 19,2 & 17,4 \\
19,2 & 20,5 & 25,9 & 29,6 \\
2,4 & 2,3 & 1,6 & 2,2
\end{tabular}

en 1996 y 46,4 en el 2006). Algo parecido ocurre en la IX Región o en los mapuches del resto del país. Sin embargo, en lo que respecta a los mapuches de la IX Región, la población mayoritariamente tiene seis o menos de seis años de educación. La Tabla $\mathrm{N}^{\circ} 3.9$ muestra que esto es aún más pronunciado en el sector rural, donde casi el 50\% de la población mapuche de la IX Región tiene seis años de educación o menos, algo que también ocurre en los mapuches del resto del país. 
Año 2002

\begin{tabular}{lccc} 
& Chile & IX Región & IX Región, rural \\
Matemáticas & 240,53 & 224,6 & 211,87 \\
Lenguaje & 245,33 & 230,96 & 219,17 \\
Comprensión & 245,66 & 230,89 & 221,33 \\
\hline
\end{tabular}

Año 2005

\begin{tabular}{lrrr} 
& Chile & IX Región & IX Región, rural \\
Matemáticas & 241,74 & 223,78 & 207,1 \\
Lenguaje & 250,37 & 235,67 & 219,67 \\
Comprensión & 251 & 234,53 & 216,8 \\
\hline
\end{tabular}

Las Tablas Nos. 3.10 y 3.11 entregan otra mirada al tema de educación. En este caso, en vez de considerar años de escolaridad, que es una medida de "cantidad" de educación, consideramos medidas de "calidad" de educación, donde se intentará medir la calidad de educación a partir de los puntajes de las pruebas Simce. La Tabla N 3.10 muestra los puntajes promedios para distintos grupos de colegios en los años 2002 y 2005. Las pruebas corresponden a $4^{\circ}$ básico en ambos años. En este caso, no es posible distinguir entre la calidad de educación que reciben los mapuches de la IX Región con la del resto de la población, pero como indicador de calidad para este grupo se ocupará el promedio de puntajes en el sector rural de la IX Región. Éste debería ser un buen indicador porque, tal como señalamos antes, casi el 70\% de los mapuches de la IX Región se encuentra en el sector rural.

Los puntajes de matemáticas en el caso de la totalidad del país alcanzan un promedio de casi 240 puntos en 2002 y 2005, mientras que la IX Región muestra promedios cercanos a 224 puntos y el sector rural de la IX Región exhibe un promedio de 211 en 2002 y 207 en 2005. De acuerdo con los informes de resultados de las pruebas SIMCE en el año 2002, una diferencia de 13 puntos o más es estadísticamente significativa mientras que en el año 2005 esta diferencia debe ser de a lo menos 10 puntos ${ }^{7}$. Esto indicaría que la IX Región obtiene promedios significativamente inferiores que el resto del país, mientras que el sector rural de la IX Región alcanza a su vez promedios significativamente inferiores a los de la IX Región en promedio.

\footnotetext{
${ }^{7}$ Para cursos con alumnos entre 26 y 50 alumnos.
} 


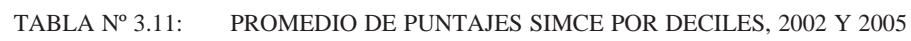

\begin{tabular}{|c|c|c|c|c|c|}
\hline \multicolumn{6}{|c|}{ Año 2002} \\
\hline & 1er decil & $2^{\circ}$ decil & $5^{\circ}$ decil & $8^{\circ}$ decil & $10^{\circ}$ decil \\
\hline Matemáticas & 188,61 & 208,53 & 234,48 & 261,55 & 300,21 \\
\hline Lenguaje & 192,27 & 214,46 & 240 & 266,64 & 302,5 \\
\hline Comprensión & 194,47 & 213,83 & 240,46 & 267,25 & 301,56 \\
\hline \multicolumn{6}{|c|}{ Año 2005} \\
\hline & 1er decil & $2^{\circ}$ decil & $5^{\circ}$ decil & $8^{\circ}$ decil & $10^{\circ}$ decil \\
\hline Matemáticas & 190,03 & 211,66 & 236,99 & 263,11 & 297,77 \\
\hline Lenguaje & 201,75 & 222,31 & 246,02 & 270,15 & 301,85 \\
\hline Comprensión & 198,01 & 219,46 & 246,44 & 272,54 & 305,69 \\
\hline
\end{tabular}

Los resultados para lenguaje y comprensión del medio, si bien son algo mejores en el sector rural de la IX Región, continúan indicando que la educación del sector rural de la IX Región es de menores resultados que en el resto del país o que en el resto de la IX Región.

Para tener una idea de cuánta es la diferencia de resultados, la Tabla $\mathrm{N}^{\circ} 3.11$ presenta la distribución de los resultados del Simce por deciles. El primer decil tiene resultados cercanos a 190 puntos en promedio en las distintas pruebas para el año 2005 y entre 190 y 200 puntos en 2005. Por su parte, el octavo decil tiene resultados promedio en el intervalo 260-275 puntos en 2002 y 2005. Nótese que los resultados obtenidos en el sector rural de la IX Región son similares a los obtenidos por el segundo decil de resultados. Esto indicaría que los resultados de calidad de educación que alcanzarían mayoritariamente los mapuches en la IX Región corresponden al $20 \%$ inferior de los resultados académicos en Chile. Las razones de este resultado pueden ser múltiples (calidad de colegios, grupos socioeconómicos, etc.), pero claramente, cualesquiera sean ellas, queda una gran brecha que reducir.

\section{III. d) Participación laboral y características de empleos}

Otro posible determinante de las tasas de pobreza del grupo de mapuches en la IX Región son sus niveles de empleo. Para analizar el mercado laboral se utiliza tradicionalmente la tasa de desempleo, sin embargo en 
nuestro caso usaremos la tasa de ocupación, esto es, la cantidad de personas empleadas entre la población mayor de 15 años (población en edad de trabajar). Esta medición se centra directamente en la creación de empleos y, por lo tanto, no inciden en ella fluctuaciones en la fuerza de trabajo, por lo que entrega una idea más directa de lo que ocurre con el empleo de la población (al respecto véase Sapelli, 2007).

Las Figuras Nos. 3.7 a 3.9 muestran la evolución de las tasas de ocupación en Chile, así como la de los mapuches de todo el país y de la IX Región, donde nuevamente esta última se separa entre mapuches y no mapuches. La Figura N $N^{0} 3.7$ presenta la evolución de esta variable sin separar entre sectores urbano o rural, y las Figuras Nos. 3.8 y 3.9 en forma separada. En 1996 la tasa de ocupación, como la hemos definido, era de casi 52\% en Chile. En 2000 se observa cómo la intensidad de la crisis asiática afecta a las tasas de ocupación, las que disminuyen cerca del 50\%. Los años 2003 y 2006 muestran reactivación, y en 2003 se alcanza una tasa de ocupación algo menor a 52\% y algo menor a los niveles de 1996. Finalmente en 2006 la tasa de ocupación sobrepasa los niveles de 1996 mostrando un escenario de consolidación en la recuperación del empleo. Los efectos en la IX Región son bastantes más intensos y la recuperación parece tardar más. Nótese que la tasa de ocupación pre-crisis de la IX Región era cercana al 49\%, y por lo tanto menor a la tasa de ocupación del país. Lo más sorprendente es el ajuste en la tasa de ocupación al ocurrir la crisis asiática. Ésta disminuye en casi cuatro puntos llegando a 45\% en el año 2000 y disminuye algo más de un punto adicional entre el año 2000 y 2003. Por lo tanto, mientras la tasa de ocupación se recuperaba en el resto del país entre 2000 y 2003, la IX Región aún sufría cierto grado de ajuste. En los años posteriores a 2003 se produce

\section{FIGURA N N 3.7: $\quad$ EVOLUCIÓN TASA DE OCUPACIÓN, DISTINTOS GRUPOS 1996-2006}

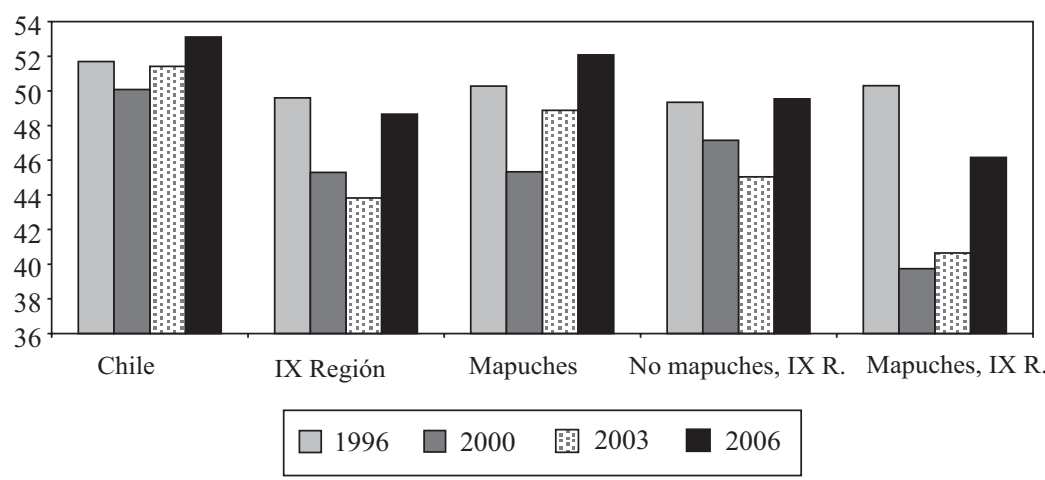


FIGURA N ${ }^{\circ}$ 3.8: $\quad$ EVOLUCIÓN TASA DE OCUPACIÓN, SECTOR URBANO, DISTINTOS GRUPOS 1996-2006

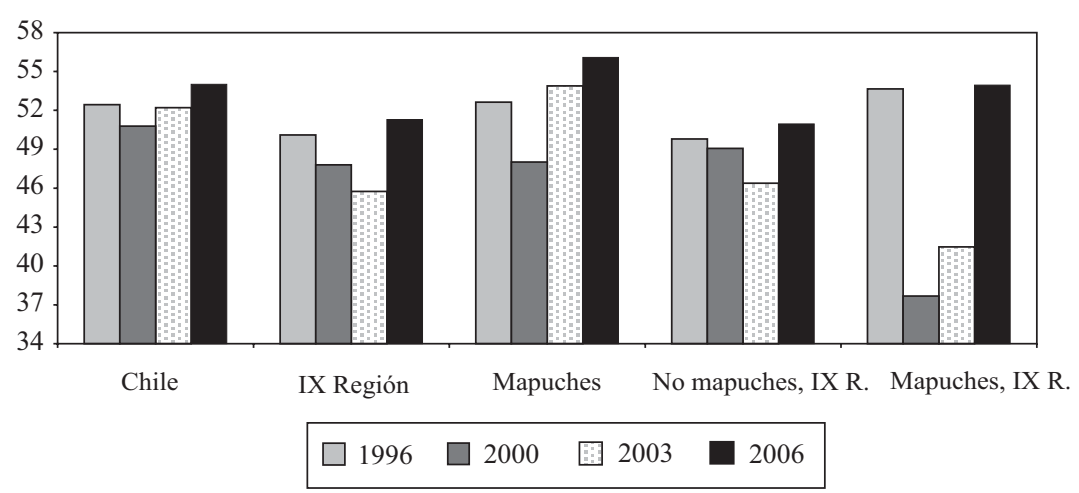

FIGURA N N $^{\circ .9:} \quad$ EVOLUCIÓN TASA DE OCUPACIÓN, SECTOR RURAL, DISTINTOS GRUPOS 1996-2006

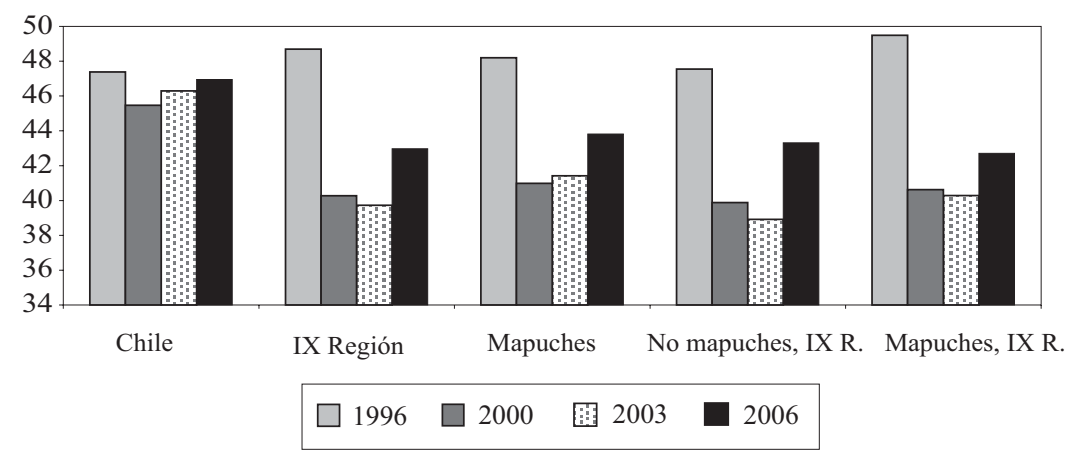

la recuperación en la tasa de ocupación, y nuevamente el ajuste, en este caso al alza, es pronunciado, llegando a una tasa de ocupación de casi $49 \%$, es decir, a niveles pre-crisis.

Resulta también muy interesante preguntarse quiénes en la IX Región realizan este ajuste tan pronunciado. Esto lo podemos contestar a partir de los datos de la Figura $N^{0}$ 3.7. Si separamos entre mapuches y no mapuches, nos damos cuenta que si bien los no mapuches disminuyen su tasa de ocupación durante el período de crisis, la intensidad de la disminución en el caso de los mapuches es bastante mayor: los individuos no mapuches de la IX Región pasan de tasas de ocupación cercanas al 49\% en 
1996 a 47\% en 2000 y 45\% en 2003, mientras que los mapuches disminuyen desde algo más de 50\% en 1996 a 39\% y 41\% en 2000 y 2003, respectivamente. Además, la recuperación permite que los no mapuches vuelvan a niveles pre-crisis en el 2006 mientras que los mapuches aún se mantienen en niveles de $46 \%$.

Las Figuras N Nos. 3.8 y 3.9 muestran además que las grandes diferencias entre mapuches y no mapuches en la IX Región en términos de tasas de ocupación ocurren en el sector urbano. De hecho, en el sector rural los mapuches de la IX Región muestran un comportamiento muy similar al de las personas no mapuches. Por otro lado, en el sector urbano los no mapuches enfrentan caídas en sus tasas de ocupación de casi 16\% entre 1996 y 2000. Entre los años 2000 y 2003, los mapuches de la IX Región en el sector urbano aún están muy rezagados comparados con los no mapuches en términos de tasas de ocupación, mientras que la recuperación en sus tasas de ocupación ocurre rápidamente entre 2003 y 2006.

Obviamente la pregunta que surge es a qué se debe esta inusual diferencia en respuestas de tasas de ocupación entre mapuches y no mapuches en la IX Región. A continuación sugerimos ciertas hipótesis. En primer lugar, el proceso de emigración de mapuches hacia el sector urbano puede tener un efecto importante. Recordemos las Tablas $N^{\text {os. }} 3.4$ y 3.5 que mostraban que los mapuches en el sector urbano de la IX Región aumentaron significativamente entre 1996 y 2003 (en ese período pasaron desde algo más de 49 mil a algo menos de 82 mil) y ese aumento se debió principalmente a los grupos de menores de treinta años. Estos datos indican, entonces, un excepcional aumento de oferta laboral de este grupo de individuos en ese período, y que ese aumento de oferta laboral estuvo muy marcado por grupos de individuos jóvenes que típicamente enfrentan altas tasas de desempleo (véase Coloma y Vial, 2003). Además, el momento del mejoramiento en las tasas de ocupación de los mapuches en el sector urbano, es decir entre los años 2003 y 2006, está marcado por un proceso a la inversa, es decir emigración desde el sector urbano y, básicamente, por individuos menores de treinta años (véase Tabla $\mathrm{N}^{\circ}$ 3.5). Estos enormes flujos de personas deben haber representado shocks significativos para la oferta de trabajo dentro de la población en edad de trabajar, y tal vez expliquen gran parte de las disminuciones en las tasas de ocupación en el sector urbano de los mapuches.

En segundo lugar, el empleo por rama de actividad puede también haber tenido algún tipo de influencia. Las Tablas $N^{\text {os. }} 3.12$ y 3.13 muestran la participación del empleo por rama de actividad económica (de acuerdo con las clasificaciones de la encuesta Casen). La Tabla N 3.12 indica que la estructura de participación del empleo en el país en su conjunto es muy 
TABLA N N $^{\circ}$ 3.12: $\quad$ EMPLEO POR RAMA DE ACTIVIDAD, \% PARTICIPACIÓN SOBRE TOTAL

\begin{tabular}{|c|c|c|c|c|}
\hline Rama de actividad & 1996 & 2000 & 2003 & 2006 \\
\hline \multicolumn{5}{|c|}{ Chile } \\
\hline Actividades no bien especificadas & 0,55 & 0,31 & 0,24 & 1,1 \\
\hline Agricultura, caza, silvicultura y pesca & 14,94 & 12,98 & 13,35 & 12,5 \\
\hline Explotación de minas y canteras & 1,91 & 1,56 & 1,49 & 1,7 \\
\hline Industrias manufactureras & 14,83 & 13,94 & 13,4 & 13,5 \\
\hline Electricidad, gas y agua & 0,68 & 0,87 & 0,56 & 0,5 \\
\hline Construcción & 8,74 & 8,13 & 8,49 & 9,3 \\
\hline Comercio por mayor y menor, restaurantes & 18,71 & 19,03 & 19,93 & 19,7 \\
\hline Transportes y comunicaciones & 7,06 & 7,42 & 7,68 & 7,7 \\
\hline Establecimientos financieros y seguros & 6,36 & 7,69 & 6,86 & 7,3 \\
\hline Servicios comunales, sociales y personales & 26,23 & 28,07 & 28 & 26,9 \\
\hline
\end{tabular}

IX Región

Actividades no bien especificadas

$\begin{array}{rrrr}0,38 & 0,44 & 0,06 & 0,17 \\ 33,48 & 25,95 & 26,81 & 25,68 \\ 0,20 & 0,16 & 0,13 & 0,32 \\ 9,25 & 10,28 & 10,37 & 11,55 \\ 1 & 0,49 & 0,46 & 0,62 \\ 8,41 & 8,37 & 8,48 & 9,24 \\ 15,94 & 17,16 & 16,15 & 17,63 \\ 5,37 & 5,58 & 5,81 & 5,63 \\ 2,68 & 4,08 & 5,06 & 4,39 \\ 23,71 & 27,48 & 26,67 & 24,76\end{array}$

Mapuches, IX Región

Actividades no bien especificadas

$\begin{array}{rrrr}0,18 & 0,17 & 0 & 0,16 \\ 63,95 & 55,29 & 54,24 & 48,81 \\ 0,15 & 0,21 & 0,18 & 0,43 \\ 5,65 & 6,83 & 6,14 & 9,24 \\ 0,12 & 0,09 & 0,2 & 0,32 \\ 7,25 & 8,31 & 5,9 & 8,38 \\ 6,17 & 9,72 & 9,19 & 10,57 \\ 2,27 & 1,72 & 4,85 & 3,2 \\ 0,54 & 0,71 & 0,33 & 1,91 \\ 13,72 & 16,95 & 18,98 & 16,99\end{array}$

Agricultura, caza, silvicultura y pesca

Explotación de minas y canteras

Agricultura, caza, silvicultura y pesca

Explotación de minas y canteras

27,48

1

2,5

3,5

0,5

9,3

7,7

7,3

6,9

Industrias manufactureras

Electricidad, gas y agua

Comercio por mayor y menor, restaurantes

Transportes y comunicaciones

Servicios comunales, sociales y personales

Industrias manufactureras

Electricidad, gas y agua

Construcción

Comercio por mayor y menor, restaurantes

Transportes y comunicaciones

Establecimientos financieros y seguros

Servicios comunales, sociales y personales

0,54
13,72

16,95

16,99 


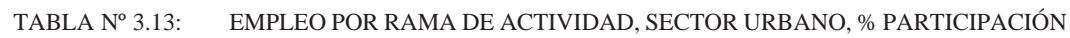
SOBRE TOTAL

Mapuches, IX Región, urbano

$\begin{array}{lrrrr}\text { Agricultura, caza, silvicultura y pesca } & 8,73 & 8,79 & 11,4 & 12,7 \\ \text { Explotación de minas y canteras } & 0 & 0,63 & 0,22 & 0,3 \\ \text { Industrias manufactureras } & 13,71 & 10,54 & 8,49 & 13,06 \\ \text { Electricidad, gas y agua } & 0 & 0,11 & 0,18 & 0,15 \\ \text { Construcción } & 15,52 & 16,84 & 9,83 & 11,51 \\ \text { Comercio por mayor y menor, restaurantes } & 15,33 & 19,35 & 17,64 & 18,85 \\ \text { Transportes y comunicaciones } & 8,82 & 3,14 & 12,75 & 7,26 \\ \text { Establecimientos financieros y seguros } & 2,39 & 2,18 & 0,82 & 3,74 \\ \text { Servicios comunales, sociales y personales } & 35,16 & 37,97 & 38,68 & 32,23\end{array}$

No mapuches, IX Región, urbano

Agricultura, caza, silvicultura y pesca

Explotación de minas y canteras

Industrias manufactureras

Electricidad, gas y agua

Construcción

Comercio por mayor y menor, restaurantes

Transportes y comunicaciones

Establecimientos financieros y seguros

Servicios comunales, sociales y personales

$\begin{array}{rrrr}9,07 & 8,23 & 8,06 & 9,89 \\ 0,1 & 0,15 & 0,12 & 0,23 \\ 12,83 & 12,6 & 12,92 & 13,51 \\ 0,72 & 0,67 & 0,51 & 0,81 \\ 9,99 & 9,21 & 10,44 & 10,08 \\ 23,52 & 21,76 & 20,44 & 22,68 \\ 7,59 & 7,42 & 6,94 & 7,02 \\ 4,22 & 6,01 & 7,85 & 5,83 \\ 31,41 & 33,46 & 32,63 & 29,78\end{array}$

Diferencia entre mapuches y no mapuches

Agricultura, caza, silvicultura y pesca

Explotación de minas y canteras

Industrias manufactureras

Electricidad, gas y agua

Construcción

Comercio por mayor y menor, restaurantes

Transportes y comunicaciones

Establecimientos financieros y seguros

Servicios comunales, sociales y personales

$-0,34$
$-0,1$
0,88
$-0,72$
5,53
$-8,19$
1,23
$-1,83$
3,75

0,56

3,34

2,81

0,48

$-2,06$

0,1

0,07

$-0,56$

$-4,43$

$-0,45$

7,63

$-0,33$

$-0,66$

$-2,41$

$-0,61$

1,43

$-4,28$

$-2,8$

$-3,83$

$-3,83$

5,81

0,24

4,51

$-7,03$

$-2,09$

6,05

distinta a la de la IX Región, siendo muy intensiva esta última en agricultura, caza, silvicultura y pesca. En el caso de los mapuches de la IX Región, esta característica es aún más nítida, donde la participación del empleo en esta rama de actividad llegó a casi 64\% en 1996 y era de 48,8\% en 2006. La Tabla $\mathrm{N}^{\circ} 3.13$ presenta un análisis similar, pero se centra en el sector urbano, que es nuestro foco de atención en el tema ocupacional. La tabla muestra los datos de empleo para mapuches y no mapuches y posterior- 


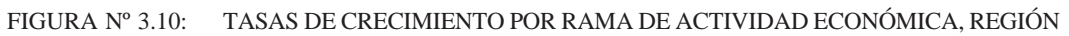
DE LA ARAUCANÍA, 1997-2003

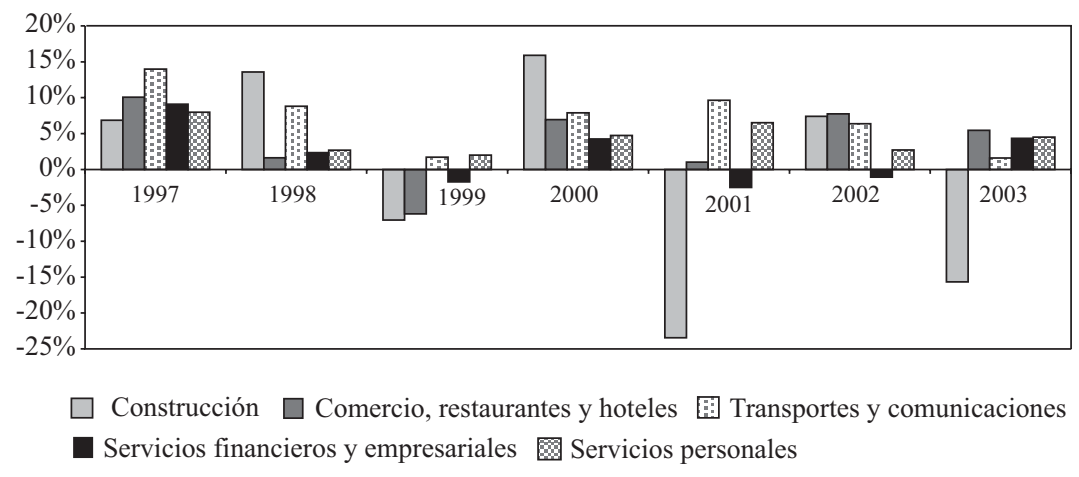

mente indica las diferencias entre ambos. Resulta interesante notar que existe diferencia en patrones de empleo, siendo los mapuches urbanos más intensivos en empleos en el sector construcción y en servicios comunales, sociales y personales. Por otro lado, las personas que se definen como no mapuches tienden a trabajar más en el sector comercio y en establecimientos financieros y de seguros.

Esta información es interesante porque si a los sectores que son más intensivos en empleo de mapuches les fue peor que a los sectores que emplean más personas no mapuches, parte de las disminuciones en tasas de ocupación observadas en el sector urbano para los mapuches puede ser explicada por factores de demanda. Para tratar de tener una idea al respecto, la Figura $\mathrm{N}^{\circ} 3.10$ muestra las tasas de crecimiento de distintos sectores por rama de actividad económica en la Región de la Araucanía desde 1997 al 2003. Ahí se observa que el sector construcción, que es de los más intensivos en empleo de personas mapuches en el sector urbano, también es uno de los sectores más golpeados por la crisis económica que irrumpe en 1996. Por otro lado, el sector comercio, que es más intensivo en el empleo de personas no mapuches, si bien muestra una caída en 1999, presenta tasas de crecimiento positivas y bastante altas desde el año 2000. Esto indicaría que posiblemente algún factor de demanda también tendería a explicar las disminuciones en tasas de ocupación en el sector urbano de los mapuches entre 1996 y el 2003.

\section{III. e) Contratos de trabajo e ingresos laborales}

En la subsección anterior hemos analizado la situación de empleo de la población mapuche de la IX Región. A continuación examinaremos con un poco más de detalle la situación laboral de aquellos que están empleados. 
Es interesante notar, primero que nada, que los contratos de trabajo de los mapuches se han formalizando cada vez más. La Tabla $N^{\circ} 3.14$ muestra si las personas que se encuentran trabajando han firmado o no contratos de trabajo. En 1996, la fracción de personas empleadas en Chile con contrato de trabajo era del orden de $76 \%$ y ese número ha subido hasta cerca del 79\% en 2006. En la IX Región, en su conjunto, los porcentajes eran de 70,9\% en 1996 y 77,1\% en 2006, los que indican, por ende, algo más de informalidad. Pero la situación laboral de los mapuches de la IX Región es bastante más precaria: en 1996 sólo el 59,4\% tenía contrato de trabajo, cifra que subió sólo al 62,3\% en 2003. En el período 1996-2003 un estable porcentaje de casi 36\% de los mapuches con empleo no tenía contrato de trabajo. Estas cifras mejoraron considerablemente en el año 2006, pero aún se encuentran por debajo de lo que ocurre en el resto de Chile.

En relación con los ingresos laborales, la Figura № 3.11 presenta los ingresos de las ocupaciones principales de los trabajadores de acuerdo con niveles educacionales en el año 2006. En la figura se muestran estos tipos de ingresos para el grupo de mapuches en la IX Región, el grupo de mapuches en el país, la IX Región como un todo y el país como un todo. Tal como era esperable, los ingresos laborales aumentan con los niveles de

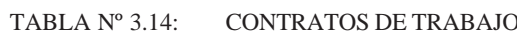

\begin{tabular}{|c|c|c|c|c|}
\hline & 1996 & 2000 & 2003 & 2006 \\
\hline & & \multicolumn{2}{|c|}{ Chile } & \\
\hline Sí & 76,2 & 75,9 & 76,4 & 78,6 \\
\hline No tiene & 22,1 & 22,6 & 22,4 & 19,9 \\
\hline \multirow[t]{2}{*}{ No se acuerda si firmó contrato } & 1,8 & 1,5 & 1,2 & 1,1 \\
\hline & & \multicolumn{2}{|c|}{ IX Región } & \\
\hline Sí & 70,9 & 69,9 & 69,0 & 77,1 \\
\hline No tiene & 26,9 & 27,5 & 29,8 & 21,1 \\
\hline \multirow[t]{2}{*}{ No se acuerda si firmó contrato } & 2,2 & 2,7 & 1,2 & 1,5 \\
\hline & & \multicolumn{2}{|c|}{ Mapuches, IX Región } & \\
\hline Sí & 59,4 & 61,8 & 62,3 & 71,7 \\
\hline No tiene & 35,9 & 35,6 & 35,94 & 26,01 \\
\hline No se acuerda si firmó contrato & 4,7 & 2,6 & 1,79 & 1,83 \\
\hline
\end{tabular}


FIGURA N ${ }^{\circ}$ 3.11: INGRESOS OCUPACIÓN PRINCIPAL, POR NIVELES DE EDUCACIÓN, AÑO 2006

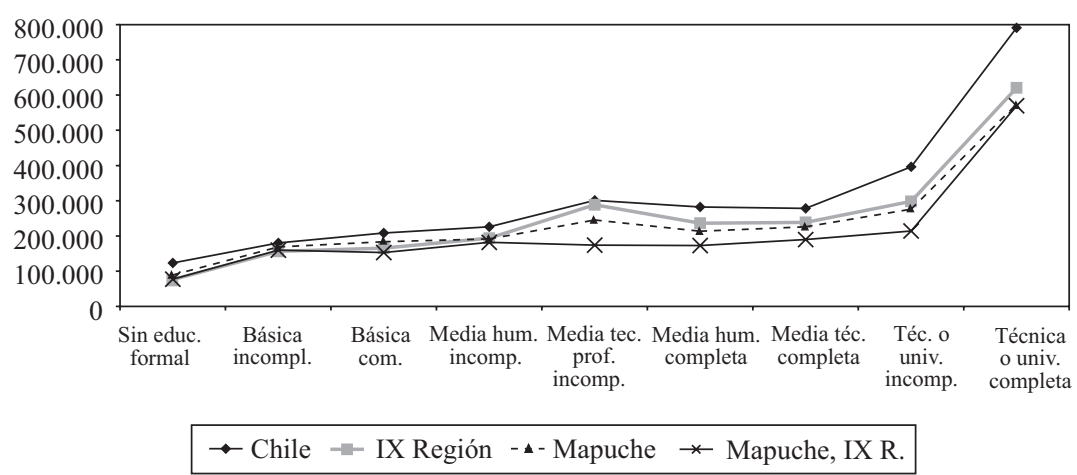

educación, y existe un premio muy alto por educación técnica o universitaria completa. Estos ingresos para el caso de Chile fluctúan, en promedio, desde algo más de los \$ 123.000 para personas sin educación formal hasta algo más de \$ 396.000 para personas con educación técnica o universitaria incompleta y algo más de \$ 790.000 para personas con educación técnica o universitaria completa.

En general, los ingresos laborales promedios por nivel de educación para Chile son mayores que los de la IX Región, los mapuches en todo el país y los mapuches de la IX Región. Esto se puede deber a múltiples razones, pero, entre ellas, a que existen regiones en Chile, como vimos en la sección II de trabajo, que tienen mayores niveles de PIB per cápita debido a sus dotaciones de recursos naturales — regiones del Norte Grande-, lo que no ocurre en la IX Región. Dicho esto, nos centraremos en analizar posibles diferencias de ingresos de los mapuches en la IX Región versus los ingresos promedio de la IX Región como un todo.

La Figura $\mathrm{N}^{\circ} 3.12$ muestra el ingreso ocupacional de los mapuches de la IX Región como porcentaje de los ingresos de otros grupos. Resulta interesante notar que en el año 2006, los mapuches de la IX Región con niveles de educación bajos (sin educación formal o básica incompleta) ganan lo mismo (o incluso un poco más) que individuos no mapuches en la IX Región con similares niveles de educación ${ }^{8}$. Sin embargo, cuando se consideran niveles

${ }^{8}$ Las comparaciones con respecto a Chile son peores incluso para este grupo de educación posiblemente por lo que indicábamos antes. Esto también ocurre aunque de forma más moderada cuando se compara con los mapuches que viven a través de Chile, posiblemente por la misma razón. 
FIGURA N ${ }^{\circ}$ 3.12: INGRESOS OCUPACIÓN PRINCIPAL DE MAPUCHES EN IX REGIÓN, MEDIDOS COMO PORCENTAJE DE INGRESOS EN OCUPACIÓN PRINCIPAL DE OTROS GRUPOS, POR NIVELES DE EDUCACIÓN, AÑO 2006

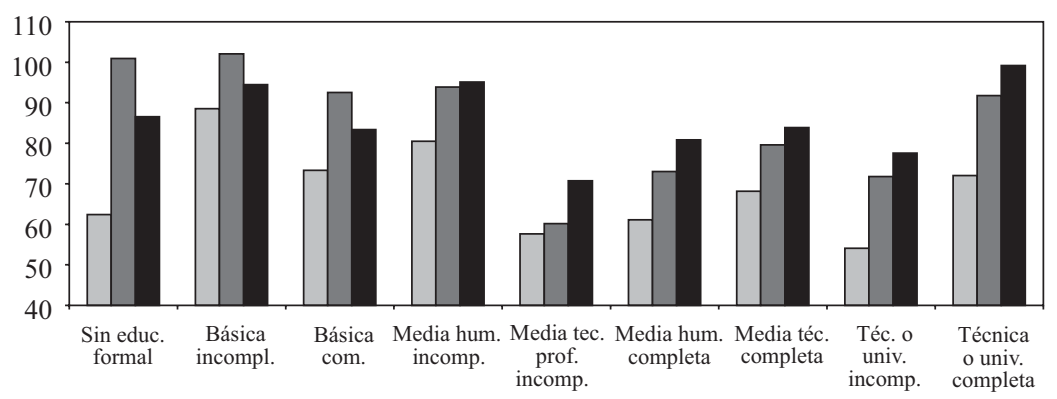

$\square$ Chile $\square$ IX Región $\quad$ Mapuche

de educación más altos aparece una brecha bastante significativa con respecto a los ingresos de otras personas comparables de la IX Región. Nótese por ejemplo el caso de educación media técnica profesional incompleta donde los ingresos de los mapuches de la IX Región corresponden sólo al 60\% de los ingresos que obtienen personas no mapuches con comparable nivel de educación en la misma IX Región. Las cifras para educación media humanista completa, media técnica completa o técnica universitaria incompleta fluctúan entre el 70\% y 80\%. La Tabla № 3.15 presenta, además, el empleo en la Región de la Araucanía por años de escolaridad ${ }^{9}$. Lo interesante de estas cifras es que indican que los tipos de trabajos donde existe mayor brecha salarial entre mapuches y no mapuches en la IX Región son aquellos donde el empleo de mapuches es menor o, dicho de otro modo, donde los mapuches son menos importantes en términos de tamaño de oferta de mercado.

La Figura N N $^{\circ} .13$ complementa la información al mostrar cómo han evolucionado estas cifras desde 1996 hasta 2006. El análisis en este caso se realiza por años de escolaridad. Lo que resulta interesante es que en general para cada uno de los años de escolaridad (salvo excepciones como en el caso de un año de escolaridad), si bien existe esta brecha entre ingresos de

${ }^{9}$ Estas cifras de empleo corresponden a los datos de la encuesta Casen y por lo tanto los totales no son exactamente iguales a los que surgen de la encuesta de empleo del INE. Sin embargo, los totales de ambas fuentes son similares. De hecho, mientras en 1996 (octubre que es la fecha de recolección de la encuesta Casen) el Ine reportaba 262.450 ocupados en la IX Región nuestros cálculos de la encuesta Casen indican 286.905 ocupados. En el 2006 las cifras son INE: 349.740 ocupados y Casen: 336.583. 


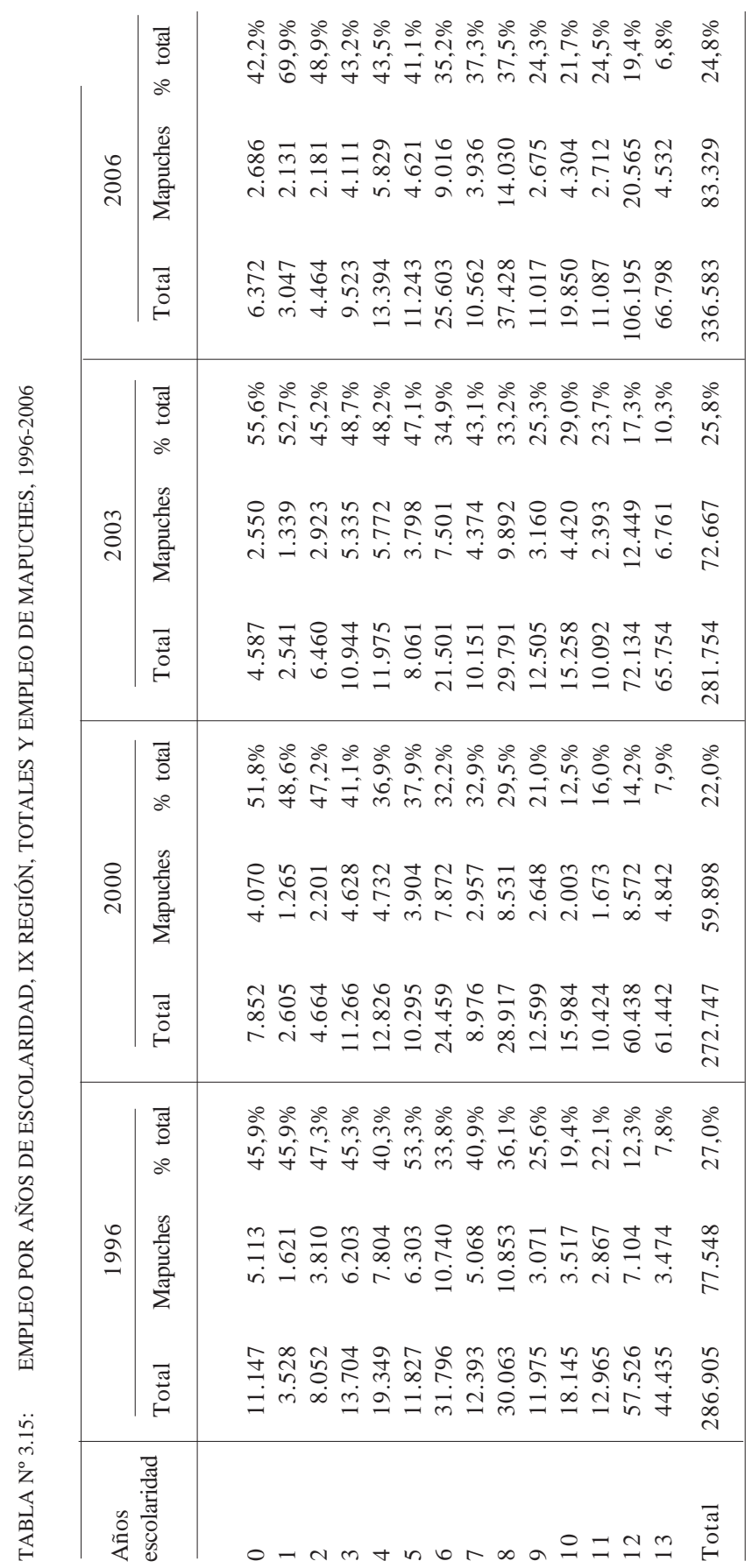




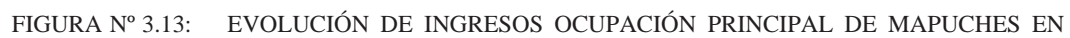
IX REGIÓN MEDIDO COMO PORCENTAJE DE INGRESOS PROMEDIOS EN OCUPACIÓN PRINCIPAL EN IX REGIÓN, POR AÑOS DE EDUCACIÓN, 19962006
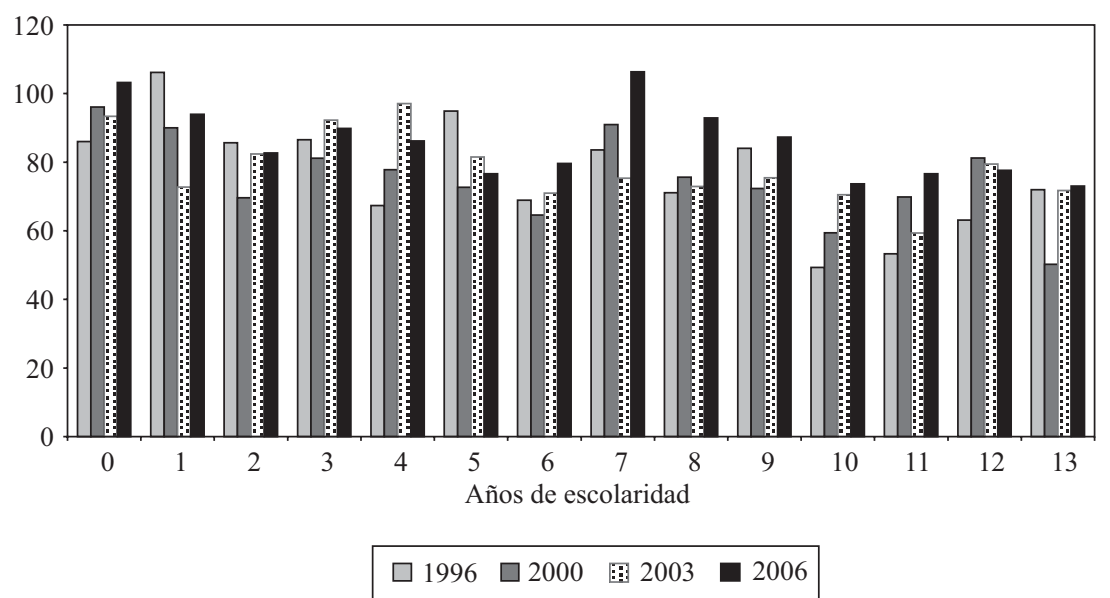

los mapuches y los no mapuches en la IX Región, la brecha ha tendido a cerrarse. Éste es el caso de personas mapuches con cero años de educación, y por lo tanto posiblemente analfabetas, que parten en 1996 con algo más de un $80 \%$ de los ingresos de personas no mapuches comparables, $\mathrm{y}$ que en 2003 llegan a cifras incluso algo mayores a 100\%. Luego, con seis a ocho años de educación (personas que potencialmente deberían haber completado 6 a 8 básico), hay aumentos significativos que van desde algo más de $60 \%$ de ingresos a casi $80 \%$ en el caso de seis años de educación, o desde algo más de $80 \%$ y llegando a más de $100 \%$ en el caso de siete años de educación.

Lo que indica por lo tanto la información de contratos e ingresos laborales es que existen desventajas en el empleo de los mapuches si se compara con los no mapuches en la IX Región. Estas desventajas son de dos tipos: (1) mayor informalidad en sus contratos de trabajos y (2) brechas salariales importantes en actividades que requieren niveles de educación algo mayores a educación básica. Tanto la brecha en informalidad así como la brecha en salarios se han ido cerrando a través del tiempo, pero aún mantienen niveles considerables.

Estas cifras podrían estar indicando algún tipo de discriminación o menor productividad de los mapuches que se refleja en la compensación laboral. Para evaluar estas posibilidades, las Tablas $N^{\text {os. }} 3.16$ y 3.17 muestran 


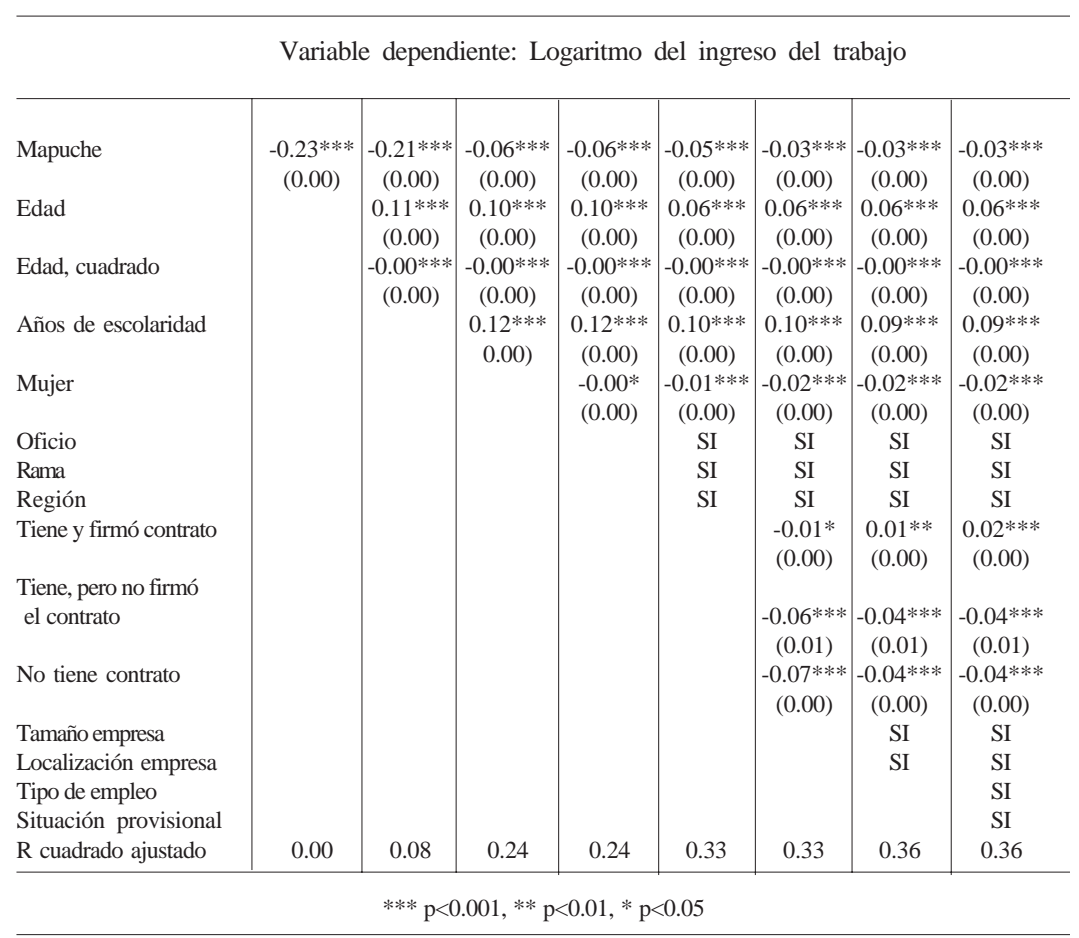

análisis econométricos que buscan determinar los fundamentos de los ingresos laborales. La Tabla $\mathrm{N}^{\circ} 3.16$ se refiere a Chile en su conjunto mientras que la Tabla $\mathrm{N}^{\circ} 3.17$ sólo a la IX Región. Ambas tablas incluyen como variable explicativa del logaritmo de los ingresos laborales una variable ficticia (dummy) que toma el valor uno cuando la persona en cuestión es mapuche y cero en caso contrario. El coeficiente de esta variable dummy correspondería a diferencias de ingresos sólo explicadas por la condición de identidad mapuche, es decir, representaría factores de posible discriminación hacia los mapuches.

Lo que señalan estas tablas es que al explicar los ingresos laborales sólo por medio de la variable dummy, esto es lo que se muestra en las primeras columnas de ambas tablas, los mapuches obtienen ingresos casi $32 \%$ menores en la IX Región y 23\% menores en el caso de Chile. Las columnas siguientes muestran que esa diferencia tiende a achicarse una vez que se consideran otros factores que podrían determinar los ingresos laborales. Por ejemplo, una vez que se controla por edad, escolaridad y sexo de 


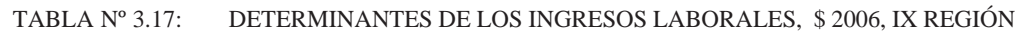

Variable dependiente: Logaritmo del ingreso del trabajo

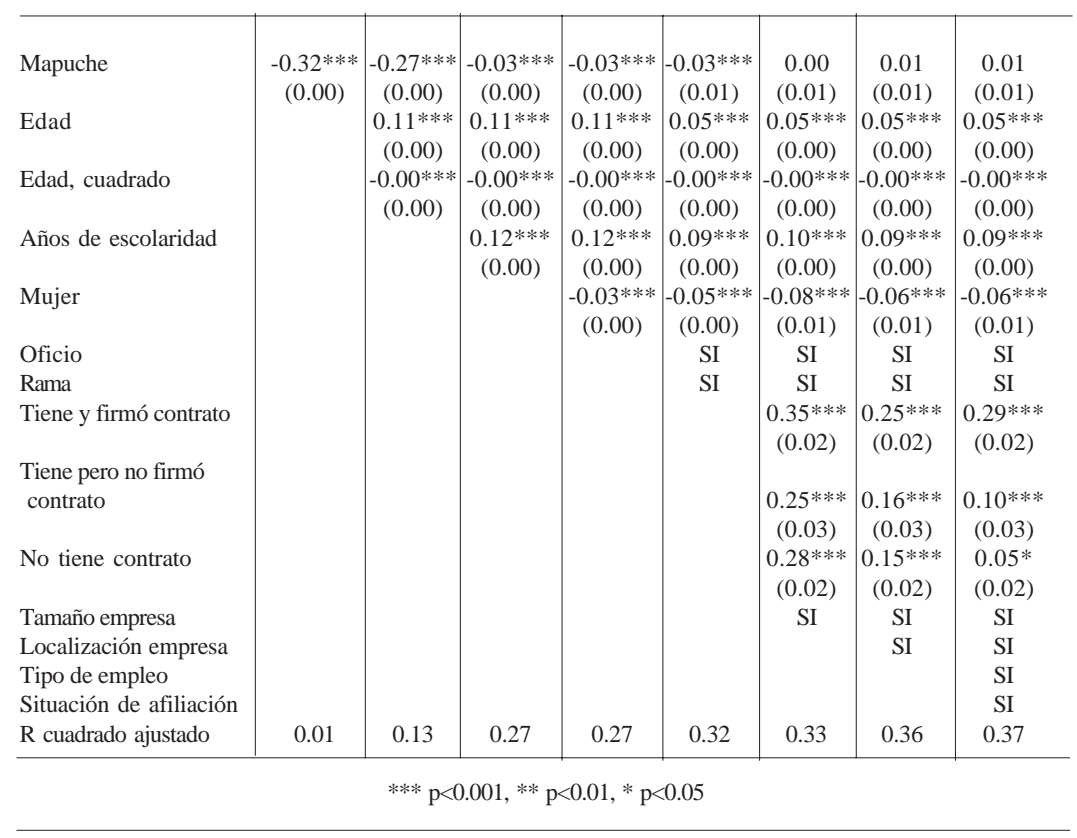

las personas, la brecha de ingresos en Chile disminuye a sólo 6\%. Esto quiere decir que de la diferencia inicial de $23 \%$, cerca de $17 \%$ se explica por años de escolaridad y por las otras variables demográficas indicadas. Cuando se incluyen además como variables de control características laborales (rama de actividad, oficio, etc.), la diferencia se estrecha aún más llegando a $3 \%$. Esto indica que una vez que se controla por características personales y del tipo de trabajo, los mapuches a nivel país muestran niveles de ingresos $3 \%$ menores a individuos no mapuches comparables (es decir, con similares niveles de educación, edad, trabajos).

Tal como indicábamos antes, la Tabla № 3.17 muestra el mismo análisis pero para la IX Región solamente. En este caso la diferencia inicial de casi 32\% disminuye a sólo 3\% al considerar características personales, sobre todo al incorporar escolaridad. Al incluir variables relativas al tipo de trabajo, la diferencia entre mapuches y no mapuches deja de ser significativa. Esto no quiere decir que no existan diferencias de ingresos laborales entre mapuches y no mapuches, sino que las diferencias están explicadas 
por características personales y del tipo de trabajo. Lo que resulta más interesante aún es que las características laborales que efectivamente hacen desaparecer la brecha de ingresos no explicada es la inclusión del tipo de contrato laboral. Esto tiende a indicar que parte de la brecha de ingresos laborales entre mapuches y no mapuches se debe a que con mayor frecuencia los mapuches no firman contratos, tal como se reportaba en la Tabla $\mathrm{N}^{\circ} 3.14$ y las personas que no firman contratos tienen ingresos menores en cerca de 7\%, como se reporta en la sexta columna de la Tabla $\mathrm{N}^{\circ}$ 3.17. Desde este punto de vista, una vez que se controla por variables como educación, tipo de contrato y otras, la discriminación entre mapuches y no mapuches en la IX Región, que estaría captada por el coeficiente de la variable dummy para mapuches, tiende a desaparecer (no es significativa). De esta forma no sería la condición de identidad mapuche per se la que está asociada con menores ingresos, sino que lo que ocurre es que las personas del grupo mapuche tienen ciertas características, como menor educación, que explican parte importante del diferencial de ingresos observado ${ }^{10}$.

\section{III. f) Situación patrimonial: Tenencia de activos, deudas y equipamiento del hogar}

El análisis de los datos de ingresos laborales y los de participación laboral permiten tener una idea acabada de la capacidad de los mapuches en la IX Región para generar flujos de ingresos. Otra dimensión económica es la situación patrimonial de este grupo de personas. Ésta es una dimensión importante por dos razones. En primer lugar, una situación patrimonial holgada, por ejemplo la de un hogar que mantiene ahorros positivos y no tiene deudas, permite sobrellevar al menos durante un tiempo problemas económicos originados por pérdidas de empleo. Hogares que muestran, por otro lado, situaciones de endeudamiento, tienen menor capacidad de maniobra ante crisis similares en el hogar. En segundo lugar, parte de la situación patrimonial del hogar la entenderemos como su tenencia de activos y bienes durables que incluyen automóviles y electrodomésticos. Estos tipos de acti-

\footnotetext{
${ }^{10}$ Valdés y Foster (2007), con datos de la encuesta Casen 2003, realizan un análisis similar para el sector agrícola chileno y encuentran que la pertenencia a un grupo indígena no tiene impacto negativo adicional sobre ingresos. Este resultado, que va en el mismo sentido del encontrado en este trabajo, se obtiene para trabajadores asalariados y auto-empleados. Sin embargo, debe notarse que en el caso de personas que pertenecen a hogares que trabajan su propia tierra y en que el tamaño del predio es pequeño, subsiste un diferencial de ingreso importante en contra de las personas que se auto-identifican como indígenas.
} 
vos también permiten obtener una idea del nivel de vida que tienen estos hogares. A continuación presentamos ciertos datos.

La encuesta Casen 2006 entrega información acerca de tenencia de activos y deudas de las personas, además de ciertos datos sobre equipamiento del hogar. Lamentablemente los datos de activos y deudas no están disponibles en encuestas Casen anteriores. La Tabla $N^{0}$ 3.18.a muestra estos datos para el caso de Chile, la IX Región, los mapuches a través de Chile y los mapuches de la IX Región. La primera dimensión de la tabla ese refiere a si los hogares tienen algún tipo de ahorros (activos) ${ }^{11}$. En general, la población muestra muy poca capacidad de ahorro. En el caso del país en su conjunto, cerca del 85\% de las personas indica no tener algún tipo de ahorros, mientras que cerca del 14\% tiene algún instrumento de ahorro, y el 1\% tiene dos o más instrumentos de ahorro. Las cifras para el resto de los grupos son similares.

Respecto a deudas ${ }^{12}$, cerca del $66 \%$ de las personas a lo largo de Chile dice no tenerlas. Esta cifra es algo mayor para los mapuches y alcanza casi al 82\% de éstos en la IX Región. De esta forma, los mapuches parecen mostrar un nivel de endeudamiento menor al del resto de la población. Las razones pueden ser múltiples, pero posiblemente se deba a que la mayoría de los mapuches de la IX Región viven en sectores rurales donde es más difícil realizar labores de cobranzas de deudas, lo que llevaría a restringir la oferta de créditos a este grupo. Otra posible explicación es que el tipo de activo que podría servir como garantía al endeudamiento son las tierras indígenas. Sin embargo, este tipo de activo no puede ser gravado de acuerdo con la Ley Indígena, lo que impide usarlo como patrimonio ${ }^{13} \mathrm{y}$, por lo tanto, que los mapuches puedan aumentar sus niveles de endeudamiento.

${ }^{11}$ Ahorros corresponde a ahorro para la vivienda, ahorro en AFV, ahorro provisional voluntario, en cuenta dos de AFP, cuenta bancaria, depósito a plazo, fondos mutuos, bonos o acciones de empresas, préstamos a terceros u otro tipo de ahorro.

${ }^{12}$ La categoría deudas comprende tarjetas de crédito bancarias, línea de crédito bancaria, casas comerciales, préstamos de consumo bancarios, préstamos de consumo en financieras, crédito automotriz, crédito social, deudas educacionales, deudas con parientes o amigos, créditos de prestamistas, casa de crédito prendario, fiado, otras deudas.

${ }^{13}$ La Ley Indígena, en su art. 13, limita gravar las tierras que son indígenas. Su articulado indica:

"Las tierras a que se refiere el artículo precedente, por exigirlo el interés nacional, gozarán de la protección de esta ley y no podrán ser enajenadas, embargadas, gravadas, ni adquiridas por prescripción, salvo entre comunidades o personas indígenas de una misma etnia.

No obstante, se permitirá gravarlas previa autorización de la Corporación. Este gravamen no podrá comprender la casa-habitación de la familia indígena y el terreno necesario para su subsistencia.” 


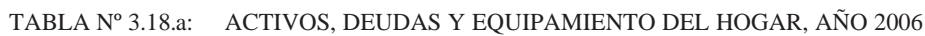

\begin{tabular}{|c|c|c|c|c|}
\hline & Chile & IX región & Mapuche & $\begin{array}{l}\text { Mapuche, } \\
\text { IX Región }\end{array}$ \\
\hline \multicolumn{5}{|c|}{ Ahorros (activos) } \\
\hline 0 & 84,96 & 84,93 & 85,16 & 89,12 \\
\hline 1 & 13,96 & 14,35 & 14,09 & 10,58 \\
\hline 2 o más & 1,08 & 0,72 & 0,74 & 0,3 \\
\hline \multicolumn{5}{|c|}{ Deudas } \\
\hline 0 & 66,24 & 71,73 & 69,63 & 81,97 \\
\hline 1 & 26,85 & 22,64 & 25,22 & 15,65 \\
\hline 2 & 5,41 & 4,47 & 4,28 & 2,07 \\
\hline 3 & 1,12 & 0,73 & 0,62 & 0,14 \\
\hline 4 & 0,37 & 0,43 & 0,24 & 0,16 \\
\hline \multicolumn{5}{|c|}{ Equipamiento del hogar } \\
\hline Vehículo particular & 22 & 17 & 11 & 9 \\
\hline Vehículo laboral & 7 & 6 & 5 & 3 \\
\hline Refrigerador & 73,92 & 64,34 & 59,62 & 45,12 \\
\hline Calefont & 52,63 & 31,79 & 29,44 & 10,36 \\
\hline Teléfono fijo & 39,39 & 23,99 & 21,41 & 8,18 \\
\hline Computador & 28,5 & 20,6 & 15,37 & 6,23 \\
\hline Teléfono móvil & 61,57 & 56,27 & 52,88 & 40,78 \\
\hline
\end{tabular}

TABLA N ${ }^{\circ}$ 3.18.b: EQUIPAMIENTO DEL HOGAR, AÑO 2006, ENCUESTA CEP

\begin{tabular}{lcccc}
\hline & $\begin{array}{c}\text { Mapuche } \\
\text { urbano }\end{array}$ & $\begin{array}{c}\text { Mapuche } \\
\text { rural }\end{array}$ & $\begin{array}{c}\text { No mapuche } \\
\text { urbano }\end{array}$ & $\begin{array}{c}\text { No mapuche } \\
\text { rural }\end{array}$ \\
\hline TV color & & & & \\
Minicomponente & 93 & 69 & 74 & 53 \\
Video & 69 & 40 & 58 & 23 \\
TV cable/satélite & 53 & 14 & 20 & 4 \\
TV blanco/negro & 16 & 1 & 11 & 19 \\
Teléfono celular & 13 & 23 & 72 & 62 \\
Teléfono red fija & 72 & 52 & 50 & 4 \\
Computadora & 46 & 3 & 25 & 7 \\
Conexión a internet & 22 & 0 & 10 & 64 \\
Lavadora & 8 & 52 & 89 & 64 \\
Refrigerador & 86 & 50 & 59 & 12 \\
Calefont & 83 & 4 & 51 & 33 \\
Secadora/centrífuga & 55 & 3 & 17 & 9 \\
Automóvil/station & 13 & & & 75 \\
\hline
\end{tabular}


En relación con el equipamiento del hogar, los mapuches de la IX Región tienen menos artículos de línea blanca, electrodomésticos y automóviles que la población del resto del país. Los datos de la encuesta del Centro de Estudios Públicos "Los mapuches rurales y urbanos hoy” (de mayo 2006), que aparecen en la Tabla No 3.18.b, permiten corroborar que la gran diferencia en términos de tenencia de bienes durables ocurre en el sector rural. Estos resultados no son sorprendentes en la medida que la adquisición de estos artículos está típicamente ligada a créditos que obtienen las personas del sistema bancario o de casas comerciales, y como los mapuches de la IX Región parecen enfrentar más restricciones para obtener esos créditos, les sería más difícil adquirir este tipo de equipamiento del hogar. Cabe mencionar que los mapuches rurales, sin embargo, muestran una menor acumulación de bienes de equipamiento del hogar que sus congéneres no mapuches, lo que indica que la dificultad para conseguir crédito no se explicaría únicamente por la ruralidad, sino que posiblemente otras variables como educación, tasas de ocupación e ingresos laborales también pesen en ello. Cualquiera sea el caso, existe una clara restricción de créditos a los mapuches de la IX Región, y ésta de seguro incide en su menor acumulación de equipamiento del hogar.

La Tabla No 3.19 muestra la situación bajo la cual se ocupa el sitio dónde está la vivienda de las personas. Mayoritariamente la población chilena tiene su vivienda en sitios propios y que ya han pagado (55\%), carac-

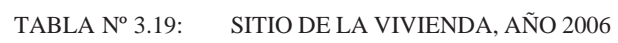

\begin{tabular}{|c|c|c|c|c|}
\hline & Chile & IX Región & Mapuche & $\begin{array}{l}\text { Mapuche, } \\
\text { IX Región }\end{array}$ \\
\hline Propio pagado & 55,98 & 61,17 & 58,68 & 69,2 \\
\hline Propio pagándose & 12,78 & 10,15 & 8,75 & 3,63 \\
\hline $\begin{array}{l}\text { Propio compartido (pagado) } \\
\text { con otras viviendas }\end{array}$ & 1,26 & 0,68 & 1,98 & 1,31 \\
\hline $\begin{array}{l}\text { Propio compartido (pagándose) } \\
\text { con otras viviendas }\end{array}$ & 0,04 & 0,04 & 0,09 & 0,15 \\
\hline Arrendado con contrato & 8,86 & 5,12 & 5,67 & 1,75 \\
\hline Arrendado sin contrato & 5,22 & 4,53 & 5,95 & 3,01 \\
\hline Cedido por servicios & 2,11 & 3,1 & 2,52 & 2,14 \\
\hline Cedido por familiar u otro & 12,49 & 13,65 & 14,75 & 16,96 \\
\hline Usufructo (sólo uso y goce) & 0,28 & 0,9 & 0,43 & 0,9 \\
\hline Ocupación irregular (de hecho) & 0,63 & 0,43 & 0,74 & 0,43 \\
\hline Otro & 0,36 & 0,24 & 0,44 & 0,52 \\
\hline
\end{tabular}


terística que es incluso mucho más acentuada en los mapuches de la IX Región (cerca del 70\% de estos individuos tiene su vivienda en sitio propio y pagado). De hecho, nótese que el sitio propio pagado es mucho más probable en los mapuches de la IX Región que en los mapuches del resto del país —este último grupo de mapuches muestra cifras similares al de los chilenos en general.

Ésta es, por lo tanto, la única característica de bienes patrimoniales que es favorable a los mapuches en la IX Región cuando se los compara con los mapuches en el resto del país. Obviamente esto se relaciona con la tenencia de tierras, tema que analizaremos un poco más adelante.

\section{III. g) Previsión social}

Como hemos señalado antes, uno de los problemas que enfrentan los mapuches en la IX Región por el lado del mercado laboral son las altas tasas de informalidad en sus contratos y las bajas tasas de ocupación. Estas características del mercado laboral pueden traer de la mano potenciales problemas de cobertura en previsión social al no realizarse cotizaciones en el sistema de pensiones o en el sistema de salud.

La Tabla $N^{\circ} 3.20$ muestra el sistema de pensiones en el que cotizan las personas que están empleadas (ocupadas). En Chile, cerca del 60\% de este grupo se encuentra cotizando en AFP mientras que alrededor del 36\% de la población no está afiliada o no cotiza. Estas cifras se han mantenido bastante estables en el período 1996-2006, tal como se observa en la tabla. Éstas son cifras similares a las que reportan Berstein, Larraín y Pino (2005). Tal como indican estos autores, este $60 \%$ que se encuentra cotizando no está compuesto siempre por los mismos individuos, lo que produce bajas densidades de cotización con su consiguiente impacto en las pensiones cuando estas personas se retiran de la vida laboral.

En la IX Región, y específicamente en los mapuches de la IX Región, las cifras no cotización/no afiliación son mucho mayores llegando al 73,5\% en 1996 y bajando paulatinamente al 58,7\% en 2006. De esta forma, al momento de pensionarse sólo 40\% de los mapuches estará en condiciones de recibir pensiones distintas a las pensiones universales originadas en la reciente reforma provisional. Más aún, ése es un escenario optimista si se considera que existe rotación en el grupo de personas que cotiza y que, en consecuencia, las densidades de cotización pueden ser bajas para ese grupo, por lo que parte de las personas que cotizan accederán también a los montos de la pensión universal debido a su baja acumulación en cuentas individuales. 


\begin{tabular}{lrrrr}
\hline & 1996 & 2000 & 2003 & 2006 \\
\hline \multicolumn{4}{c}{ Chile } \\
INP (otra) & \multicolumn{2}{c}{. } & \\
AFP & 4,3 & 3,1 & 2,09 & 1,78 \\
Capredena & 58,1 & 58,14 & 53,4 & 57,94 \\
Otra & 1,7 & 1,58 & 0,88 & 0,76 \\
No está afiliado/no cotiza & 0,3 & 0,48 & 0,77 & 0,69 \\
No sabe & 35,1 & 36,51 & 41,11 & 36,38 \\
& 0,4 & 0,18 & 1,71 & 2,47
\end{tabular}

\begin{tabular}{lrrrr} 
& \multicolumn{2}{c}{ IX Región } \\
\cline { 3 - 4 } INP (otra) & 3,0 & 3,3 & 1,18 & 2,11 \\
AFP & 42,0 & 45 & 43,49 & 48,74 \\
Capredena & 1,1 & 1 & 0,27 & 0,23 \\
Otra & 0,3 & 0,79 & 0,62 & 0,64 \\
No está afiliado/no cotiza & 53,2 & 49,6 & 53,33 & 45,19 \\
No sabe & 0,3 & 0,13 & 1,1 & 3,07 \\
& & & & \\
& & & & \\
& & & & \\
INP (otra) & 1,8 & 1,8 & 1,35 & 2,06 \\
AFP & 23,7 & 29 & 29,32 & 34,6 \\
Capredena & 0,1 & 1 & 0,02 & 0,1 \\
Otra & 0,5 & 0,43 & 0,024 & 0,4 \\
No está afiliado/no con & Región & \\
No sabe & 73,5 & 68,23 & 68,02 & 58,7 \\
& 0,4 & 0,06 & 1,06 & 4,14 \\
\hline
\end{tabular}

La segunda implicancia de la informalidad y las bajas tasas de ocupación en el mercado laboral es la ausencia de cotizaciones en el sistema de salud. La Tabla $\mathrm{N}^{\circ} 3.21$ presenta tasas de afiliaciones para distintos sistemas previsionales de salud. Estas tasas se miden para toda la población. En la tabla se observa que menos de un $25 \%$ de la población chilena estaba afiliada a alguna Isapre en 1996, cifra que disminuyó al 13,5\% en 2006. Por otro lado, en este mismo período aumenta considerablemente la afiliación a Fonasa, fundamentalmente a los grupos A y $\mathrm{B}^{14}$.

\footnotetext{
${ }^{14}$ La afiliación al grupo A de Fonasa es básicamente para aquellas personas carentes de recursos o indigentes que no están afectas a régimen de seguridad social de salud alguno. Este grupo tiene sólo acceso al sistema de atención institucional (es decir, otorgadas por los hospitales, consultorios de especialidades públicos y consultorios de atención primaria municipalizada), no al sistema de libre elección. La cobertura es del $100 \%$ en las atenciones de salud, salvo en atención dental.
} 


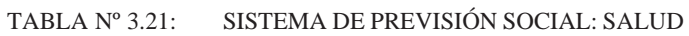

\begin{tabular}{|c|c|c|c|c|}
\hline & 1996 & 2000 & 2003 & 2006 \\
\hline & \multicolumn{4}{|c|}{ Chile } \\
\hline Sistema público grupo A & 23,7 & 24,0 & 28,5 & 29,4 \\
\hline Sistema público grupo B & 13,5 & 20,5 & 23,1 & 24,2 \\
\hline Sistema público grupo C & 8,9 & 8,9 & 11,6 & 12,8 \\
\hline Sistema público grupo D & 10,2 & 10,9 & 8,0 & 8,8 \\
\hline Sistema público no sabe grupo & 3,2 & 1,1 & 0,9 & 1,7 \\
\hline FF.AA. y de orden & 3,1 & 3,1 & 3,1 & 2,7 \\
\hline Isapre & 24,9 & 20,8 & 16,4 & 13,5 \\
\hline Ninguno (particular) & 11,1 & 9,7 & 7,3 & 5,1 \\
\hline Otro sistema & 0,5 & 0,4 & 0,2 & 0,5 \\
\hline \multirow[t]{2}{*}{ No sabe } & 1,0 & 0,6 & 1,1 & 1,4 \\
\hline & \multicolumn{4}{|c|}{ IX Región } \\
\hline Sistema público grupo A & 47,8 & 42,8 & 46,5 & 47,9 \\
\hline Sistema público grupo B & 12,0 & 19,6 & 19,8 & 21,9 \\
\hline Sistema público grupo C & 7,1 & 7,0 & 8,5 & 9,0 \\
\hline Sistema público grupo D & 6,3 & 6,1 & 5,7 & 5,7 \\
\hline Sistema público no sabe grupo & 1,7 & 1,0 & 0,3 & 0,7 \\
\hline FF.AA. y de orden & 2,2 & 2,1 & 2,1 & 1,7 \\
\hline Isapre & 12,5 & 12,6 & 9,3 & 7,7 \\
\hline Ninguno (particular) & 8,7 & 7,9 & 7,1 & 3,9 \\
\hline Otro sistema & 0,6 & 0,2 & 0,1 & 0,5 \\
\hline \multirow[t]{2}{*}{ No sabe } & 1,2 & 0,7 & 0,6 & 1,1 \\
\hline & & \multicolumn{2}{|c|}{ Mapuches, IX Región } & \\
\hline Sistema público grupo A & 76,6 & 72,1 & 71,4 & 70,6 \\
\hline Sistema público grupo B & 6,7 & 12,4 & 12,6 & 14,5 \\
\hline Sistema público grupo C & 2,9 & 3,3 & 4,4 & 6,1 \\
\hline Sistema público grupo D & 2,8 & 2,4 & 1,7 & 2,3 \\
\hline Sistema público no sabe grupo & 1,8 & 0,7 & 0,1 & 0,4 \\
\hline FF.AA. y de orden & 0,2 & 0,9 & 0,6 & 0,4 \\
\hline Isapre & 2,7 & 2,8 & 2,1 & 1,8 \\
\hline Ninguno (particular) & 4,8 & 4,9 & 6,6 & 2,5 \\
\hline Otro sistema & 0,5 & 0,0 & 0,0 & 0,7 \\
\hline No sabe & 1,0 & 0,5 & 0,5 & 0,8 \\
\hline
\end{tabular}

Los datos para la IX Región y para los mapuches de la IX Región son dramáticamente distintos. En 2006 cerca del 71\% de los mapuches en la Región de la Araucanía estaba afiliado al grupo A de Fonasa y cerca del 93\% estaba afiliado a algún grupo de Fonasa. El que la mayoría de la población mapuche se afilie al grupo A de Fonasa debe estar muy relacionado 
con la informalidad en contratos de trabajo debido a que el grupo A es el grupo para individuos indigentes mientras que aquellos individuos con ingresos imponibles positivos deben afiliarse a los grupos B, C o D de Fonasa o a alguna Isapre.

\section{III. h) Tierras}

El tema de las tierras parece central en la cultura mapuche por múltiples razones. En primer lugar, de acuerdo con Valenzuela (2007), tanto la lengua como las tierras son los factores primordiales de la identidad y cultura mapuche en la actualidad. En ese sentido, las tierras pasan a ser un eslabón fundamental para sostener y desarrollar la cultura e identidad de este grupo. Desde ese punto de vista, la tierra tiene una connotación bastante más amplia que su dimensión económica, esto es, como fuente de ingresos. Una vez dicho esto, debemos indicar que nuestro análisis se centrará, precisamente, en la dimensión económica, por lo que para análisis más sociológicos sobre la tierra y los mapuches se sugiere al lector ver los artículos publicados en el número de verano 2007 de Estudios Públicos (por ejemplo, el citado Valenzuela, 2007, o alternativamente Mascareño, 2007, e Irarrázaval y Morandé 2007).

En segundo lugar, se trata de un tema que ha estado en la palestra pública debido a la difusión que han tenido los hechos de violencia ocurridos en el sur del país y provocados por movimientos violentistas que ponen la tierra al centro de sus reivindicaciones.

En tercer lugar, es un tema sensible para la opinión pública y los mapuches en particular. De acuerdo a la encuesta de opinión pública de mayo del 2006 del CEP, cerca del 91\% de los mapuches de la IX Región considera que el país debería reparar a los mapuches por el tratamiento histórico que ellos han recibido. Entre los no mapuches esta cifra era 79\%. Cuando se les pregunta a su vez como realizar esa reparación, una gran mayoría estima que debería hacerlo por medio de tierras (véase Tabla No 3.22) y muy por detrás se sitúa educación u otros tipos de reivindicaciones sociales, como escucharlos/reconocerlos/respetarlos, empleo, vivienda o salud.

Además, las tierras han sido el tema central del debate y de la política pública dirigida a los mapuches. La importancia de la política de tierra y aguas seguida por el gobierno chileno desde 1994 es un ejemplo de ello. Esta política se ha implementado a través del Fondo de Tierras y Aguas Indígenas (FTAI). De acuerdo al informe final del grupo de trabajo económico y social de la Comisión de Verdad Histórica y Nuevo Trato (2003), la 
TABLA No ${ }^{\circ}$ 3.22: ¿ ¿CÓMO DEBE EL PAÍS REPARAR A LOS MAPUCHES ${ }^{15}$ MENCIONES SOBRE 5\%

\begin{tabular}{lcc}
\hline & Mapuches & No mapuches \\
\hline Tierras & 61 & 63 \\
Educación & 26 & 23 \\
Escucharlos/reconocerlos/respetarlos & 25 & 20 \\
Fomento lengua y cultura & 14 & 10 \\
Subsidios/créditos & 14 & 11 \\
Terminar con discriminación & 12 & 12 \\
Empleo & 12 & 12 \\
Vivienda & 8 & 7 \\
Salud & 6 & 7 \\
Demandas políticas & 6 & 6 \\
\hline
\end{tabular}

Fuente: CEP: "Estudio de Opinión Pública. Los Mapuche Rurales y Urbanos Hoy. Mayo 2006” (2007).

importancia de este fondo se podía ilustrar de la siguiente forma: "para el año 2003, la Conadi cuenta con un presupuesto nacional de 19.300 millones de pesos, de los cuales 14.500 millones (75\%) fueron destinados al FTAI, 2.613 millones (10\%) para la administración, reservando sólo un 15\% para otros fines ${ }^{16 ”}$. Las cifras para el año 2007 de acuerdo al informe de ejecución presupuestaria de la Dipres señalan que la Conadi tenía disponible un presupuesto de 37.651 millones de pesos, de los cuales 22.061 millones (58.5\%) se destinaron al FTAI ${ }^{17}$.

En síntesis, el tema de las tierras parece ser clave en el análisis de la problemática de la IX Región y de los mapuches que viven en esa región. En esta parte del trabajo, describiremos la situación de la propiedad de tierras en la IX Región.

La Figura $\mathrm{N}^{\circ} 3.14$ muestra el plano de títulos de merced otorgado a indígenas durante los siglos XIX y XX en la Región de la Araucanía. Obviamenciones.

${ }^{15} \mathrm{Al}$ responder esta pregunta, la encuesta permite entregar un máximo de tres

${ }^{16}$ Informe de Ejecución Presupuestaria segundo semestre 2003 (DIPRES)

${ }^{17}$ Este fondo se utiliza para:
a) Regularización de títulos de tierra
b) Subsidio para la compra de tierras
c) Compra de predios en conflicto
d) Traspaso de predios fiscales
e) Subsidio para la compra de derechos de agua
f) Saneamiento de derechos de agua
g) Subsidio para obras de riego. 
FIGURA N ${ }^{\circ}$ 3.14: $\quad$ MAPA DE TIERRAS INDÍGENAS SIGLO XIX Y XX

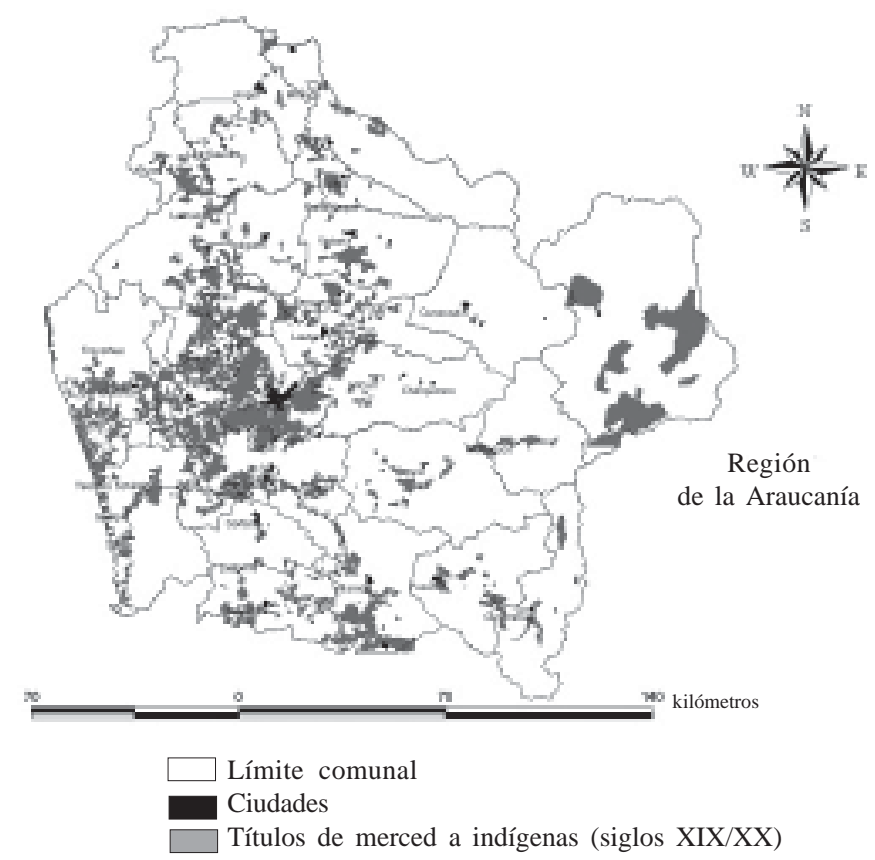

Fuente: Conadi de la IX Región.

mente mucha de esta tierra indígena fue transferida a otras personas durante los años treinta y posteriores, por lo que no necesariamente indica la tenencia de tierras en manos de mapuches en la actualidad, pero debe ser un buen indicador acerca de la ubicación general de estas tierras.

¿Cuán importantes son las tierras de mapuches en la Región de la Araucanía? De acuerdo a los datos actualmente disponibles del Censo Agropecuario del 2007, los pueblos originarios tienen algo más de 946.000 hectáreas en el país cuya finalidad es ser utilizadas con fines forestales o agropecuarios. Esto representa cerca del 2,5\% del total de superficie censada en el país para esos fines. Estos datos aparecen en la Tabla $\mathrm{N}^{\circ} 3.23$. Es interesante notar que del total de informantes de pueblos originarios en el país, más del 92\% son del pueblo mapuche y del total de mapuches cerca de 73\% corresponden a la Región de la Araucanía. Además, nótese que los mapuches en la IX Región tienen algo más de 383.000 hectáreas, lo que representa cerca de 15\% de la superficie total en esa región. Finalmente, el número de personas informantes del pueblo mapuche en la Región de la Araucanía fue algo más de 31.000, lo que representa una cifra bastante alta si se considera que de acuerdo a la encuesta Casen 2006 habría algo más de 
TABLA No 3.23: $\quad$ SUPERFICIE (HECTÁREAS), AÑO 2007

\begin{tabular}{|c|c|c|c|c|c|c|}
\hline \multirow{3}{*}{$\begin{array}{l}\text { País, región, provincia } \\
\text { y comuna }\end{array}$} & \multicolumn{4}{|c|}{ Pueblos originarios } & \multirow{2}{*}{\multicolumn{2}{|c|}{$\begin{array}{c}\text { Población total } \\
\text { Chile }\end{array}$}} \\
\hline & \multicolumn{2}{|c|}{ Total } & \multicolumn{2}{|c|}{ Mapuche } & & \\
\hline & Informantes & $\begin{array}{l}\text { Superficie } \\
\text { (ha) }\end{array}$ & Informantes & $\begin{array}{l}\text { Superficie } \\
\text { (ha) }\end{array}$ & $\begin{array}{c}\text { Número } \\
\text { explotaciones }\end{array}$ & $\begin{array}{l}\text { Superficie } \\
\text { es (ha) }\end{array}$ \\
\hline Total país & 46.368 & 946.598 & 42.807 & 653.706 & 301.2543 & 37.112 .450 \\
\hline I de Tarapacá & 1.219 & 143.480 & 9 & 24 & 1.974 & 343.522 \\
\hline II de Antofagasta & 937 & 2.331 & 7 & 15 & 2.000 & 720.368 \\
\hline III de Atacama & 135 & 2.300 & 1 & 4 & 2.920 & 3.773 .422 \\
\hline IV de Coquimbo & 21 & 111 & 11 & 53 & 15.774 & 4.001 .351 \\
\hline V de Valparaíso & 331 & 1.910 & 7 & 15 & 17.725 & 1.381.041 \\
\hline VI de O’Higgins & 7 & 100 & 6 & 92 & 25.248 & 1.570 .535 \\
\hline VII del Maule & 15 & 172 & 15 & 172 & 41.880 & 2.679.461 \\
\hline VIII del Bío-Bío & 2.632 & 75.154 & 2.631 & 75.152 & 62.793 & 3.138.351 \\
\hline IX de La Araucanía & 31.434 & 383.967 & 31.434 & 383.967 & 58.051 & 2.586 .772 \\
\hline X de Los Lagos & 4.480 & 120.673 & 4.477 & 120.644 & 35.700 & 3.860 .192 \\
\hline XI Aysén & 40 & 9.891 & 39 & 9.842 & 3.991 & 4.203.417 \\
\hline XII de Magallanes y Antártica & 28 & 9.578 & 26 & 4.423 & 1.376 & 5.711 .045 \\
\hline Región Metrop. de Santiago & 13 & 82 & 10 & 54 & 12.803 & 1.302 .419 \\
\hline XIV de Los Ríos & 4.126 & 59.245 & 4.125 & 59.238 & 16.524 & 1.637 .426 \\
\hline XV de Arica y Parinacota & 950 & 137.602 & 9 & 9 & 2.495 & 203.128 \\
\hline
\end{tabular}

61.000 hogares mapuches en la IX Región. Estas cifras, entonces, indican que los mapuches de la IX Región tienen una fracción significativa de las tierras agropecuarias y forestales de la zona y que la propiedad de la tierra parece estar bastante distribuida entre la población mapuche de la zona.

Un mapa más actualizado se puede observar en la Figura $\mathrm{N}^{\circ} 3.15$ que muestra la participación de las explotaciones mapuches en el número total de explotaciones agrícolas de acuerdo a los datos ${ }^{18}$ del VI Censo Agropecuario de 1997 en las regiones VIII, IX y X. Como puede observarse, comunas como Temuco, Nueva Imperial, Padre Las Casas y Galvarino mantienen una altísima participación de los mapuches en las explotaciones totales (todas estas mayores al 70\% en 1997). La Figura $N^{\circ} 3.16$ clasifica la superficie disponible en las regiones VIII, IX y X de acuerdo a áreas homogéneas definidas por la Odepa (2001). De acuerdo a los datos de 1997, cerca de $66 \%$ del total de explotaciones mapuches en la IX Región están en el valle secano, lo que corresponde a cerca de $47 \%$ de la superficie de explotación y a $55 \%$ de la superficie agrícola utilizada. Le siguen de lejos el secano costero y el secano interno, ambos con cifras de aproximadamente 11\% de explotaciones. Así, destaca una gran concentración de tierras mapuches en la zona centro de la Región de la Araucanía, muy bien ubicadas (en la cercanía de Temuco) y, en general, de aptitud forestal y agropecuaria.

${ }^{18}$ La fuente de estos datos y de varios de los que se presentan a continuación es ODEPA-Conadi (2001) y el VI Censo Agropecuario de 1997. 
FIGURA N ${ }^{\circ}$ 3.15: $\quad$ MAPA DE PARTICIPACIÓN MAPUCHE, 1997

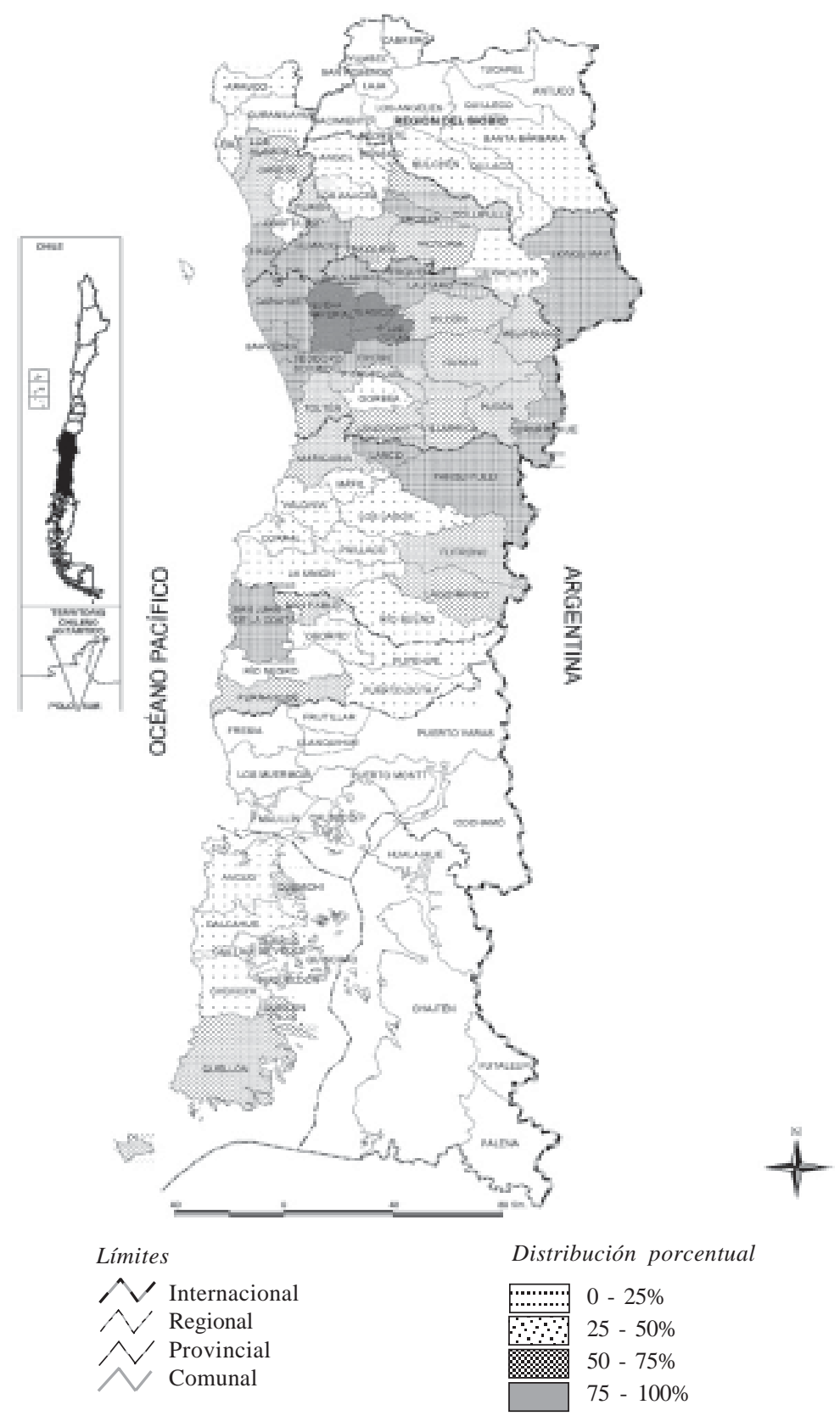

Fuente: ODEPA-Conadi (2001). 
FIGURA No 3.16: MAPA DE TIERRAS INDÍGENAS, 1997

(Agricultura mapuche, áreas homogéneas ambientales)
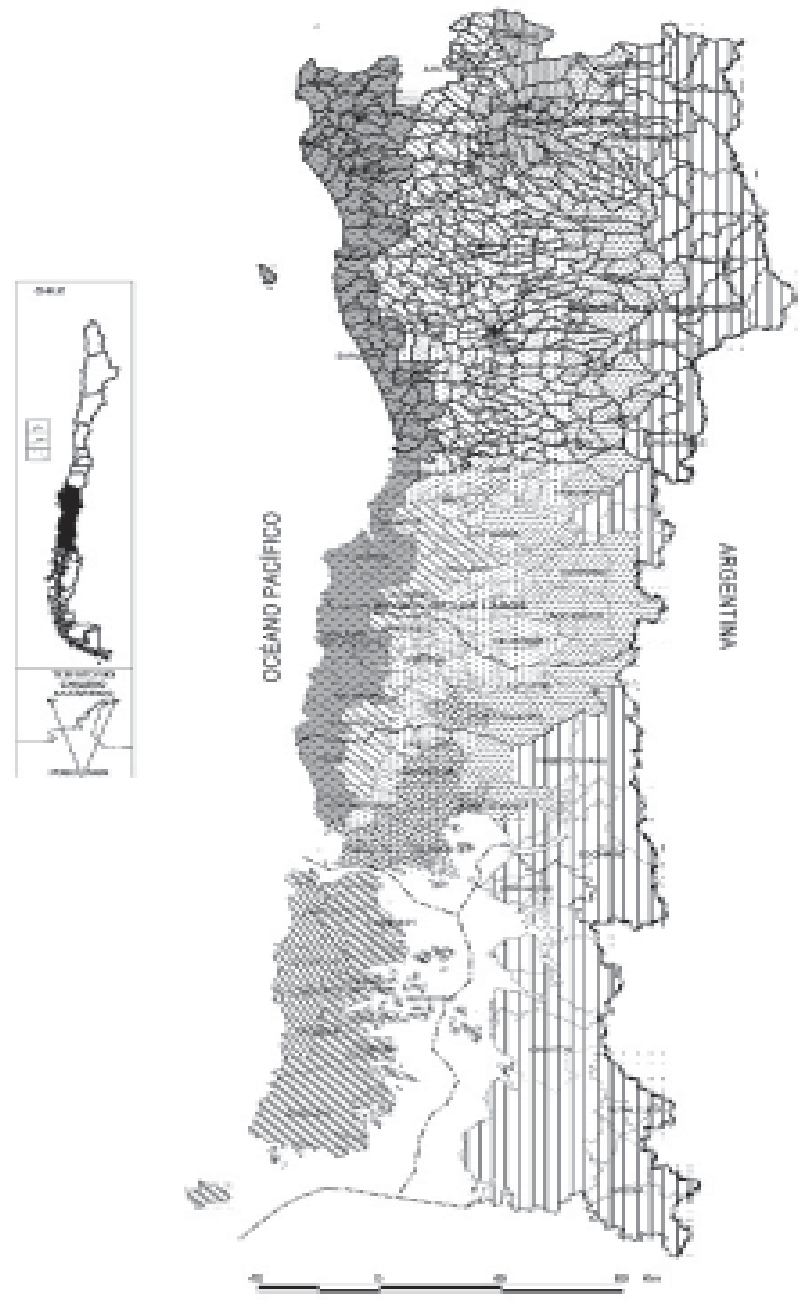

Límites

Áreas hemogéneas

$\checkmark$ Internacional

$\widehat{\wedge}$ Regional

$\widehat{\gamma}$ Provincial

Comunal

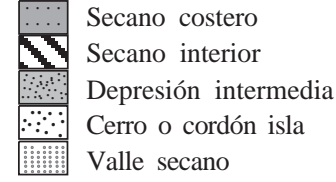

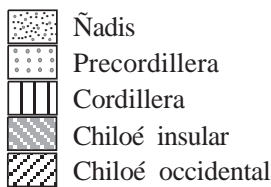

Fuente: ODEPA-Conadi (2001). 
La Tabla No 3.24 entrega varios datos acerca de las explotaciones mapuches en la IX Región y en las regiones vecinas. Los mapuches de las regiones VIII, IX y X tienen cerca del 15\% de las explotaciones totales de Chile, mientras que los mapuches de la IX Región tienen cerca del 70\% de las explotaciones mapuches de esas tres regiones. La superficie de explotaciones y la superficie agrícola utilizada corresponden a porcentajes menores del total nacional, lo cual indica que los predios explotados por los mapuches tienden a ser de tamaño pequeño. De hecho, esto se ratifica en la Tabla $N^{\circ} 3.26$ que muestra que casi el 40\% de las explotaciones agrícolas de los mapuches de la IX Región se lleva a cabo en predios cuyo tamaño va de una a cinco hectáreas y casi otro $40 \%$ se lleva a cabo en predios con dimensiones entre cinco y quince hectáreas. La Tabla Nº 3.25, además, permite separar la propiedad de las explotaciones agropecuarias de acuerdo a la

TABLA N ${ }^{\circ}$ 3.24: $\quad$ AGRICULTURA MAPUCHE EN LA IX REGIÓN: NÚMERO DE LAS EXPLOTACIONES, SUPERFICIE PRODUCTIVA Y CABEZAS DE GANADO

\begin{tabular}{|c|c|c|c|c|c|}
\hline Variables & $\begin{array}{c}\text { Total } \\
\text { nacional }\end{array}$ & $\begin{array}{c}\text { Total } \\
\text { mapuche } \\
\text { VIII, IX y } \\
\text { X Región }\end{array}$ & $\begin{array}{l}\text { IX Región } \\
\text { mapuches }\end{array}$ & $\begin{array}{c}\text { Porcentaje } \\
\text { total mapuche } \\
\text { VIII, IX y X } \\
\text { Región respecto } \\
\text { al total nacional }\end{array}$ & $\begin{array}{c}\text { Porcentaje } \\
\text { IX Región } \\
\text { respecto } \\
\text { al total } \\
\text { mapuche }\end{array}$ \\
\hline Número de explotaciones $\left(\mathrm{N}^{\circ}\right)$ & 329.705 & 48.535 & 34.137 & 14,7 & 70,3 \\
\hline Superficie explotaciones (ha) & 51.300 .314 & 756.510 & 426.243 & 1,5 & 56,3 \\
\hline Superficie agrícola utilizada (ha) & 17.680 .239 & 507.707 & 318.705 & 2,9 & 62,8 \\
\hline Cultivos anuales (ha) & 955.161 & 71.276 & 58.138 & 7,5 & 81,6 \\
\hline Hortalizas (ha) & 127.305 & 4.101 & 2.639 & 3,2 & 64,4 \\
\hline Viñas (ha) & 82.174 & 128 & 0 & 0,2 & 0,0 \\
\hline Plantaciones frutales (ha) & 237.363 & 6.277 & 3.869 & 2,6 & 61,6 \\
\hline Plantaciones forestales (ha) & 2.232 .798 & 28.032 & 19.262 & 1,3 & 68,7 \\
\hline Bosque natural y matorrales (ha) & 98.447 .000 & 196.894 & 75.523 & 0,2 & 38,4 \\
\hline Praderas naturales (ha) & 12.143 .822 & 323.070 & 198.855 & 2,7 & 61,6 \\
\hline Praderas mejoradas (ha) & 20.866 .747 & 45.023 & 13.614 & 0,2 & 30,2 \\
\hline Praderas sembradas (ha) & 454.170 & 12.465 & 6.169 & 2,7 & 49,5 \\
\hline Barbechos (ha) & 445.307 & 17.336 & 16.159 & 3,9 & 93,2 \\
\hline Bovinos (cab) & 4.140 .247 & 272.665 & 142.352 & 6,6 & 52,2 \\
\hline Vacas lecheras (cab) & 617.612 & 36.657 & 11.020 & 5,9 & 30,1 \\
\hline Ovinos (cab) & 3.710 .459 & 205.261 & 118.735 & 5,5 & 57,8 \\
\hline Caprinos (cab) & 1.253 .574 & 49.272 & 27.060 & 3,9 & 54,9 \\
\hline Cerdos (cab) & 1.722 .407 & 134.712 & 99.337 & 7,8 & 73,7 \\
\hline Camélidos (cab) & 124.654 & 40 & 17 & 0,0 & 42,5 \\
\hline
\end{tabular}

Fuente: Elaborado por ODEPA a partir de la información del VI Censo Nacional Agropecuario, INE 1997. 


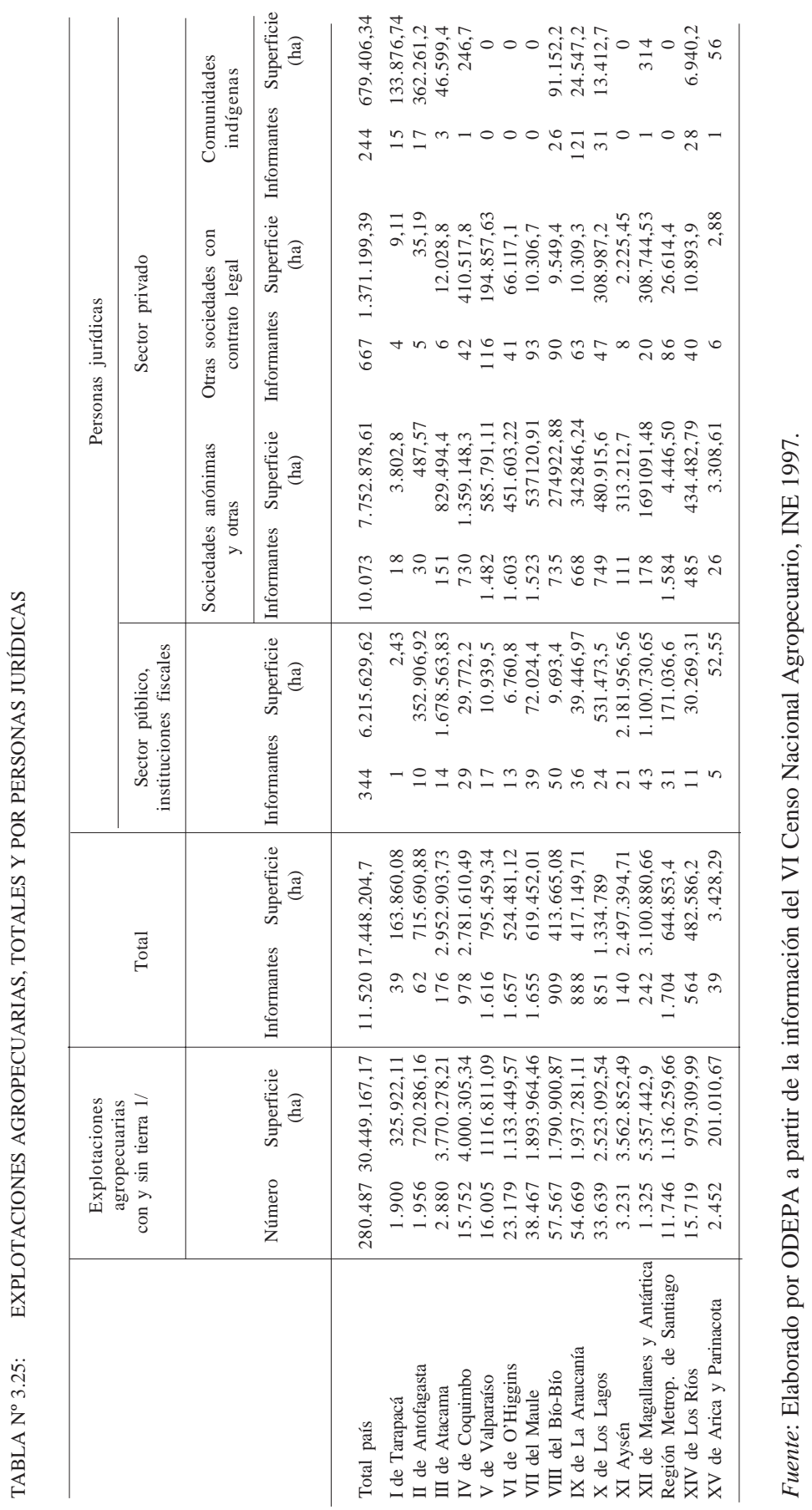




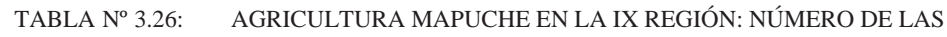
EXPLOTACIONES SEGÚN RANGO DE TAMAÑO

\begin{tabular}{|c|c|c|c|c|c|c|}
\hline $\begin{array}{l}\text { Rangos de } \\
\text { tamaño de la } \\
\text { explotación (ha) }\end{array}$ & $\begin{array}{c}\mathrm{N}^{\circ} \text { de } \\
\text { explotaciones }\end{array}$ & $\begin{array}{l}\text { Superficie } \\
\text { total }\end{array}$ & $\begin{array}{l}\text { Superficie } \\
\text { agrícola } \\
\text { utilizada }\end{array}$ & $\begin{array}{c}\mathrm{N}^{\mathrm{o}} \text { de } \\
\text { explotaciones } \\
\text { (\%) }\end{array}$ & $\begin{array}{c}\text { Superficie } \\
\text { total } \\
\text { (\%) }\end{array}$ & $\begin{array}{c}\text { Superficie } \\
\text { agrícola } \\
\text { utilizada } \\
\text { (\%) }\end{array}$ \\
\hline Sin tierra & 26 & 0 & 0 & 0,1 & 0,0 & 0,0 \\
\hline 0,5 a 0,9 & 1.710 & 1.025 & 947 & 5,0 & 0,2 & 0,3 \\
\hline 1 a 4,9 & 13.024 & 35.559 & 32.522 & 38,2 & 8,3 & 10,2 \\
\hline 5 а 9,9 & 8.634 & 61.443 & 54.710 & 25,3 & 14,4 & 17,2 \\
\hline 10 a 14,9 & 4.323 & 52.337 & 45.213 & 12,7 & 12,3 & 14,2 \\
\hline 15 а 19,9 & 2.178 & 37.301 & 31.412 & 6,4 & 8,8 & 9,9 \\
\hline 20 а 39,9 & 2.893 & 77.783 & 62.972 & 8,5 & 18,2 & 19,8 \\
\hline 40 а 59,9 & 658 & 31.484 & 23.231 & 1,9 & 7,4 & 7,3 \\
\hline 60 а 99,9 & 381 & 28.634 & 18.060 & 1,1 & 6,7 & 5,7 \\
\hline 100 а 199,9 & 191 & 25.932 & 15.006 & 0,6 & 6,1 & 4,7 \\
\hline 200 a 499,9 & 94 & 28.088 & 18.289 & 0,3 & 6,6 & 5,7 \\
\hline 500 а 999,9 & 21 & 14.298 & 8.681 & 0,1 & 3,4 & 2,7 \\
\hline 1000 a 1999,9 & 1 & 1.220 & 1.161 & 0,0 & 0,3 & 0,4 \\
\hline Más de 2000 & 3 & 31.140 & 6.501 & 0,0 & 7,3 & 2,0 \\
\hline Total general & 34.137 & 426.243 & 318.705 & 100 & 100 & 100 \\
\hline
\end{tabular}

Fuente: Elaborado por ODEPA a partir de la información del VI Censo Nacional Agropecuario, INE 1997.

tenencia jurídica. Nótese que en la IX Región de la Araucanía las comunidades indígenas tienen cerca del 5\% de las superficies totales informadas, cifra algo mayor al promedio nacional (cercano al 4\%) y bastante menor al de las informadas en las Regiones de Tarapacá, Antofagasta y del Bío-Bío. Desde ese punto de vista, las tierras correspondientes a comunidades indígenas en la IX Región representan una fracción menor de las tierras en manos de personas del pueblo mapuche en la región y, de acuerdo a la evidencia aquí mostrada, esto estaría indicando que una fracción muy importante de las tierras en manos de mapuches se encuentran divididas en predios pequeños.

Volviendo al análisis de la Tabla $\mathrm{N}^{0} 3.24$, nótese que una cantidad muy importante de la superficie de los predios de los mapuches en la IX Región corresponde a praderas naturales (casi 62\% de la superficie explotada), superficie que generalmente es utilizada con fines ganaderos. De hecho, los mapuches de la IX Región tienen la mayor parte de los recursos ganaderos de los mapuches entre la VIII y X Regiones, llegando a un 52\% 
de los bovinos, 58\% de los ovinos, 55\% de los caprinos y 74\% de los cerdos.

La Tabla $N^{0} 3.27$ nos permite ahondar sobre el uso que hacen los mapuches del suelo agrícola en la IX Región. Es interesante notar que los cultivos se encuentran primordialmente en predios de pequeña extensión, lo que posiblemente indique que se trata de cultivos con la finalidad de consumo propio y subsistencia. Además, algo similar sucede con las praderas naturales. Los bosques naturales y matorrales se concentran en tierras de mayor extensión, lo que indica que predios de mayor extensión no han sido explotados aún por los mapuches.

En relación a los tipos de cultivos, la Tabla $N^{0} 3.28$ muestra que la mayor producción es la de papas y trigo y en menor medida avena y porotos. El rendimiento por hectárea para los cultivos en general es bastante bajo, y salvo algunas excepciones como los garbanzos y las lentejas, es bastante menor que en el resto del país. Por ejemplo, los rendimientos obtenidos por los mapuches en el caso del maíz, remolacha azucarera e incluso el trigo son muy inferiores a los promedios del país.

TABLA N ${ }^{\circ}$ 3.27: AGRICULTURA MAPUCHE EN LA IX REGIÓN: USO DEL SUELO SEGÚN RANGO DE TAMAÑO DE LAS EXPLOTACIONES

\begin{tabular}{lrrrrrrrr}
\hline $\begin{array}{l}\text { Rangos } \\
\text { de tamaño en ha }\end{array}$ & $\begin{array}{c}\text { Cultivos } \\
\text { anuales }\end{array}$ & $\begin{array}{c}\text { Horta- } \\
\text { lizas }\end{array}$ & Frutales & $\begin{array}{c}\text { Planta- } \\
\text { ciones } \\
\text { forestales }\end{array}$ & $\begin{array}{r}\text { Bosque } \\
\text { nat. y ma- } \\
\text { torrales }\end{array}$ & $\begin{array}{r}\text { Praderas } \\
\text { nales }\end{array}$ & $\begin{array}{r}\text { Praderas } \\
\text { ram- } \\
\text { bradas }\end{array}$ & $\begin{array}{r}\text { Praderas } \\
\text { mejo- } \\
\text { radas }\end{array}$ \\
\hline Sin tierra & & & & & & & & \\
0,5 a 0,9 & 0 & 0 & 0 & 0 & 0 & 0 & 0 & 0 \\
1 a 4,9 & 11.375 & 701 & 667 & 1.665 & 1.269 & 14.295 & 418 & 635 \\
5 a 9,9 & 14.151 & 719 & 1.006 & 3.241 & 3.567 & 29.670 & 941 & 1.475 \\
10 a 14,9 & 9.691 & 431 & 661 & 2.707 & 4.039 & 26.533 & 788 & 1.772 \\
15 a 19,9 & 5.740 & 222 & 398 & 1.884 & 3.700 & 19.692 & 533 & 1.262 \\
20 a 39,9 & 9.485 & 350 & 650 & 3.905 & 9.819 & 40.366 & 1.254 & 3.642 \\
40 a 59,9 & 2.913 & 60 & 159 & 1.728 & 6.092 & 15.291 & 486 & 1.756 \\
60 a 99,9 & 1.815 & 45 & 138 & 1.332 & 8.428 & 12.834 & 382 & 991 \\
100 a 199,9 & 750 & 45 & 80 & 600 & 8.673 & 11.856 & 389 & 928 \\
200 a 499,9 & 1.396 & 1 & 88 & 1.439 & 6.947 & 13.564 & 512 & 889 \\
500 a 999,9 & 402 & 0 & 1 & 734 & 3.583 & 6.827 & 458 & 256 \\
1000 a 1999,9 & 0 & 0 & 0 & 0 & 30 & 1.157 & 2 & 2 \\
más de 2000 & 0 & 0 & 0 & 0 & 19.364 & 6.501 & 0 & 0 \\
Total general & 58.138 & 2.639 & 3.869 & 19.262 & 75.523 & 198.855 & 6.169 & 13.614 \\
\hline
\end{tabular}

Fuente: Elaborado por ODEPA a partir de la información del VI Censo Nacional Agropecuario, INE 1997. 
TABLA No 3.28: AGRICULTURA MAPUCHE EN LA IX REGIÓN: NÚMERO DE EXPLOTACIONES, SUPERFICIE, PRODUCCIÓN Y RENDIMIENTO DE CULTIVOS ANUALES

\begin{tabular}{lrrrr}
\hline Cultivo & $\begin{array}{c}\text { No de } \\
\text { explotaciones }\end{array}$ & $\begin{array}{c}\text { Superficie } \\
\text { (ha) }\end{array}$ & $\begin{array}{c}\text { Rendimiento } \\
\text { (qqm/ha) }\end{array}$ & $\begin{array}{r}\text { Rendimiento } \\
\text { (qqm/ha) Chile }\end{array}$ \\
\hline Arveja (grano seco) & 909 & 372 & 7,9 & 10,1 \\
Avena (grano seco) & 8.164 & 8.022 & 17,4 & 32,2 \\
Cebada cervecera & 245 & 451 & 25,6 & 40,4 \\
Cebada forrajera & 407 & 354 & 17,3 & 28,2 \\
Centeno & 110 & 106 & 14,2 & 29,2 \\
Chícharo & 126 & 27 & 7,4 & 6,2 \\
Garbanzo & 65 & 58 & 7,4 & 5,5 \\
Lenteja & 599 & 286 & 6,2 & 6,2 \\
Lupino (grano seco) & 1.843 & 3.351 & 16,0 & 22,2 \\
Má́z (grano seco) & 55 & 22 & 11,5 & 90,5 \\
Maravilla & 6 & 29 & 15,7 & 19,5 \\
Otros & 23 & 21 & 5,5 & - \\
Papa & 12.298 & 6.684 & 118,3 & 161,7 \\
Poroto de consumo interno & 2.934 & 928 & 5,6 & 11,4 \\
Poroto de exportación & 74 & 26 & 7,5 & 13,3 \\
Raps & 6 & 86 & 21,9 & 26,4 \\
Remolacha azucarera & 256 & 247 & 371,1 & 576,8 \\
Trigo blanco & 21.420 & 32.220 & 18,4 & 37,8 \\
Trigo candeal & 16 & 22 & 15,3 & 57,6 \\
Triticale & 214 & 237 & 41,5 & 49,6 \\
Total general & & & & \\
& 49.770 & 53.548 & 32,0 & \\
\hline & & & & \\
\hline
\end{tabular}

Fuente: Elaborado por ODEPA a partir de la información del VI Censo Nacional Agropecuario, INE 1997. Además qqm indica quintales métricos.

Una de las posibles fuentes de la baja productividad en los cultivos de los mapuches de la IX Región es el insuficiente nivel de capital físico disponible para realizar las labores agrícolas. La Tabla $N^{\circ} 3.29$ muestra que del total de 34.137 explotaciones, sólo una fracción menor cuenta con maquinaria para la realización de estas actividades. Además, la clase de maquinaria que está más disponible es la de tipo "tiro animal” y, salvo las excepciones de arados, carros de arrastre, cultivadoras y rastras, es mayoritariamente de propiedad ajena. Ésta es una característica mucho más acentuada cuando la maquinaria es de tipo mecanizada. Estos datos tienden a indicar que este tipo de agricultores y ganaderos no pueden optar a tecnología que les facilite el proceso productivo. Las razones posiblemente son restricciones de acceso al crédito, como habíamos indicado antes. De hecho, la maquinaria mecanizada, que de seguro es más costosa de adquirir, en su gran mayoría es de propiedad ajena. 
TABLA N ${ }^{\circ}$ 3.29: $\quad$ AGRICULTURA MAPUCHE EN LA IX REGIÓN: PARQUE DE MAQUINARIA PROPIA, AJENA Y NUEVA UTILIZADA EN EXPLOTACIONES MAPUCHES

\begin{tabular}{|c|c|c|c|c|c|}
\hline Tipo de maqu & $\begin{array}{l}\text { Maquinaria } \\
\text { o equipo }\end{array}$ & $\begin{array}{c}\mathrm{N}^{\circ} \text { de } \\
\text { explotaciones* }\end{array}$ & $\begin{array}{c}\mathrm{N}^{\circ} \mathrm{de} \\
\text { maquinaria } \\
\text { propia }\end{array}$ & $\begin{array}{c}\mathrm{N}^{\circ} \mathrm{de} \\
\text { maquinaria } \\
\text { propia } \\
\text { nueva** }\end{array}$ & $\begin{array}{c}\mathrm{N}^{\circ} \text { de } \\
\text { maquinaria } \\
\text { ajena }\end{array}$ \\
\hline \multirow[t]{9}{*}{ Tiro animal } & Arados (todo tipo) & 23.876 & 21.046 & 513 & 6.097 \\
\hline & Carros de arrastre & 17.972 & 15.093 & 377 & 4.507 \\
\hline & Cultivadoras & 821 & 452 & 10 & 396 \\
\hline & Enfardadoras & 3.082 & 1.041 & 84 & 2.064 \\
\hline & Pulverizadoras & 5.875 & 1.258 & 252 & 4.642 \\
\hline & Rastras (todo tipo) & 22.301 & 15.684 & 438 & 7.909 \\
\hline & Rastrillos pasteros & 265 & 106 & 2 & 162 \\
\hline & Segadoras de pasto & 1.178 & 300 & 7 & 885 \\
\hline & Sembradoras/abonadoras por surco & 1.157 & 182 & 3 & 977 \\
\hline \multirow[t]{17}{*}{ Mecanizado } & Acondicionadoras de forraje & 95 & 3 & 0 & 93 \\
\hline & Arados de punta y disco & 3.930 & 188 & 11 & 3.769 \\
\hline & Camiones (de 2 ton y más) & 178 & 54 & 8 & 128 \\
\hline & Camionetas (menores de 2 ton) & 589 & 387 & 72 & 218 \\
\hline & Carro de arrastre (todo tipo) & 562 & 229 & 21 & 388 \\
\hline & Cosechadoras de grano (trilladoras) & 19.577 & 323 & 5 & 19.497 \\
\hline & Cosechadoras de papas y remolacha & 122 & 4 & 0 & 119 \\
\hline & Cultivadoras & 230 & 26 & 4 & 209 \\
\hline & Enfardadoras & 1.593 & 32 & 5 & 1.568 \\
\hline & Pulverizadoras y nebulizadoras & 1.009 & 49 & 8 & 967 \\
\hline & Rastras de disco & 10.796 & 320 & 20 & 10.519 \\
\hline & Rastrillos pasteros & 1.055 & 28 & 4 & 1.033 \\
\hline & Segadoras & 1.587 & 41 & 6 & 1.557 \\
\hline & Sembradoras/abonadoras por surco & 7.085 & 111 & 11 & 6.979 \\
\hline & Tractores de 60 a menos de $90 \mathrm{HP}$ & 9.501 & 256 & 26 & 9.300 \\
\hline & Tractores de 90 HP y más & 1.374 & 23 & 3 & 1.352 \\
\hline & Tractores de menos de $60 \mathrm{HP}$ & 2.460 & 117 & 2 & 2.354 \\
\hline
\end{tabular}

* Corresponde a las explotaciones que usaron maquinaria propia o ajena.

** La maquinaria propia nueva está incluida en la propia.

Fuente: Elaborado por ODEPA a partir de la información del VI Censo Nacional Agropecuario, INE 1997.

La Tabla No 3.30 nos muestra además que en los hogares mapuches que tienen algún tipo de explotación agrícola, cerca de la mitad de sus miembros trabaja en los predios. Cabe notar que algo más de la mitad de los hombres adultos trabaja en los predios mientras que en el caso de las mujeres adultas la cifra es casi un tercio. El empleo permanente remunerado es menor al número de trabajadores del hogar, lo que indicaría que los predios son bastante atomizados y tienen pocos trabajadores adicionales a las personas del hogar que trabajan en ellos. 


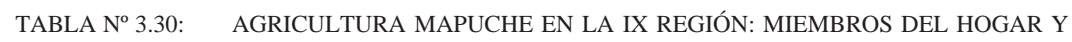
TRABAJADORES SEGÚN EDAD, SEXO Y TIPO DE CONTRATO

\begin{tabular}{lrr}
\hline Variables & Total & Porcentaje* \\
Número de explotaciones & 34.137 & - \\
& & \\
\hline
\end{tabular}

Miembros del hogar

Miembros del hogar menores

36.827

31,3

Miembros del hogar hombres

42.326

36,0

Miembros del hogar mujeres

38.474

117.627

32,7

Miembros del hogar total

Trabajadores del hogar

Hogar trabajadores menores

1.931

3,8

Hogar trabajadores hombres

32.285

63,5

Hogar trabajadores mujeres

16.632

32,7

Hogar trabajadores total

50.848

100,0

Empleo permanente remunerado

Permanente remunerado menores

33

31.097

0,1

Permanente remunerado hombres

6.910

81,7

Permanente remunerado mujeres

38.040

18,2

Permanente remunerado total

100,0

Empleo permanente no remunerado

Permanente no remunerado menores

2.184

8,1

Permanente no remunerado hombres

11.581

43,0

Permanente no remunerado mujeres

13.147

Permanente no remunerado total

26.912

48,9

100,0

Empleo temporal

Temporal menores

130

3.313

Temporal hombres

335

Temporal mujeres

3.778

3, 4

87,7

Temporal total

8,9

100,0

* Cifras aproximadas a un decimal.

Nota: los menores son personas de hasta 15 años de edad.

Fuente: Elaborado por ODEPA a partir de la información del VI Censo Nacional Agropecuario, INE 1997. 
TABLA N ${ }^{\circ}$ 3.31: $\quad$ AGRICULTURA MAPUCHE EN LA IX REGIÓN: NÚMERO DE LAS EXPLOTACIONES SEGÚN RANGO DE TAMAÑO

\begin{tabular}{|c|c|c|c|c|c|c|c|c|c|}
\hline $\begin{array}{l}\text { Rangos de } \\
\text { tamaño en ha }\end{array}$ & \begin{tabular}{|c} 
Propio \\
con \\
título \\
inscrito
\end{tabular} & $\begin{array}{c}\text { Propio } \\
\text { con } \\
\text { título } \\
\text { irregular }\end{array}$ & $\begin{array}{l}\text { Recibido } \\
\text { en goce } \\
\text { o regalía }\end{array}$ & $\begin{array}{l}\text { Tomado } \\
\text { en } \\
\text { arriendo }\end{array}$ & $\begin{array}{l}\text { Recibido } \\
\text { en } \\
\text { mediería }\end{array}$ & $\begin{array}{l}\text { Que le } \\
\text { han } \\
\text { cedido }\end{array}$ & $\begin{array}{l}\text { Que ha } \\
\text { ocupado }\end{array}$ & $\begin{array}{c}\text { No } \\
\text { corres- } \\
\text { ponde }\end{array}$ & $\begin{array}{l}\text { Total } \\
\text { general }\end{array}$ \\
\hline Sin tierra & & & & & & & & 26 & 26 \\
\hline 0,5 a 0,9 & 942 & 199 & 8 & 14 & 44 & 401 & 13 & 89 & 1.710 \\
\hline 1 a 4,9 & 5.842 & 1.627 & 17 & 128 & 168 & 1.612 & 156 & 3.474 & 13.024 \\
\hline 5 а 9,9 & 2.720 & 884 & & 39 & 45 & 594 & 65 & 4.287 & 8.634 \\
\hline 10 a 14,9 & 1.190 & 396 & 1 & 13 & 32 & 218 & 42 & 2.431 & 4.323 \\
\hline 15 а 19,9 & 555 & 190 & & 3 & 15 & 112 & 21 & 1.282 & 2.178 \\
\hline 20 а 39,9 & 695 & 253 & & 9 & 10 & 164 & 25 & 1.737 & 2.893 \\
\hline 40 а 59,9 & 213 & 47 & & & & 28 & 4 & 366 & 658 \\
\hline 60 а 99,9 & 103 & 38 & & & 1 & 22 & 3 & 214 & 381 \\
\hline 100 а 199,9 & 33 & 9 & & & & 11 & 2 & 136 & 191 \\
\hline 200 а 499,9 & 19 & & & & & 1 & & 74 & 94 \\
\hline 500 а 999,9 & 5 & & & & & & & 16 & 21 \\
\hline 1000 а 1999,9 & & & & & & & & 1 & 1 \\
\hline Más de 2000 & & & & & & 1 & & 2 & 3 \\
\hline \multirow[t]{2}{*}{ Total general } & 12.317 & 3.643 & 26 & 206 & 315 & 3.164 & 331 & 14.135 & 34.137 \\
\hline & \multicolumn{8}{|c|}{ Porcentajes } & \\
\hline Sin tierra & 0,00 & 0,00 & 0,00 & 0,00 & 0,00 & 0,00 & 0,00 & 0,08 & 0,08 \\
\hline 0,5 a 0,9 & 2,76 & 0,58 & 0,02 & 0,04 & 0,13 & 1,17 & 0,04 & 0,26 & 5,01 \\
\hline 1 a 4,9 & 17,11 & 4,77 & 0,05 & 0,37 & 0,49 & 4,72 & 0,46 & 10,18 & 38,15 \\
\hline 5 а 9,9 & 7,97 & 2,59 & 0,00 & 0,11 & 0,13 & 1,74 & 0,19 & 12,56 & 25,29 \\
\hline 10 а 14,9 & 3,49 & 1,16 & 0,00 & 0,04 & 0,09 & 0,64 & 0,12 & 7,12 & 12,66 \\
\hline 15 a 19,9 & 1,63 & 0,56 & 0,00 & 0,01 & 0,04 & 0,33 & 0,06 & 3,76 & 6,38 \\
\hline 20 а 39,9 & 2,04 & 0,74 & 0,00 & 0,03 & 0,03 & 0,48 & 0,07 & 5,09 & 8,47 \\
\hline 40 а 59,9 & 0,62 & 0,14 & 0,00 & 0,00 & 0,00 & 0,08 & 0,01 & 1,07 & 1,93 \\
\hline 60 а 99,9 & 0,30 & 0,11 & 0,00 & 0,00 & 0,00 & 0,06 & 0,01 & 0,63 & 1,12 \\
\hline 100 а 199,9 & 0,10 & 0,03 & 0,00 & 0,00 & 0,00 & 0,03 & 0,01 & 0,40 & 0,56 \\
\hline 200 а 499,9 & 0,06 & 0,00 & 0,00 & 0,00 & 0,00 & 0,00 & 0,00 & 0,22 & 0,28 \\
\hline 500 а 999,9 & 0,01 & 0,00 & 0,00 & 0,00 & 0,00 & 0,00 & 0,00 & 0,05 & 0,06 \\
\hline 1000 а 1999,9 & 0,00 & 0,00 & 0,00 & 0,00 & 0,00 & 0,00 & 0,00 & 0,00 & 0,00 \\
\hline Más de 2000 & 0,00 & 0,00 & 0,00 & 0,00 & 0,00 & 0,00 & 0,00 & 0,01 & 0,01 \\
\hline Total general & 36,08 & 10,67 & 0,08 & 0,60 & 0,92 & 9,27 & 0,97 & 41,41 & 100,00 \\
\hline
\end{tabular}

La Tabla № 3.31 nos entrega algo más de información acerca de los productores. En primer lugar, cerca del 36\% de los productores son dueños de los predios con títulos de propiedad inscritos, y de ellos casi la mitad corresponde a dueños de predios pequeños (menos de cinco hectáreas). En segundo lugar, una fracción algo superior de los predios (41\%) corresponde a sucesiones, sociedades y comunidades indígenas (clasificación “no co- 
TABLA N N $^{\text {3.32: }}$ AGRICULTURA MAPUCHE EN LA IX REGIÓN: NÚMERO DE EXPLOTACIONES SEGÚN NIVEL DE EDUCACIÓN Y EDAD DE LOS PRODUCTORES

\begin{tabular}{l|rrrrrr|c}
\hline Rangos de edad & Básica & Media & Superior & Técnica & Ninguna & $\begin{array}{c}\text { No } \\
\text { corresponde* }\end{array}$ & $\begin{array}{c}\text { Total } \\
\text { general }\end{array}$ \\
& & & & & & & \\
$18-21$ & 151 & 43 & 1 & 1 & 1 & & 197 \\
$22-25$ & 463 & 107 & 4 & 12 & 11 & 597 \\
$26-30$ & 1.194 & 242 & 12 & 19 & 35 & 1.502 \\
$21-25$ & 1.669 & 308 & 8 & 14 & 76 & 2.075 \\
$26-40$ & 2.700 & 444 & 26 & 24 & 167 & 3.361 \\
$41-45$ & 2.577 & 340 & 36 & 22 & 197 & & 3.172 \\
$46-50$ & 2.964 & 193 & 38 & 24 & 373 & & 3.592 \\
$51-55$ & 2.683 & 148 & 28 & 23 & 499 & & 3.381 \\
$56-60$ & 2.804 & 142 & 21 & 25 & 826 & & 3.455 \\
$61-65$ & 2.418 & 86 & 14 & 15 & 922 & & 2.812 \\
$66-70$ & 1.794 & 60 & 15 & 8 & 935 & & 1.719 \\
$71-75$ & 1.065 & 31 & 10 & 10 & 603 & & 2.023 \\
76 y más & 1.108 & 38 & 7 & 11 & 859 & & 2.433 \\
No corresponde* & & & & & & 2.433 & \\
Total general & 23.590 & 2.182 & 220 & 208 & 5.504 & 2.433 & 34.137 \\
& & & & & & & \\
\hline
\end{tabular}

* "No corresponde" indica sucesiones, sociedades y comunidades indígenas.

Fuente: Elaborado por ODEPA a partir de la información del VI Censo Nacional Agropecuario, INE 1997.

rresponde” en la tabla). En este caso, la mayoría de los predios también son de tamaño pequeño. La categoría predios propios sin título de propiedad regularizado representa sólo el 11\% mientras que las ocupaciones irregulares alcanzan sólo al 1\% de los predios, lo que indica que las ocupaciones ilegales son escasas en cuanto a explotaciones agropecuarias se refiere.

Finalmente, la Tabla $\mathrm{N}^{\circ} 3.32$ señala que la mayoría de los productores (85\%) tiene sólo educación básica o menos y por lo tanto el nivel de capital humano en este sector es bajo. Ésta es una característica que habíamos identificado anteriormente cuando analizamos niveles de educación usando datos de la encuesta Casen.

\section{DISCUSIÓN}

Como decíamos en la introducción de este trabajo, en general existe la idea de que entre los mapuches de la IX Región hay una alta prevalencia de situaciones de pobreza y bajos ingresos. Los datos que se muestran en este trabajo corroboran esa impresión, y señalan que esto ha llevado a una 
creciente emigración desde el sector rural y desde la IX Región, sobre todo en el caso de los más jóvenes.

Además, la Región de la Araucanía enfrenta una situación compleja. Por un lado su tasa de crecimiento de tendencia parece ubicarse actualmente en niveles cercanos al 3\%, por debajo de la tasa de crecimiento de tendencia del país ${ }^{19}$. Además, esta región ha ido incrementando paulatinamente sus tasas de desempleo a través del tiempo. Desde ese punto de vista, su escenario macroeconómico parece haberse hecho más complejo en los últimos diez años, posiblemente debido a los profundos cambios en su estructura productiva, los que la región aún está acomodando.

La situación de los mapuches al interior de la IX Región también es compleja debido a las múltiples desventajas que enfrentan en el mercado laboral y productivo. Como hemos visto, en la actualidad los mapuches de la IX Región tienen bajos niveles educacionales y los datos del Simce muestran además que la calidad de la educación es todavía deficiente, en especial en el sector rural. Además las tasas de ocupación de los mapuches en el sector urbano de la IX Región han sido bastante menores que las de los no mapuches. Esto último va de la mano de una alta informalidad en los contratos de trabajo, lo que a su vez implica alta desprotección en materia de pensiones para la vejez o sistema de salud.

¿Qué tipo de políticas públicas debería implementar el Estado de Chile para los mapuches de la IX Región en el contexto socioeconómico que hemos caracterizado en este trabajo? Esta pregunta es importante porque la actual combinación de políticas públicas no parece ser suficientemente efectiva. De hecho, hay alta persistencia en algunos fenómenos (como pobreza y bajo empleo) que no parecen estar abordándose de manera adecuada.

Para pensar en políticas públicas, nuestros datos pueden leerse de múltiples maneras. La primera lectura que uno podría hacer es que existen movimientos migratorios importantes, y los movimientos de los años 2000 y 2003 nos hablan de un proceso de reversión de la migración, en que personas que habrían emigrado del sector rural de la IX Región hacia el sector urbano y hacia otras regiones parecen volver a sus lugares de origen o, por lo menos, hacia la IX Región. ¿Qué nos dicen estos datos? Posiblemente exista algún “colchón” importante en la tenencia de tierras del sector rural, debido al cual ante escenarios económicos complicados se vuelva al sector rural, donde a lo menos hay tierras que se pueden auto-explotar. Ésa es

${ }^{19}$ Estas cifras deben tomarse con cuidado. Ellas emergen del uso de la metodología estadística de Hodrick-Prescott y los resultados pueden obedecer más bien a la metodología utilizada antes que a verdaderos cambios en la tendencia de crecimiento. 
obviamente una primera lectura, pero también puede haber otras como por ejemplo, que existe una red de protección social muy poco adecuada en el sector urbano - lo que parece ser el caso si se considera la alta informalidad de los contratos de los trabajadores mapuches con sus consecuentes bajas tasas de cotizaciones en los sistemas de salud y de pensiones. De hecho esto indicaría que posiblemente las políticas sociales tienen un sesgo más bien rural, al poner el acento en la tenencia de tierras, olvidando otras dimensiones importantes, como pueden ser las políticas públicas en el sector urbano, donde parece estar el núcleo de pobreza más rebelde. En esta segunda lectura surge la pregunta, entonces, de qué tipo de políticas públicas deberían implementarse, sobre todo en el sector urbano.

De este modo, en principio debe diferenciarse entre políticas para el sector rural y para el sector urbano. Como hemos visto, las características de ambos grupos son muy distintas. Las políticas públicas destinadas al pueblo mapuche han estado generalmente más bien orientadas al sector rural. Sin embargo, la población mapuche en el sector urbano de la IX Región es de una magnitud considerable, esto es, cerca de 80.000 personas en 2006, lo que representa aproximadamente el 30\% de la población mapuche de la IX Región. Más aún, las políticas públicas para el sector urbano parecen cada vez más relevantes porque dada la baja productividad de la tierra en el sector rural, se hace cada día más probable que continúe el proceso de emigración desde el sector rural ${ }^{20}$, sobre todo de los más jóvenes. En ese caso, y dado que existen bajas tasas de ocupación para este grupo de personas, la forma de enfrentar su llegada al sector urbano y la forma de acceder a empleos pasan a ser altamente relevantes.

Como hemos visto, la situación de pobreza de los mapuches en el sector urbano de la IX Región es bastante rebelde y de magnitudes muy considerables. Posiblemente esto tenga algo que ver con bajos niveles de educación. De hecho, el promedio de años de escolaridad de los mapuches urbanos era sólo de 7,83 en 1996, mientras que el promedio de la región en el sector urbano era 9,29. Si bien esta diferencia se ha atenuado, aún persiste, siendo algo menos de un año de escolaridad en 2006. Sin perjuicio de estos diferenciales de educación, una de las principales fuentes de pobreza para los mapuches urbanos de la IX Región parece ser la baja tasa de participación laboral, que se resiente fuertemente con los ciclos económicos. Como

${ }^{20}$ Esto debería ocurrir sobre todo en periodos en que la economía general del país se encuentre en proceso de crecimiento, y por lo tanto se ofrezcan más y mejores trabajos en el sector urbano y en otras regiones. Durante periodos de crisis económicas, por el contrario, el proceso podría ser en dirección contraria, debido a que el sector urbano se contrae y ofrece menos empleos. 
se mostró en el Gráfico No 3.8, la tasa de participación laboral de este grupo disminuyó desde algo más de 52\% en 1996 a cerca de 38\% en el 2000, y sólo se recuperó el año 2006. Estas fluctuaciones tan fuertes en la participación laboral sorprenden. Como hemos discutido en la sección III.d), ellas podrían ser explicadas al menos en parte por fluctuaciones de demanda, es decir, por menores expansiones de los sectores productivos en los que trabajan más intensivamente los mapuches urbanos, y por olas migratorias desde y hacia el sector urbano por parte de los mapuches de la IX Región. Sin perjuicio de ello, es muy posible que los menores niveles de escolaridad de los mapuches expliquen una parte considerable de este fenómeno en la medida que personas con menores niveles de educación son generalmente las que más disminuyen su tasa de ocupación en las crisis económicas. De hecho, la evidencia reportada en Cowan y otros (2005, p. 39), muestra que en la crisis económica de finales de los noventa, quienes vieron afectada mayormente su tasa de empleo fueron las personas con menos de doce años de escolaridad y menos de diez años de experiencia. En efecto, el trabajo de Cowan et al. muestra que la caída del empleo en ese grupo entre 1997 y 2000 fue de -32\%, cifra bastante más alta que las caídas en el grupo de doce años de educación o más y mismo nivel de experiencia, que mostró una disminución de empleo de sólo $-7 \%{ }^{21}$.

Otra razón por la que las políticas de educación y de capacitación son cada día más relevantes radica en que la estructura productiva de la región ha evolucionado concentrándose cada vez más en sectores intensivos en capital humano como la industria manufacturera, transporte y comunicaciones y servicios personales, y por otro lado han disminuido su importancia sectores como agricultura, que no son tan intensivos en capital humano calificado. De esta manera, el mercado laboral requiere trabajadores cada vez más calificados, y nuestros datos muestran que las personas que se identifican como mapuches están muy atrasadas en ese sentido. Se requieren, por lo tanto, no sólo políticas educacionales de largo plazo, sino también políticas de capacitación que les permitan insertarse en la estructura laboral actual.

Un elemento adicional que ha emergido del análisis es la alta informalidad en los empleos de los mapuches, la que seguramente también está relacionada con bajos niveles de educación. Esta informalidad tiene claras

${ }^{21}$ En este mismo periodo de tiempo, el grupo de personas con menos de 12 años de escolaridad y 10 años de experiencia o más diminuyó su nivel de empleo en $4 \%$ mientras que el grupo de personas con 12 años o más de educación y con 10 años o más de experiencia aumentó su empleo en $1 \%$. 
implicancias sociales. Como hemos visto, una fracción muy importante de personas de identidad mapuche de la IX Región no cotiza en sistema de previsión alguno (casi 60\% en 2006), y también una fracción muy importante de ellos (casi 48\% en 2006) sólo tiene acceso al sistema público de salud tipo A.

De acuerdo a este diagnóstico de los mapuches del sector urbano, parece claro que es necesario implementar políticas de mejoramiento de acceso a educación de calidad. Este tipo de políticas tienen impactos de más largo plazo porque apuntan a los que hoy son jóvenes. Para las actuales generaciones de adultos deben implementarse políticas alternativas, donde claramente la formalización de empleos debe ser clave. Incentivar la formalización, tal como hemos visto en las Tablas Nos. 3.16 y 3.17, va de la mano con mejores ingresos laborales y con mayor y mejor cobertura de protección social.

En cuanto al sector rural, la ventaja que los mapuches del sector rural parecen tener como grupo es una tenencia de tierras bastante importante como fracción de las tierras totales de la IX Región. Lamentablemente, como lo indicaba la Tabla No 3.23, la producción agrícola por hectárea para los distintos cultivos considerados es muy baja comparada con el resto de Chile. Cuando uno observa este tipo de cifras de productividad de las tierras surgen inmediatamente a lo menos dos tipos de preguntas. La primera de ellas tiene que ver con la efectividad de las políticas del Estado. Como hemos discutido antes, el Estado de Chile ha tenido en los últimos años una política muy activa en el traspaso de tierras y se han implementado algunos programas de apoyo productivo. Sin embargo los datos nos muestran una baja productividad. La pregunta es, entonces, ¿qué pasa con la efectividad de políticas de Indap y Conaf? Para responder se requiere llevar a cabo evaluaciones de sus programas, y así realizar los cambios que sean necesarios. Aquí hay por lo tanto un vacío que llenar de forma urgente.

Un segundo tipo de preguntas se relaciona con cómo aumentar la productividad del sector rural. En este sentido, parece haber a lo menos dos posibles cuellos de botella. Por un lado, existen deficiencias en capital físico, y en específico de maquinaria, que les impiden realizar los procesos productivos de forma más eficiente. Posiblemente esto se debe a escasez de capital de trabajo, debido a su vez a un deficiente acceso al crédito. Por otro lado, el nivel de capital humano de los productores es bajo - la mayoría de los productores tiene sólo educación básica o no tiene ninguna educación-, lo que les impide acceder y posiblemente implementar nuevos procesos de producción de mayor eficiencia (véase Díaz, 2003). 
En este escenario parece obvio que en términos de metas de largo plazo es necesario mejorar la calidad de la educación entregada en los colegios rurales de la IX Región, lo que beneficiaría tanto a los mapuches que permanezcan en el sector rural, los que podrán en el futuro acceder a mejores procesos de producción o administrar sus predios de manera más eficiente, como a aquellos que emigren a los sectores urbanos. En ambos casos, la mejor calidad de educación debería tener impactos positivos en la generación de ingresos.

En el corto plazo, como hemos indicado, la ventaja de los mapuches de la IX Región en el sector rural parece ser la propiedad de tierras indígenas, que por el momento no estarían siendo bien aprovechadas debido a las deficiencias antes enunciadas. Una forma de soslayar ese tipo de deficiencias es generar algún tipo de asociación entre mapuches dueños de predios y terceros, donde estos últimos provean de capital de trabajo, tecnologías y de capital humano para mejorar el proceso productivo. Esto también permite reaccionar frente a cambios exógenos en los procesos de producción, como pueden ser las mejoras tecnológicas, si los terceros están especializados en esta parte del proceso de producción.

Una experiencia de este tipo es la de Bosques Cautín en la Región de la Araucanía ${ }^{22}$. Ésta es una sociedad anónima que basa sus operaciones en el sector forestal, en específico en las plantaciones de eucaliptus, y que tiene dos tipos de predios para explotación: predios propios y predios de terceros en convenio. Estos convenios se basan en acuerdos entre Bosques Cautín y el propietario de la tierra, quien aporta la tierra mientras que la empresa aporta la gestión y la tecnología. Al cabo de doce años (el proceso productivo de los eucaliptus) se reparte el bosque en proporciones previamente acordadas entre las partes ${ }^{23}$.

Esta clase de asociaciones parece auspiciosa porque permite aumentar la productividad de las tierras disponibles, introducir nuevos insumos y procesos en la explotación de tierras en manos de mapuches, y compartir este aumento de recursos entre el dueño de la tierra y los terceros que proveen los insumos complementarios. Sin embargo, estas asociaciones posiblemente necesiten cierto tipo de regulación para la resolución de conflictos entre las partes, y requieran el establecimiento de seguros para casos de fluctuaciones fuertes en los precios de los productos agropecuarios o forestales que se obtengan del proceso productivo o para casos de pérdidas en la producción debido a sequías, inundación o cualquier otro impondera-

\footnotetext{
${ }^{22}$ Véase www.bosquescautin.cl.

${ }^{23}$ La bonificación del Estado se reparte por partes iguales, pero Cautín se las adelanta a los mapuches.
} 
ble de la naturaleza. Estos seguros son importantes porque esta clase de asociación reparte utilidades pero posiblemente también pérdidas, y la repartición de pérdidas puede ser devastadora para los dueños de predios cuando no tienen respaldo de garantías económicas, como es el caso de los mapuches de la IX Región.

En la actualidad el gobierno de Chile se encuentra implementando el programa Re-conocer, dirigido a la comunidad indígena. Este programa tiene tres grandes ejes. A continuación se describen brevemente sus áreas prioritarias. El primero de los ejes es el sistema político, derechos e institucionalidad. En esta área se persigue generar un ordenamiento jurídico que permita una relación fluida entre el Estado, los pueblos indígenas y el resto de los chilenos. Con esto en mente se busca implementar, entre otras, medidas tales como el reconocimiento constitucional de los pueblos indígenas como parte del Estado, aprobación y puesta en marcha del Convenio 169 de la OIT, participación política de los pueblos indígenas por medio de representantes en el Congreso, en Consejos Regionales (Cores) en regiones de alta representación indígena, concejos municipales ${ }^{24}$.

El segundo eje es el desarrollo integral de los pueblos indígenas. Entre otras metas, aquí se contemplan el traspaso de tierras y la resolución de solicitudes de tierras. Además se considera el desarrollo productivo a partir de la reestructuración del plan Orígenes y de una propuesta de desarrollo de las economías de pueblos indígenas, "protegiendo recursos naturales y fomentando energías alternativas y tecnologías adecuadas”25. A su vez se busca implementar un programa de infraestructura, relacionado con vivienda rural, agua potable y electrificación rural, además de un programa de conectividad rural. Finalmente, en este eje se incluyen programas educacionales y en materia de salud. En general, los planes de educación se centran en entregar becas de educación, extendiendo cobertura a programas de educación superior, así como a la educación intercultural partiendo desde la etapa de jardines infantiles, e iniciativas de fomento de la lengua indígena. Por otro lado, los planes de salud enfatizan la recuperación de la biodiversidad y la medicina indígena.

El tercer eje de la política del plan Re-conocer persigue la integración de los pueblos indígenas en la sociedad. Para llevar a cabo esta meta se busca, en primer lugar, implementar una política indígena urbana que se

${ }^{24}$ Además, se busca implementar otro tipo de medidas institucionales tales como la creación de una subsecretaría de Asuntos Indígenas y un consejo de pueblos indígenas.

${ }^{25}$ Véase www.gobiernodechile.cl, “Tercera parte: Plan de Acción y condiciones para su puesta en marcha” de plan Re-conocer. 
basa en el "mejoramiento de la calidad de vida (emprendimiento productivo, vivienda e infraestructura); fortalecimiento de la identidad (deportes, salud, señalética, jardines infantiles, visibilización de la diversidad cultural); y promoción de los derechos y no discriminación (atención municipal, programas de género, capacitación, medios, sedes comunitarias y acciones contra la discriminación)”26; además de crear una mesa indígena regional donde se discutan las políticas indígenas a implementarse en cada región ${ }^{27}$. Finalmente, en esta área de acción se busca acelerar la aprobación de la ley contra la discriminación y la creación de un marco legal para regular inversiones privadas y públicas en áreas de desarrollo indígena y tierras indígenas (código de conducta responsable).

De la descripción de estos ejes de acción, se desprende que estamos frente a un plan que abarca múltiples áreas de la temática indígena. En lo que respecta a los mapuches de la IX Región, que es el foco de este estudio, varias de las medidas pueden resultar útiles. Nos referiremos a continuación básicamente a medidas que tengan efecto socioeconómico a la luz de la discusión de políticas públicas que hemos realizado más arriba. Partiremos por el sector rural, debido que es de mayor tamaño que el sector urbano. Como hemos indicado, es fundamental mejorar la explotación de las tierras indígenas y para ello la asociación de los mapuches dueños de las tierras (o comunidades) con terceros parece ser necesario debido a que los terceros podrían aportar tanto capital físico como capital de trabajo, y sobre todo gestión en la administración y explotación de predios, que son factores que hoy parecen escasear en la explotación de predios indígenas en la región. Obviamente que una alternativa a la asociación con terceros es entregar capacitación y créditos blandos a los dueños de predios para que ellos lleven a cabo directamente y por sí solos la explotación de los predios. Ésta puede ser una alternativa válida, pero con altos riesgos en la medida que deben mejorarse múltiples aspectos del proceso de explotación y, en ese sentido, la asociación con terceros expertos en estos procesos parece más razonable y con mayores probabilidades de éxito. Tal como hemos discutido antes, en la medida que se siga el camino de la asociación con terceros debe establecerse un marco regulatorio apropiado debido a los altos riesgos involucrados en el proceso de explotación y, en ese sentido, el establecimiento del marco regulatorio del "código de conducta responsa-

\footnotetext{
${ }^{26}$ Véase nota al pie $\mathrm{N}^{\circ} 24$.

${ }^{27}$ Este eje de trabajo también contempla implementar políticas orientadas a que la sociedad civil conozca la problemática indígena. En ese sentido se busca difundir en colegios el Informe de la Comisión Verdad Histórica y Nuevo Trato, así como realizar modificaciones curriculares en programas educacionales para incorporar este informe en los contenidos educacionales.
} 
ble” presenta una excelente oportunidad para incentivar y regular las asociaciones entre dueños de tierras y terceros del sector privado.

En cuanto a la informalidad del mercado laboral para los mapuches, lamentablemente las medidas del programa no apuntan a resolverla. Eventualmente alguien podrían decir que la ley de no discriminación apuntaría en este sentido, pero, como hemos señalado, los diferenciales de ingresos laborales obedecen más bien a diferencias objetivas no atribuibles a la condición de pertenecer a un pueblo originario. Lamentablemente este es un ámbito de mucha importancia debido a que la informalidad impacta la protección social por el lado de la salud y la previsión. Éste es un problema que queda por resolver aún ${ }^{28}$.

El plan de acción, como hemos dicho, también contempla medidas relacionadas con la educación, sobre todo en términos de becas de educación superior. Sin embargo, uno de los problemas que enfrentan los mapuches de la región es la baja calidad de la educación y la falta de políticas de capacitación para su inserción en el mercado laboral. En ese sentido, el esfuerzo por mejorar la calidad y la cobertura educacional para este grupo de chilenos debería incluir a su vez una fuerte política de capacitación laboral para inserción en trabajos intensivos en capital humano calificado.

\section{REFERENCIAS}

Barro, R. J., y X. Sala-i-Martin (2004): Economic Growth. McGraw-Hill, second edition.

Berstein, S., G. Larraín y F. Pino (2005): “Cobertura, Densidad y Pensiones en Chile: Proyecciones a 20 años Plazo”. Documento de Trabajo $N^{\circ}$ 12, Superintendencia de Administradoras de Fondos de Pensiones.

Centro de Estudios Públicos (2007): "Estudio de Opinión Pública: Los Mapuche Rurales y Urbanos Hoy, mayo 2006”. Documento de Trabajo No 367, Santiago, Chile.

Cerda, R., A. Donoso y A. Lema (2005): “Análisis del Tipo de Cambio Real: Chile 19861999”. En Cuadernos de Economía (Latin American Journal of Economics), Vol. 42 No 126: 329-356, Instituto de Economía. Pontificia Universidad Católica de Chile.

Coloma, F. y B. Vial (2003): "Desempleo e Inactividad Juvenil”. En Cuadernos de Economía, Vol. 40 № 119: 149-171.

Comisión Verdad Histórica y Nuevo Trato, gobierno de Chile (2003): “Informe Final Grupo de Trabajo Desarrollo Económico y Social: Análisis y Propuestas para un Nuevo Trato”. Santiago.

${ }^{28}$ La reciente propuesta de subsidios a los ingresos del trabajo de personas de bajos ingresos elaborado en el Consejo Asesor Presidencial de Trabajo y Equidad puede cumplir un rol en este sentido porque es un subsidio que se aplicaría siempre y cuando existiera un empleo formal. 
Cowan, K, A. Micco, A. Mizala, C. Pagés y P. Romaguera (2005): “Un Diagnóstico del Desempleo en Chile”. Santiago. Centro de Microdatos, Universidad de Chile.

Dirección de Presupuestos, gobierno de Chile (2007): “Informe de Ejecución Trimestral Período 2007”. Santiago: Ministerio de Hacienda.

Donoso, S. (2008): "Chile y el Convenio 169 de la OIT: Reflexiones sobre un Desencuentro”. Temas de la Agenda Pública, año 3, No 16, Vicerrectoría de Comunicaciones y Asuntos Públicos, Pontificia Universidad Católica de Chile.

Díaz, M. (2001): “El Desarrollo de Pequeñas Empresas Forestales Indígenas en Chile”. Santiago: Corporación Nacional Forestal (Conaf).

(2003): "Empresas Forestales y Comunidades Mapuche: Ideas para una Política de Apoyo al Desarrollo Local”. En M. Díaz y A. Peña (eds.), Árboles, Recursos Naturales y Comunidades Indígenas en Chile. Santiago: Corporación Nacional Forestal (Conaf).

Irarrázaval, I. y M. A. Morandé (2007): “Cultura Mapuche: Entre la Pertenencia Étnica y la Integración Nacional”. En Estudios Públicos, № 105 (verano): 37-60.

Ministerio de Planificación, gobierno de Chile (2006): "Logros de la Política Indígena de Chile 1993-2006”. Santiago.

Ministerio de Educación, gobierno de Chile (2002): “Sistema de Medición de la Calidad de la Educación, SIMCE, Informe de Resultados 2002”. Santiago.

- (2005): "Sistema de Medición de la Calidad de la Educación, SIMCE, Informe de Resultados 2005”. Santiago.

Odepa-Conadi, gobierno de Chile (2001): “Agricultura Mapuche: Análisis Socioespacial a partir del VI Censo Nacional Agropecuario”. Documento de Trabajo No 6, Oficina de Estudios y Políticas Agrarias, Odepa, Santiago.

Soto, R. y A. Torche (2004): "Spatial Inequality, Migration and Economic Growth in Chile”. En Cuadernos de Economía (Latin American Journal of Economics), Vol. 41 No 124: 401-424, Instituto de Economía, Pontificia Universidad Católica de Chile.

Sapelli, C. (2007): “Algunas Reflexiones sobre los Problemas que Presenta el Funcionamiento del Mercado Laboral”. En Puntos de Referencia N ${ }^{\circ} 289$ (noviembre), Centro de Estudios Públicos, Santiago.

Valdés, A. y W. Foster (2007): "Structural Characteristics of Agricultural Households and Policy Options in Chile. A typology of rural households and income determinants from the 2003 CASEN”. Trabajo preparado para la OECD. [Véase traducción al castellano en esta edición de Estudios Públicos.]

Valenzuela, E. (2007): “Tierra, Comunidad e Identidad Mapuche”. En Estudios Públicos, $\mathrm{N}^{\mathrm{0}} 105$, (verano): $25-36$. 